\title{
EFFECT OF CROSSLINKING ADDITIVES ON THE PROPERTIES OF CARBONS DERIVED FROM SELECTED PRECURSORS
}
O. J. Horne
B. Napier, Jr
W. E. Smith

\section{MASTER}

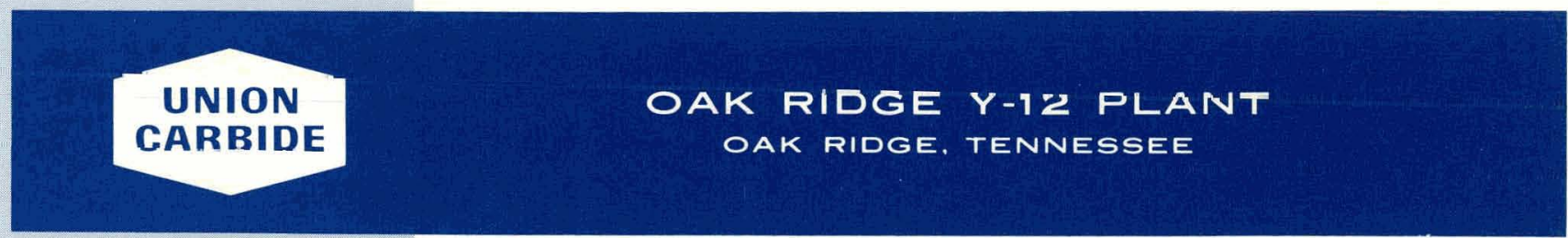

prepared for the U.S. ATOMIC ENERGY COMMISSION

under U.S. GOVERNMENT Contract W.7405 eng 26 


\section{DISCLAIMER}

This report was prepared as an account of work sponsored by an agency of the United States Government. Neither the United States Government nor any agency Thereof, nor any of their employees, makes any warranty, express or implied, or assumes any legal liability or responsibility for the accuracy, completeness, or usefulness of any information, apparatus, product, or process disclosed, or represents that its use would not infringe privately owned rights. Reference herein to any specific commercial product, process, or service by trade name, trademark, manufacturer, or otherwise does not necessarily constitute or imply its endorsement, recommendation, or favoring by the United States Government or any agency thereof. The views and opinions of authors expressed herein do not necessarily state or reflect those of the United States Government or any agency thereof. 


\section{DISCLAIMER}

Portions of this document may be illegible in electronic image products. Images are produced from the best available original document. 
Reference to a company or product name does not imply approval or recommendation of the product by Union Carbide Corporation or the U.S. Atomic Energy Commission to the exclusion of others that may meet specifications.

Printed in the United States of America. Available from Nátiunal Teclunical Information Service

U.S. Department of Commerce

5285 Port Royal Road, Springfield, Virginia 22151

Price: Printed Copy $\$ 4.00$; Microfiche $\$ 1.45$

This report was prepared as an account of work sponsored by the United States Government. Neither the United States nor the United States Atomic Energy Commission, nor any of their employees, nor any of their contractors, subcontractors, or their employees, makes any warranty, express or implied, or assumes any legal liability or responsibility for the accuracy, completeness or usefulness of any information, apparatus, product or process disclosed, or represents that its use would not infringe privately owned rights. 


\title{
EFFECT OF CROSSLINKING ADDITIVES ON THE PROPERTIES OF CARBONS DERIVED FROM SELECTED PRECURSORS
}

\author{
O. J. Horne \\ B. Napier, Jr \\ W. E. Smith
}

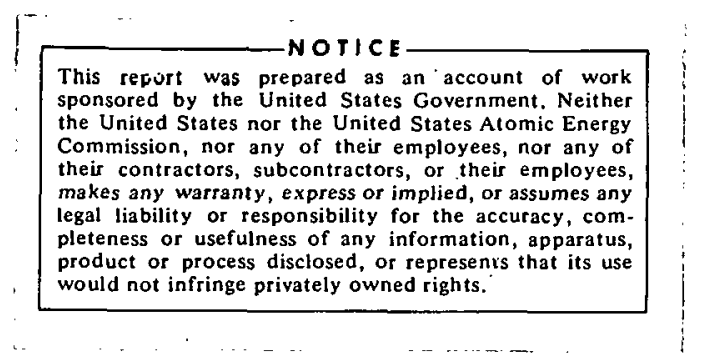

Oak Ridge Y-12 Plant

P.O. Box Y, Oak Ridge, Tennessee 37830

Date Issued - May 15, 1974

Prepared for the U.S. Atomic Energy Commission

Uituter U.S. Covernment Contract W.7105eng.26 


\begin{abstract}
A study has been made of the effect of various crosslinking additives on the properties of carbons derived from several precursors. Included in the group of additives were: furfurylideneindene, furfurylidenefluorene, $\underline{p}$-xylylideneindene, $\underline{p}$-xylylidenefluorene, pyromellitic dianhydride, H-Resin Type 3, dicyclopentadiene, and norbornadiene. By blending one of these additives with either a synthetic or commercial carbon precursor, a wide variety of carbon properties was obtained, thus affording avenues to control these properties by a controlled modification of the precursors.
\end{abstract}




\section{CONTENTS}

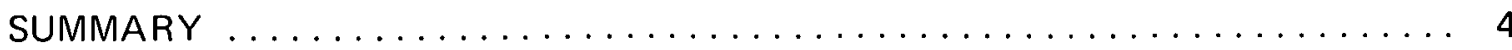

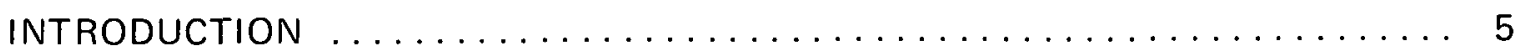

EFFECT OF ADDITIVES ON PRECURSOR-DERIVED CARBONS $\ldots \ldots \ldots \ldots \ldots 6$

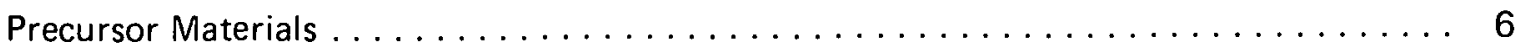

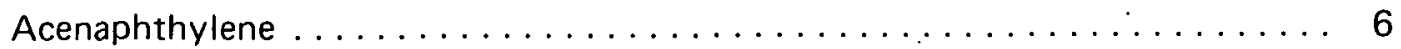

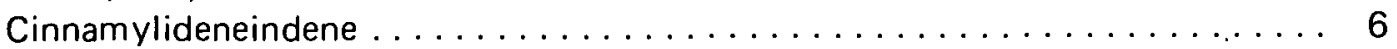

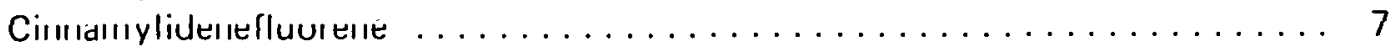

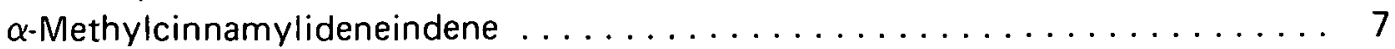

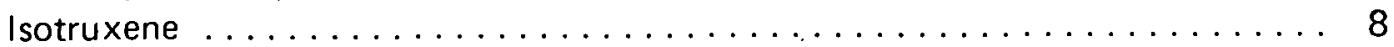

Ashland-240 Pitch ........................... 8

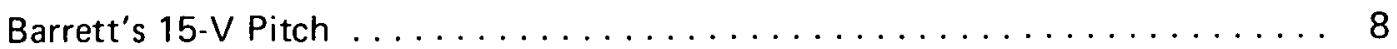

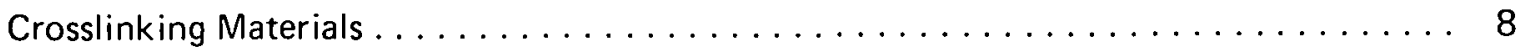

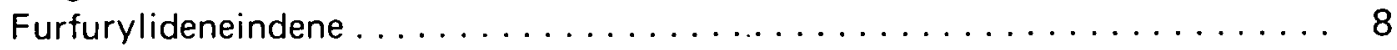

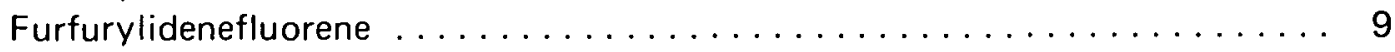

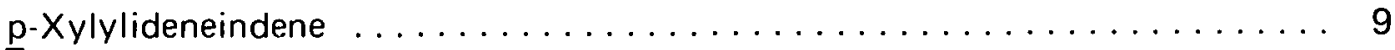

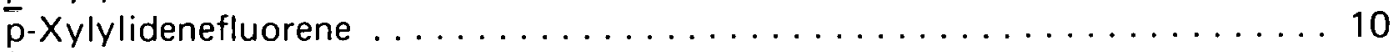

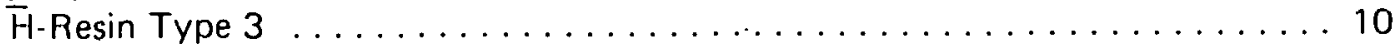

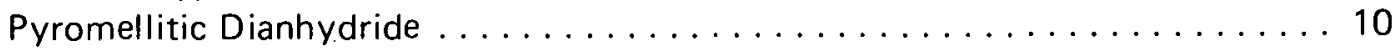

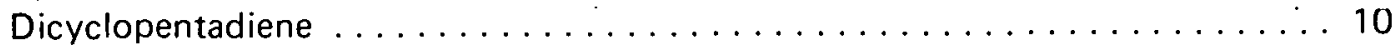

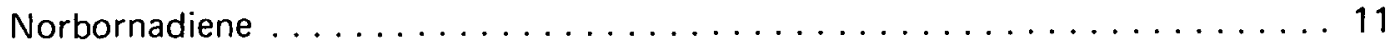

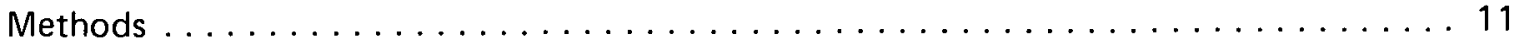

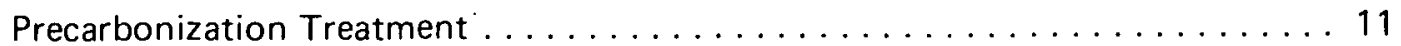

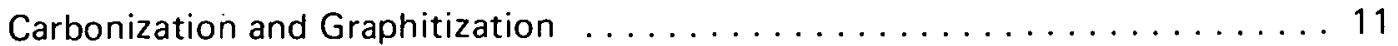

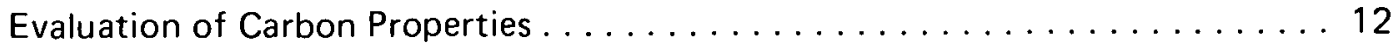

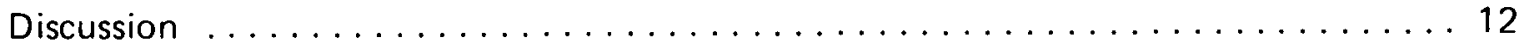

Evaluation of Furfurylideneindene as a Crosslinking Additive . . . . . . . 12

Evaluation of Furfurylidenefluorene as a Crosslinking Additive . . . . . . . 13

Evaluation of $\mathrm{p}$-Xylylideneindene as a Crosslinking Additive $\ldots \ldots \ldots \ldots \ldots$

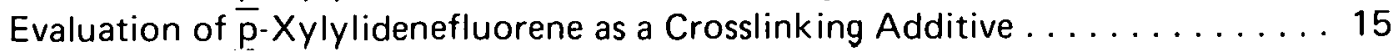

Evaluation of $\overline{\mathrm{H}}$-Resin Type 3 as a Crosslinking Additive . . . . . . . . . 16

Evaluation of Pyromellitic Dianhydride as a Crosslinking Additive . . . . . . 29

Evaluation of Dicyclopentadiene as a Crosslinking Additive . . . . . . . . 30

Evaluation of Norbornadiene as a Crosslinking Additive . . . . . . . . 34

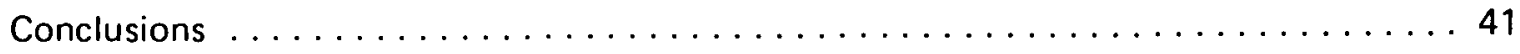

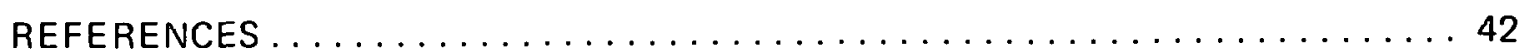




\section{SUMMARY}

The primary goal of this study was to evaluate the crosslinking capability of various materials by correlating properties of carbons derived from blends of the additive and a well-characterized precursor with the additive type and content. Included in the group of additives were: furfurylideneindene (FAI), furfurylidenefluorene (FAF), p-xylylideneindene (XYN), p-xylylidenefluorene (XYF), pyromellitic dianhydride (PMDA), H-Resin Type 3 ( $\mathrm{H}-3$ ), dicylcopentadiene (DCPD), and norbornadiene (NBD). Blends of these additives with an appropriate precursor resulted in carbons exhibiting a wide range of properties. Crosslinking agents that were found to be effective with the following precursors in producing controlled carbon with homogeneous properties were: (1) acenaphthylene- $\mathrm{H}-3$ resin and DCPD; (2) cinnamylideneindene-FAF, XYF, DCPD, and NBD: (3) cinnamylidenefluorene-FAI, XYN, and PMDA; (4) Ashland-240 Pitch-XYF and NBD. 


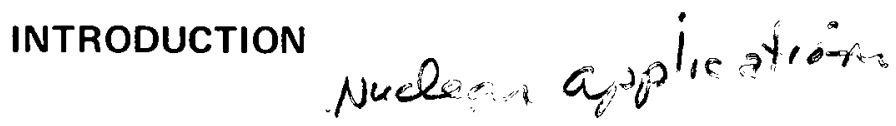

Recent developments associated with reactor and aerospace technology place emphasis on strong, low-density materials such as carbon. Thus, there is a renewed interest in carbon and particularly in those factors which influence its properties.

Properties of carbon are largely determined by the molecular structure of the precursor materials and the reaction mechanisms which the precursors undergo to become carbon. In general, the ability of a precursor to yield a graphitic structure depends upon the precursor's ability to assume the planar aromatic structure characteristic of the graphite unit cell. Thus, processes such as bond cleavage, molecular rearrangements, cyclization, aromatization, and dehydrogenation are involved in the transition of a precursor to carbon. Factors which prevent these processes from occurring in a prescribed order and at prescribed rates favor the formation of a nongraphitic carbon, and varying degrees of inhibition would result in varying graphiticity. Materials which "thermoset" into highly crosslinked polymers do not tend to rearrange prior to pyrolysis due to the reduced degrees of molecular freedom. These materials do not tend to yield graphitic carbon. However, thermoplastic materials or materials with a low degree of crosslinking allow viscosities in which molecular rearrangements with reorientations can occur, and tend to form graphitic carbons unless stable, nonplanar intermediates are formed.

Efforts in this study at the Oak Ridge $Y-12$ Plant ${ }^{(a)}$ are directed toward correlating carbon properties with precursor properties. By knowing the relation between precursor properties and precursor-derived carbon properties, control over the latter may be exercised.

This report describes an evaluation of the effect of various crosslinking additives on carbons derived from several precursors. Properties of carbons derived from blends of the precursor and crosslinking additives were determined in efforts to correlate carbon properties with precursor composition.

(a) Operated by the Union Carbide Corporation's Nuclear Division for the US Atomic Energy Commission. 


\section{EFFECT OF ADDITIVES ON PRECURSOR-DERIVED CARBONS}

\section{PRECURSOR MATERIALS}

\section{Acenaphthylene}

Acenaphthylene (ACN) was obtained from the usual chemical supply sources. Upon carbonization and subsequent graphitization, ACN:<smiles></smiles>

\section{Acenaphthylene}

vields a highly crystalline carbon. Factors which influence the properties of ACN-derived carbon have been the subject of earlier reports. $(1,2)$

\section{Cinnamylideneindene}

Cinnamylideneindene (CAI) was prepared by the room-temperature condensation of indene with cinnamaldehyde in the presence of an alcoholic base. (3) The structure of CAl is:

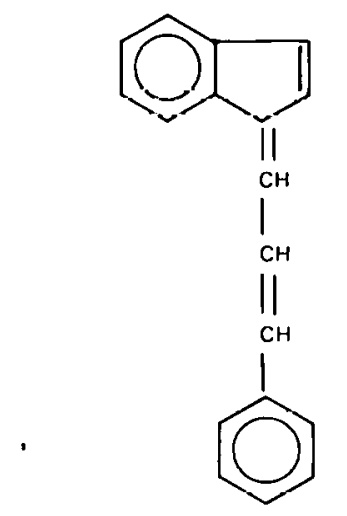

Cinnamylideneindene

Properties of carbon derived from CAl are those of a highly crystalline, heterogeneous carbon. Factors which influence the properties of CAl-derived carbon have been presented in earlier reports. $(1-4)$

The CAI polymer used in this study (CAI-340) was prepared by heating the monomer in a gas-pressure autoclave for two hours at $340^{\circ} \mathrm{C}$. Carbon derived from CAI-340 is also highly crystalline. 


\section{Cinnamylidenefluorene}

Cinnamylidenefluorene (CAF):<smiles>C(#Cc1ccccc1)C=C1c2ccccc2-c2ccccc21</smiles>

Cinnamylidenefluorene

was prepared by slowly adding 300 milliliters of a methanolic solution containing 198 grams of cinnamaldehyde to 1500 milliliters of a methanolic solution containing $166 \mathrm{grams}$ of fluorene (an indene analogue):

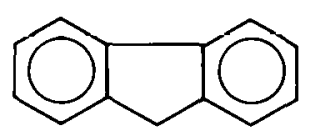

Fluorene

and 50 grams of potassium hydroxide. ${ }^{(5)}$ The reaction mixture was heated under reflux during the addition and for one hour afterward. On cooling, a light-yellow, crystalline solid was collected, representing a product yield of 63 percent. Carbon derived from CAF is highly crystalline. (4)

$\alpha=$ Metliylcimmanylideneindene

Preparation of $\alpha$-methylcinnamylideneindene (MCAI):<smiles>CC(=Cc1ccccc1)C=C1C=Cc2ccccc21</smiles>

$\alpha$-Methylcinnamylideneindene 
involves the reacting of indene and $\alpha$-methylcinnamaldehyde $(3: 2$ molar ratio $)$ in the presence of methanol and tetramethylammonium hydroxide (TMAH) solutions. In practice, indene $(58 \mathrm{gms})$ was added to a solution of methanol $(300 \mathrm{~m} / \mathrm{s})$ and TMAH $(55.8 \mathrm{gms}$ of $20 \%$ TMAH in methanol), and the aldehyde (49 gms) was subsequently added in one portion. After stirring for one hour, the bright-yellow product $\left(\mathrm{MP}=83^{\circ} \mathrm{C}\right)$ was collected by filtration. Product yields were approximately $20 \%$. Carbon derived from MCAl is highly crystalline.

\section{Isotruxene}

Isotruxene (ITX) was prepared by the reaction of indene and 1,4-naphthoquinone in the presence of a tertiary amine. (3) Properties of carbon derived from ITX correspond to those of a fine-arain, issotropic carbon with a low order of graphiticity. The ITX used in this study was oxidatively polymerized by heating for $40 \mathrm{hr}$ at $300^{\circ} \mathrm{C}$ with an air flow of $300 \mathrm{~cm} 3 / \mathrm{min}$. This pretreatment results in a polymerıc torm of ITX ànd yields a hlyhly crystalline carbon on carbonization and subsequent graphitization. (4)

\section{Ashland-240 Pitch}

The Ashland-240 pitch (A-240) was a petroleum distillate fraction obtained from the Ashland Oil Company. A highly crystalline carbon is obtained from A-240. Properties of carbon derived from A-240 are the subject of an earlier report. (6)

\section{Barrett's 15-V Pitch}

Barrett's 277 15-V Pitch (15-V) was obtained from the Barrett Division of the Allied Chemical Corporation. Carbon derived from $15-\mathrm{V}$ is highly crystalline.

\section{CROSSLINKING MATERIALS}

\section{Furfurylideneindene}

Furfurylideneindene: (7)<smiles>C1=COC(C=C2C=Cc3ccccc32)C1</smiles>

Furfurylideneindene

was prepared by the dropwise addition of furfural (32 gms) to indene (58 gms) in a methanol $(300 \mathrm{mls}) / \mathrm{TMAH}(55.8 \mathrm{gms})$ solution. The reaction exothermed as the furfural was added and the product formed only after the reactants had cooled to approximately 
$30^{\circ} \mathrm{C}$. The yellow product (MP $=80^{\circ} \mathrm{C}$ ) was collected by filtration. Product yields were approximately $40 \%$. A noncrystalline carbon was obtained from FAl.

\section{Furfurylidenefluorene}

Furfurylidenefluorene (FAF):

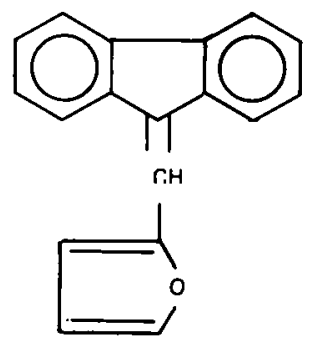

Furfurylidenefluorene

was prepared by the dropwise addition of a solution of furfural $(144 \mathrm{~m} / \mathrm{s})$ and methanol $(100 \mathrm{mls})$ to a refluxing solution of fluorene $(166 \mathrm{gms})$, potassium hydroxide $(50 \mathrm{gms})$, and methanol $(1,500 \mathrm{~m} / \mathrm{s})$. (5) Reflux conditions were necessary, due to the decreased reactivity of the methylene group compared to indene. The reaction mixture was stirred under reflux for one hour after the aldehyde addition, then poured, while hot, into two approximately equal fractions and allowed to cool. Approximately $\mathbf{2 0 0 0}$ milliliters of water were added to each of the fractions, and the resulting solutions filtered and dried. A light-yellow, crystalline solid with a melting point of approximately $85^{\circ} \mathrm{C}$ was collected at $50 \%$ of the theoretical yield. Upon carbonization and subsequent graphitization, a noncrystalline carbon was obtained.

\section{p-Xylylideneindene}

Synthesis of $\underline{p}-x y l y l i d e n e i n d e n e(X Y N)$ :<smiles>C=C1C=Cc2ccccc21</smiles>

p-Xylylideneindeire 
was accomplished by the room-temperature reaction of indene with terephthalaldehyde in the presence of an alcoholic base $(3)$ The structure of XYN shows a highly conjugated system of unsaturated bonding. Upon carbonization and subsequent graphitization, a noncrystalline carbon is obtained from $X Y N$.

\section{p-Xylylidenefluorene}

$\underline{p}-X y l y l i d e n e f l u o r e n e(X Y F):$<smiles>C(=C1c2ccccc2-c2ccccc21)c1ccc(C=C2c3ccccc3-c3ccccc32)cc1</smiles>

$\underline{p}-X y l y l i d e n e f l u o r e n e$

was prepared by addıng terephthalaldekyde $(87$ yıı1s) in one portion to a refluxing mixture of fluorene $(207.5 \mathrm{gms})$, potassium hydroxide $(50 \mathrm{gms})$, and methanol $(1700 \mathrm{~m} / \mathrm{s})$. After refluxing and stirring for two hours after aldehyde addition, the solution was filtered and the yellow precipitate (MP $=160^{\circ} \mathrm{C}$ ) collected and dried. Product yield was 78 percent of theoretıcal. A noncrystalline carboin was obtained from XYF.

\section{H-Resin Type 3}

$\mathrm{H}$-Resin Type $3(\mathrm{H}-3)$ is a thermosetting resin available from Haveg Industries, Inc. Due to the chemical nature of the resin, heating rates dur iny carbonization must bc slow $1-25 / 1$ iniı or less).

\section{Pyromellitic Dianhydride}

Pyromellitic dianhydride (PMDA) was obtained as a white powder from the usual chemical supply sources. No carbon residue was observed when PMDA was heated to carbonization temperatures.

\section{Dicyclopentadiene}

Dicyclopentadiene (DCPD): 

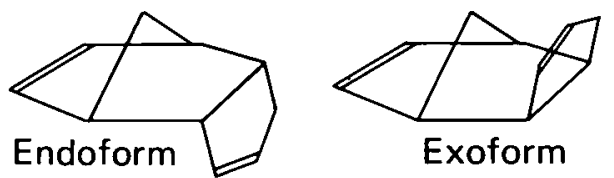

Dicyclopentadiene

was obtained from the usual chemical supply sources and used as received. No carbon residue was observed when DCPD was heated to carbonization temperatures. When heated in a gas-pressure autoclave for two hours at $340^{\circ} \mathrm{C}$ and an initial room-temperature nitrogen pressure of 300 pounds per square inch, a heterogeneous carbon with a fine-grain and noncrystalline region was obtained.

\section{Norbornadiene}

Norbornadiene (NBD):

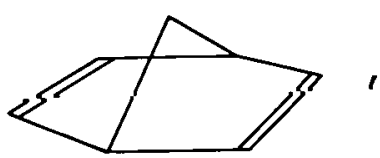

Norbornadiene

was purchased from the usual chemical supply sources and used as received. Carbon derived from autoclaved NBD is described in a later section of this report (page 34).

\section{METHODS}

\section{Precarbonization Treatment}

Blends involving DCPD and NBD were heated for two hours at $340^{\circ} \mathrm{C}$ and an initial room-temperature nitrogen pressure of 300 pounds per square inch in a gas-pressure autoclave prior to carbonization. All other blends were carbonized as mixed and received no precarbonization treatment.

\section{Carbonization and Graphitization}

Carbonization ususally consisted of heating 30 grams (when available) of the precursors or precursor blends in a three-inch-diameter crucible to $1000^{\circ} \mathrm{C}$ under an inert atmosphere. For all the blends, except those involving the $\mathrm{H}-3$ resin, this procedure was rate controlled and required approximately 60 hours. Carbonization of the $\mathrm{H}-3$ resin containing blends was also rate controlled, but approximately 150 hours were required for completion of the cycle. Coke yields were calculated as the percent residue after the $1000^{\circ} \mathrm{C}$. carbonization stcp.

After carbonization, samples were fired for one hour at $2800^{\circ} \mathrm{C}$ by using a carbon induction furnace. The resulting samples were then evaluated by metallography and $\dot{X}$-ray diffraction. 


\section{Evaluation of Carbon Properties}

Metallographic samples were mounted in epoxy resin and placed under vacuum to remove adherent air bubbles and to impregnate flakes. The mounted specimens were then ground successively on silicon carbide grits of $240,320,400$, and 600 size. After cleaning to remove loose adherent silicon carbide, the samples were polished with Linde $\mathrm{A}\left(0.3 \mu \mathrm{m} \mathrm{Al}_{2} \mathrm{O}_{3}\right.$ powder) while suspended in water on Pellon cloth on a Syntron vibrating polisher. This work was followed by a final polish on the Syntron with Gamel cloth and a water suspension of Linde $\mathrm{B}\left(0.05 \mu \mathrm{m} \mathrm{Al}_{2} \mathrm{O}_{3}\right.$ powder). The samples were then cleaned in flowing water with a cotton swab and blown dry with compressed air. Photomicrographs were made using sensitive-tint illumination on a Bausch and Lomb Research 1 metallograph.

A Siemen's Crystalloflex IV recording diffractometer with copper $K_{\alpha}$ radiation was used to obtain the $X$-ray diffraction data. An internal standard of sodium chlorıde wás analyzed with each sample. Interlayer spacings were calculated from the $x$-ray dala using the methods described by Ruland. (8) The degree of graphiticity of the carbons was also expressed in terms of a $\mathrm{g}$ factor defined as follows by Maire and Mering: (9)

$$
d_{002}=g(3.355)+(1-g) 3.44
$$

\section{DISCUSSION}

\section{Evaluation of Furfurylideneindene as a Crosslinking Additive}

As reported previously, $(2,6)$ furfurylideneindene (FAl) was an effective crosslinking agent for cinnamylideneindene (C.AI), arenaphthylene (ACN), and Ashland-240 pitch. In this study, FAl was blended with $\alpha$-methylcinnamylideneindene (MCAI) and cinnamylidenefluorene (CAF) in efforts to utilize the thermosetting properties of the $\mathrm{FAl}$ as a crosslinking agent for these two precursors.

$\alpha$-Methylcinnamylideneindene/Furfurylideneindene Blends - As indicated in Figure 1, coke vields of MCAI/FAl blends increased gradually with increasing $\mathrm{FAI}$ content. Examination of the $2800^{\circ} \mathrm{C}$ carbuns by metallography indicated no significant microstructural changes as the $\mathrm{FAl}$ concentration increased to 40 percent. Apparently, copolymerization of MCAl and FAl is significantly hindered by the presence of the branched methyl group so that the effect of crosslinking was not reflected in the carbon properties.

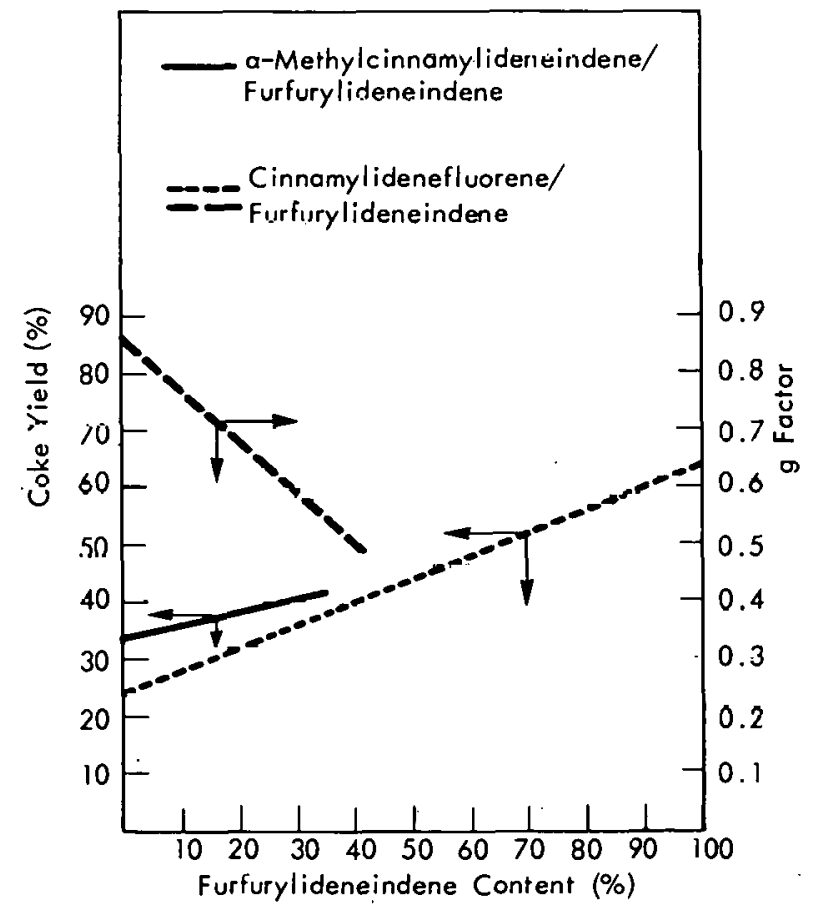

Figure 1. PROPERTIES OF CARBONS DERIVED FROM CINNAMYLIDENEFLUORENE/FURFURYLIDENEINDENE AND $\alpha$-METHYLCINNAMYLIDENEINDENE/FURFURYLI. DENEINDENE MIXTURES AS FUNCTIONS OF THE FURFURYLIDENEINDENE CONTENT. 
Cinnamylidenefluorene/Furfurylideneindene Blends - As also shown in Figure 1, coke yields of CAF/FAI blends increased steadily as the FAl content increased, while the degree of graphiticity decreased rapidly with increasing FAl content. Thus, the degree of crosslinking in the CAF/FAI system must be increasing with increasing FAI content.

Microstructures of the $2800^{\circ} \mathrm{C}$ carbons, seen in Figure 2, revealed a gradual decrease in crystallinity from a highly crystalline carbon typical of CAF to a fine-grain, homogeneous carbon as the $\mathrm{FAl}$ content increased from 0 to $40 \%$.

In summary, the copolymerization of CAF and FAI resulted in an increased amount of crosslinking and/or nonplanarity in the polymeric system as the FAl content increased, while no significant amount of interaction was noted for the MCAI/FAI blends.

\section{Evaluation of Furfurylidenefluorene as a Crosslinking Additive}

Furfurylidenefluorene (FAF) was blended in binary mixtures with heat-treated isotruxene (ITX), A-240, ACN, and CAl in efforts to evaluate FAF as a crosslinking agent for these precursors.

Blends of Furfurylidenefluorene with Heat-Treated Isotruxene, Acenaphthylene, and Ashland-240 Pitch-As noted in Figure 3, coke yields of heat-treated ITX/FAF, A-240/FAF, and ACN/FAF mixtures decreased steadily with increasing FAF content. Metallographic examination of the $2800^{\circ} \mathrm{C}$ carbons derived from these respective blends revealed no visible change in microstructure with increasing FAF content, indicating that little or no crosslinking interaction occurred for these mixtures.

Blends of Furfurylidenefluorene with Cinnamylideneindene - As can be seen in Figure 4, coke yields and g factors of CAI/FAF blends slowly increased and decreased, respectively, indicating some effect of the FAF on CAI-derived carbons. Microstructures of the $2,800^{\circ} \mathrm{C}$ carbons (see Figure 5) indicated a subtle decrease in carbon crystallinity with increasing FAF content.

Thus, FAF was not an effective crosslinking additive for heat-treated ITX, A-240, and ACN, while being only moderately effective for CAI. Decrease in the reactivity of FAF when compared with FAl was expected since the ethylene linkings of the five-atom ring are rendered more inactive by the extra benzene nuclei.

\section{Evaluation of p-Xylylideneindene as a Crosslinking Additive}

Effect of p-xylylideneindene (XYN) on the properties of carbons derived from CAI, ACN, and $A-24 \overline{0}$ has been reported previously. $(2,6$, Efforts to further evaluate $X Y N$ as a crosslinking additive involved the evaluation of properties of carbons derived from MCAI/XYN and CAF/XYN blends.

$\alpha$-Methylcinnamylideneindene/p-Xylylideneindene Blends - Coke yields increased steadily for mixtures of MCAI and $X Y \bar{N}$ as the XYN content increased (Figure 6). Crystallinity of the $2800^{\circ} \mathrm{C}$ carbons, as indicated by the $\mathrm{g}$ factor, indicated a gradual decrease in crystallinity with increasing XYN content. Microstructures of the $2800^{\circ} \mathrm{C}$ carbons 

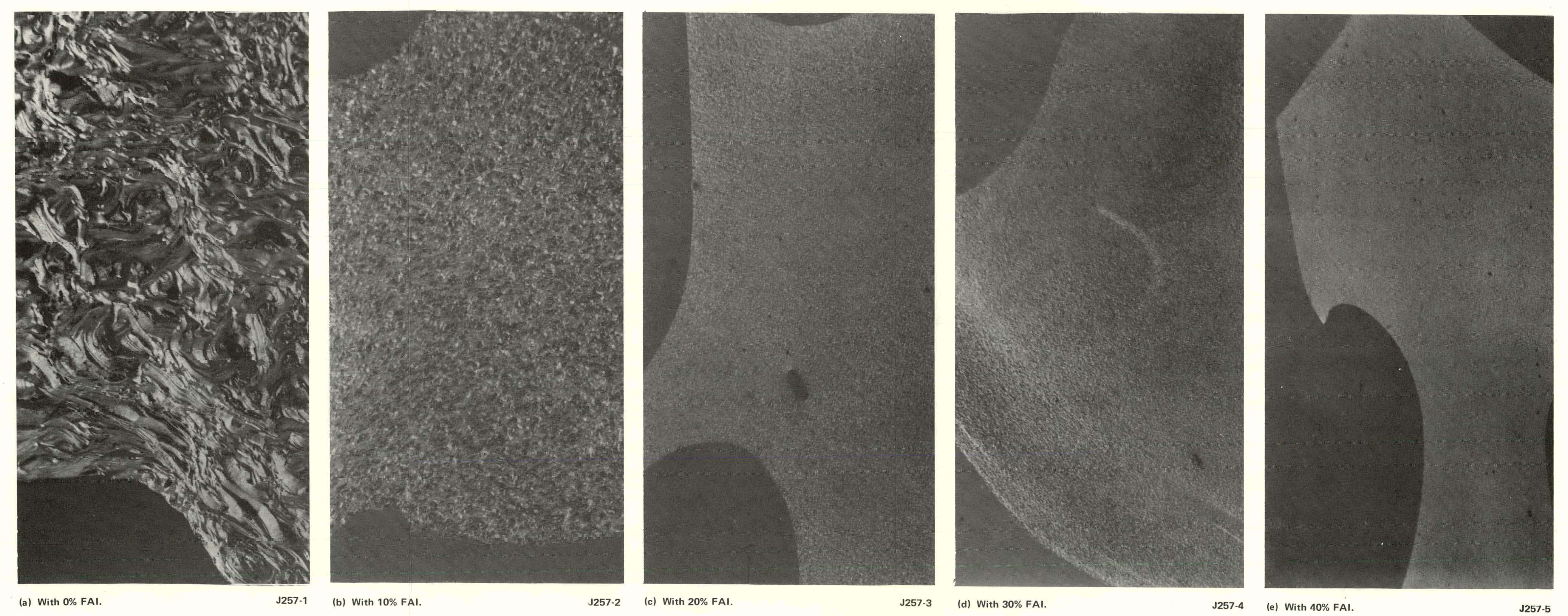

Figure 2. MICROSTRUCTURES OF CARBONS (AFTER 2,800 C) DERIVED FROM CINNAMYLIDENEFLUORENE/FURFURYLIDENEINDENE MIXTURES. (Sensitive
Tint; 250X) 
(Figure 7) revealed a subtle decrease in crystallinity as the $\mathrm{XYN}$ content increased from 30 to $40 \%$. As reported previously, (2) blends of $\mathrm{CAI}$ and $\mathrm{XYN}$ containing $40 \% \quad X Y N$ resulted in a fine-grain, homogeneous carbon. Therefore, as noted for the MCAI/FAI blends, the branched methyl group resulted in a decreased reactivity between the MCAl and $X Y N$, requiring higher concentrations of $X Y N$ to effect a significant decrease in carbon crystallinity.

Cinnamylidenefluorene/p-Xylylideneindene Blends - Coke yields and $g$ factors of CAF/XYN blends, reported in Figure 8, increased and decreased, respectively, with increasing $X Y N$ content. Microstructures of the $2800^{\circ} \mathrm{C}$ carbons (seen in Figure 9) reveal a dccredse in carbon crystallinity from a highly crystalline carbon typical of that derived from CAF (Figure 2, View a) to a fine-grain, homogeneous carbon derived from the blend containing 30\% $X Y N$. A similar effect was noted for carbons derived from CAI/XYN blends. (2)

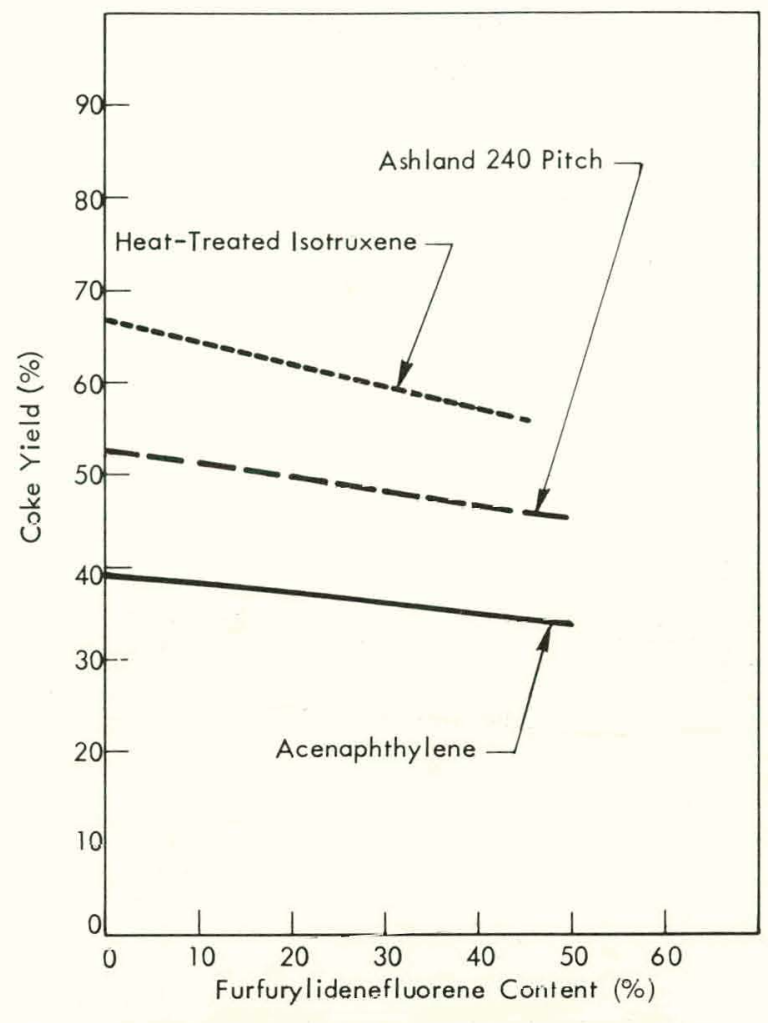

Figure 3. COKE YIELDS OF CARBONS DERIVED FROM BINARY MIXTURES OF FURFURYLIDENEFLUORENE WITH HEAT-TREATED ISOTRUXENE, ASHLAND-240 PITCH, AND ACENAPHTHYLENE AS FUNCTIONS OF THE FURFURYLIDENEFLUORENE CONTENT.

In summary, copolymerization of CAF and

$X Y N$ resulted in an increased amount of crosslinking which altered the properties of the carbon derived from CAF. Subtle changes in properties of MCAI-derived carbon were effected by the inclusion of XYN.

\section{Evaluation of $\mathbf{p}$-Xylylidenefluorene as a Crosslinking Additive}

Effectiveness of $p$-xylylidenefluorene (XYF) as a crosslinking additive for CAI, heat-treated ITX, ACN, and $\bar{A}-240$ was determined by evaluating the properties of carbon derived from mixtures of the respective precursor with XYF. A certain decrease in reactivity of XYF compared to $X Y N$ was expected, due to the presence of the additional benzene rings in the $X Y F$.

Acenaphthylene/p-Xylylidenefluorene Blends - Coke yields of ACN/XYF blends varied only slightly and were in the range from 38 to $40 \%$. Metallographic examination of the $2800^{\circ} \mathrm{C}$ carbons revealed no visible change in microstructure with increasing XYF content, indicating little or no interaction hetween the twvu. A simılar trend was noted for ACN/XYN inixtures. (2)

Cinnamylideneindene/p-Xylylidenefluorene Blends - Coke yields of carbons derived from $\mathrm{CAI} / \mathrm{XYF}$ blends were essentially constant over the XYF concentration range studied 
(Figure 10), while the degree of graphiticity, as indicated by the $\mathrm{g}$ factor, decreased rapidly with increasing XYF content. Microstructures of the $2800^{\circ} \mathrm{C}$ carbons, shown in Figure 11 ,

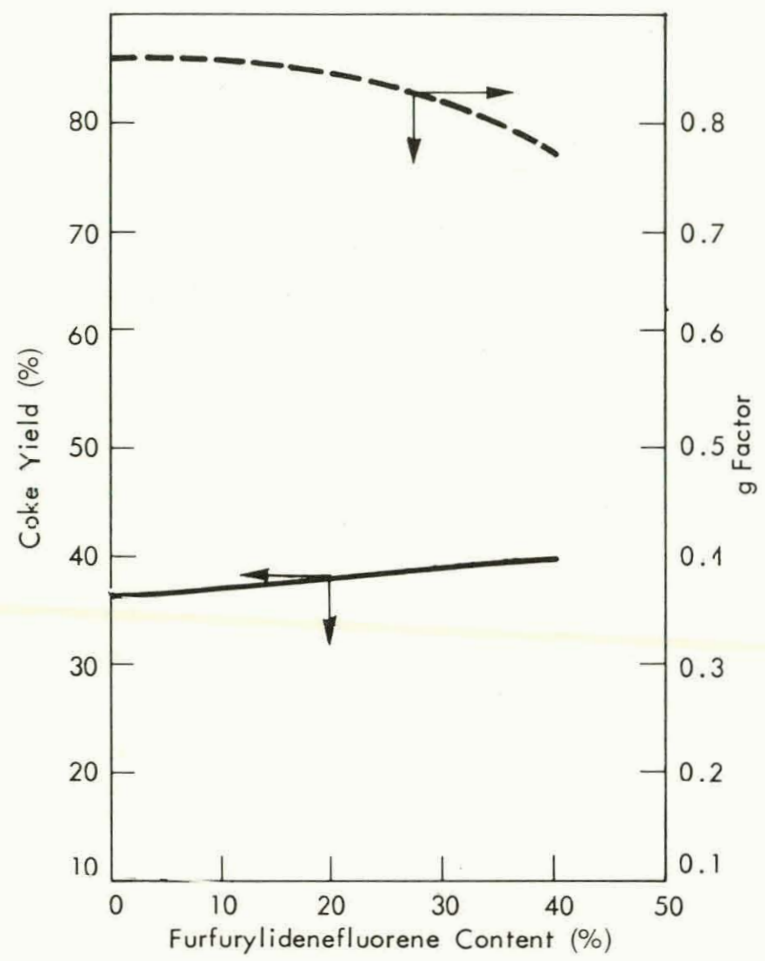

Figure 4. PROPERTIES OF CARBONS DERIVED FROM CINNAMYLIDENEINDENE/FURFURYLIDENEFLUORENE BLENDS AS FUNCTIONS OF THE FURFURYLIDENEFLUORENE CONTENT. indicated a decrease in crystallinity from a highly crystalline, heterogeneous carbon to a fine-grain, homogeneous carbon. Properties of CAI-derived carbons are affected similarly by the inclusion of XYN.(2)

Heat-Treated Isotruxene/p-Xylylidenefluorene Blends - Coke yields and $g$ factors of carbons derived from heat-treated ITX/XYF blends appeared to obtain a maximum at a XYF content of approximately $15 \%$, and then both properties decreased with increasing XYF content (Fiqure 12). Microstructures, shown in Figure 13, revealcd the decrease in carbon crystallinity with increasing XYY rnntent, indicating some interaction between the XYF and heat-treated ITX.

Ashland-240 Pitch/p-Xylylidenefluorene Blends - Coke yields and $\mathrm{g}$ factors of carbons derived from A-240/XYF blends decreased slowly with increasing XYF content (Figure 14). A subtle change in the texture of the $2800^{\circ} \mathrm{C}$ carbon can be seen in Figure 15 as the $X Y Y^{\prime}$ content increased from 20 to $40 \%$. Carbon properties of A-240/XYN blends (6) varied more noticeably than properties of carbons deriven from these A-240/XYF blends.

In summary, XYF was an ineffective crosslinking additive for $A C N$, while being only moderately effective for CAI, heat-treated ITX, and A-240. Thus, the effectiveness of XYF as a crosslinking additive is less than that of its indene homologue, $X Y N$.

\section{Evaluation of $\mathrm{H}$-Resin Type 3 as a Crosslinkıng Additive}

Further efforts to control the properties of derived carbons led to the evaluation of a thermosetting resin [H-Resin Type 3 ( $\mathrm{H}-3$ resin)]. (b) Binary mixtures of $\mathrm{H}-3$ resin with ACN, CAI, heat-treated ITX, A-240, Barrett-277 15-V Pitch (15-V), and a CAI polymer (CAI-340) were carbonized in efforts to determine if the properties of the respective derived carbons were altered. Figures 16 and 17 point out that there was an Increase in llie coke yields of the binary mixtures as the $\mathrm{H}-3$ resin content increased.

(b) Obtained from Haveg Industries, Inc. 


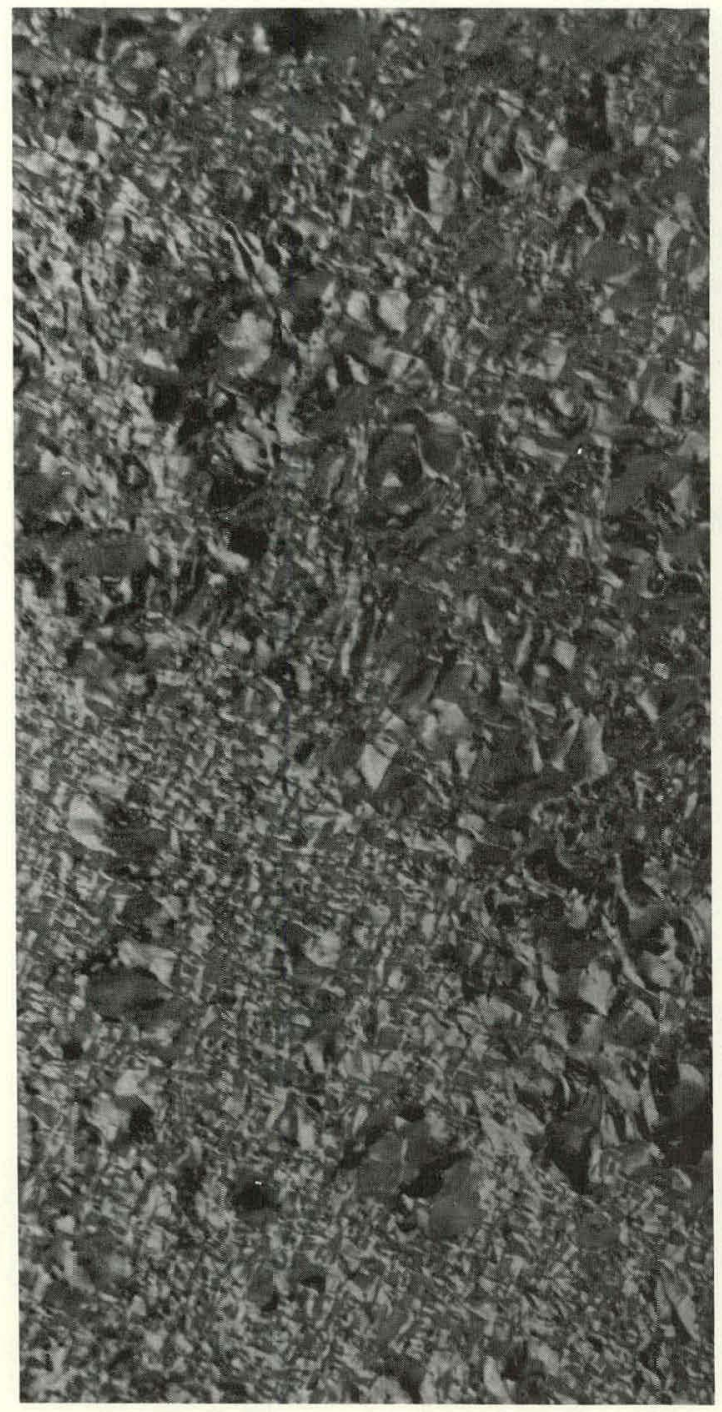

(a) With $20 \%$ FAF.

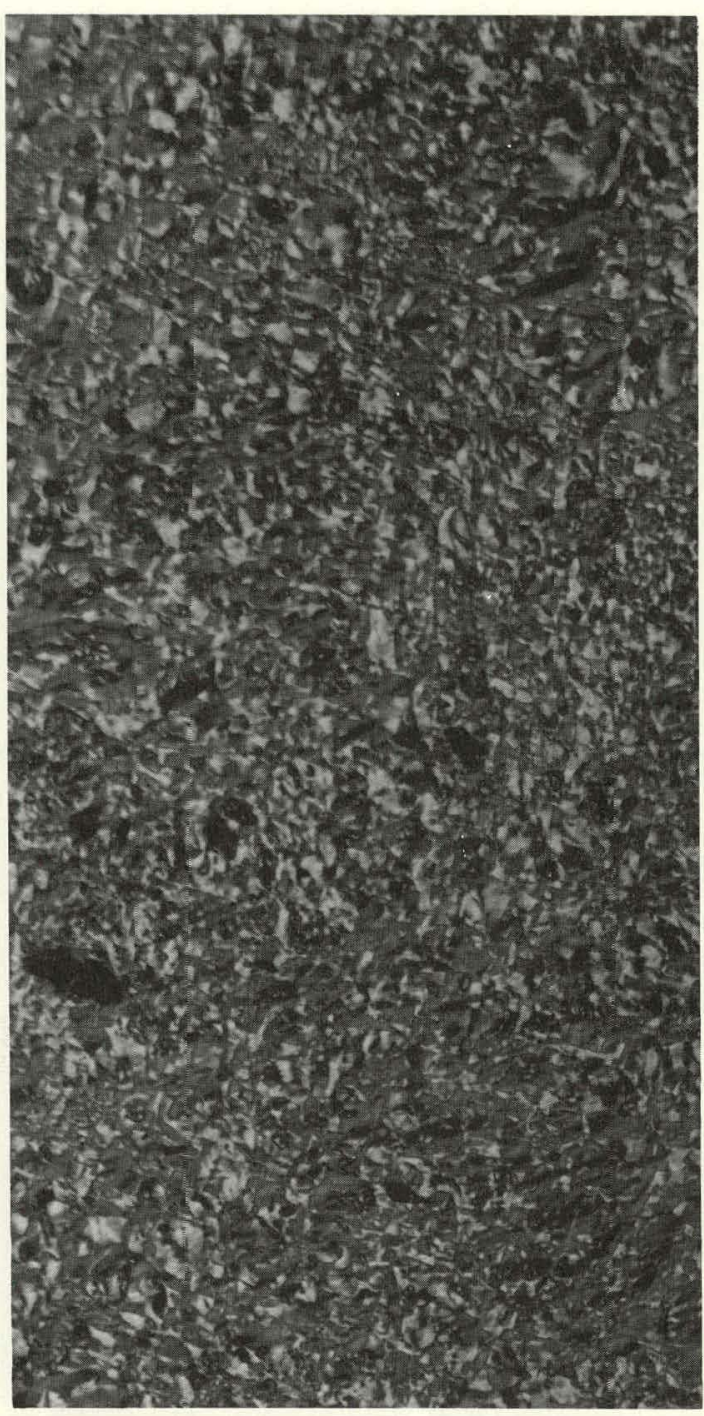

(b) With $30 \%$ FAF.

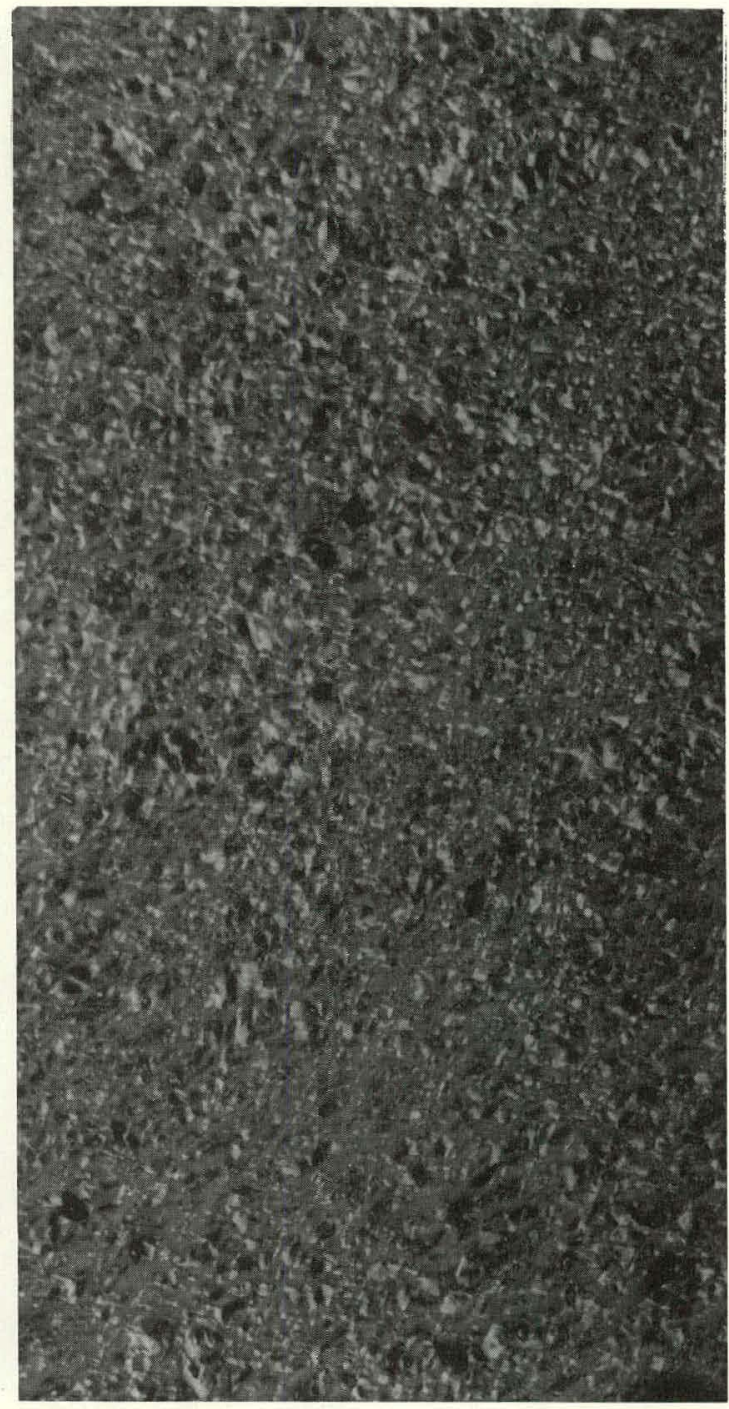

J250-7

Figure 5. MICROSTRUCTURES OF CARBONS (AFTER $2,800^{\circ} \mathrm{C}$ ) DERIVED FROM CINNAMYLIDENEINDENE/FURFURYLIDENEFLUORENE MIXTURES. (SEnSitive Tint; 250X) 


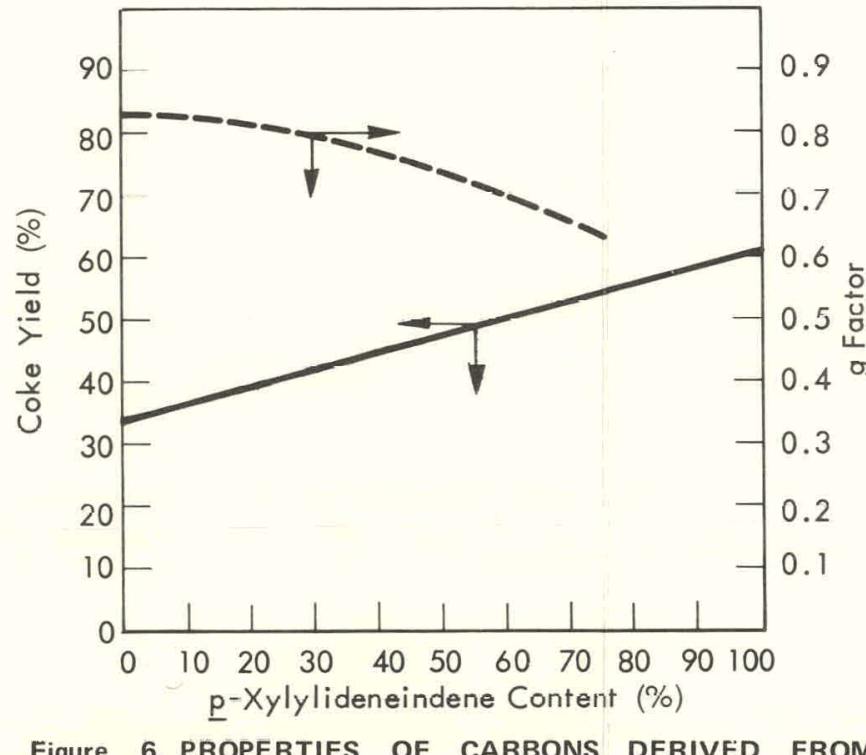

Figure 6. PROPERTIES OF CARBONS DERIVED FROM $\alpha$-METHYLCINNAMYLIDENEI MIXTURES AS FUNCTIONS OF THE $\bar{p}$-XYLYLIDENEINDEN CONTENT.

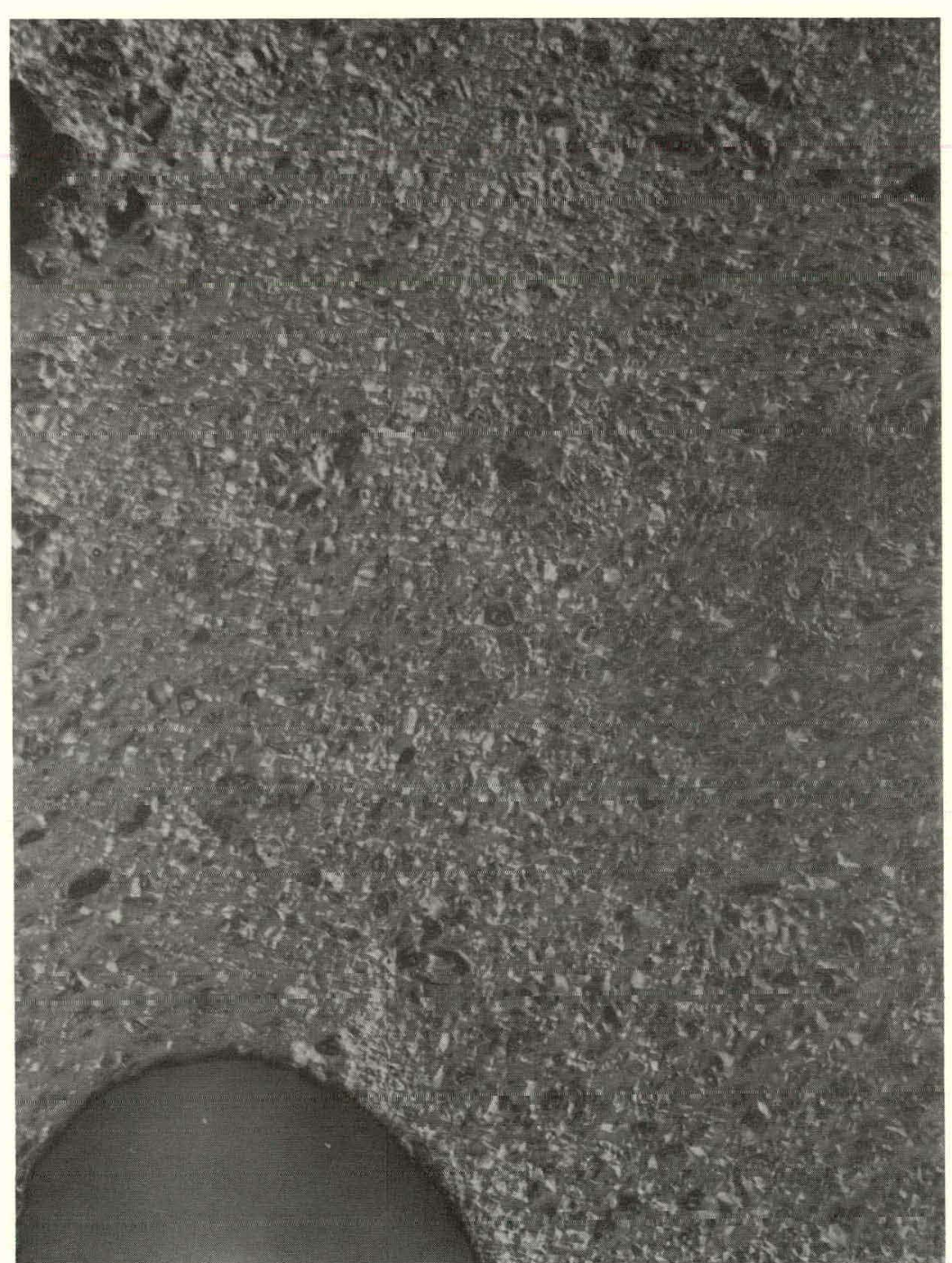

(a) With $30 \% \mathrm{XYN}$.

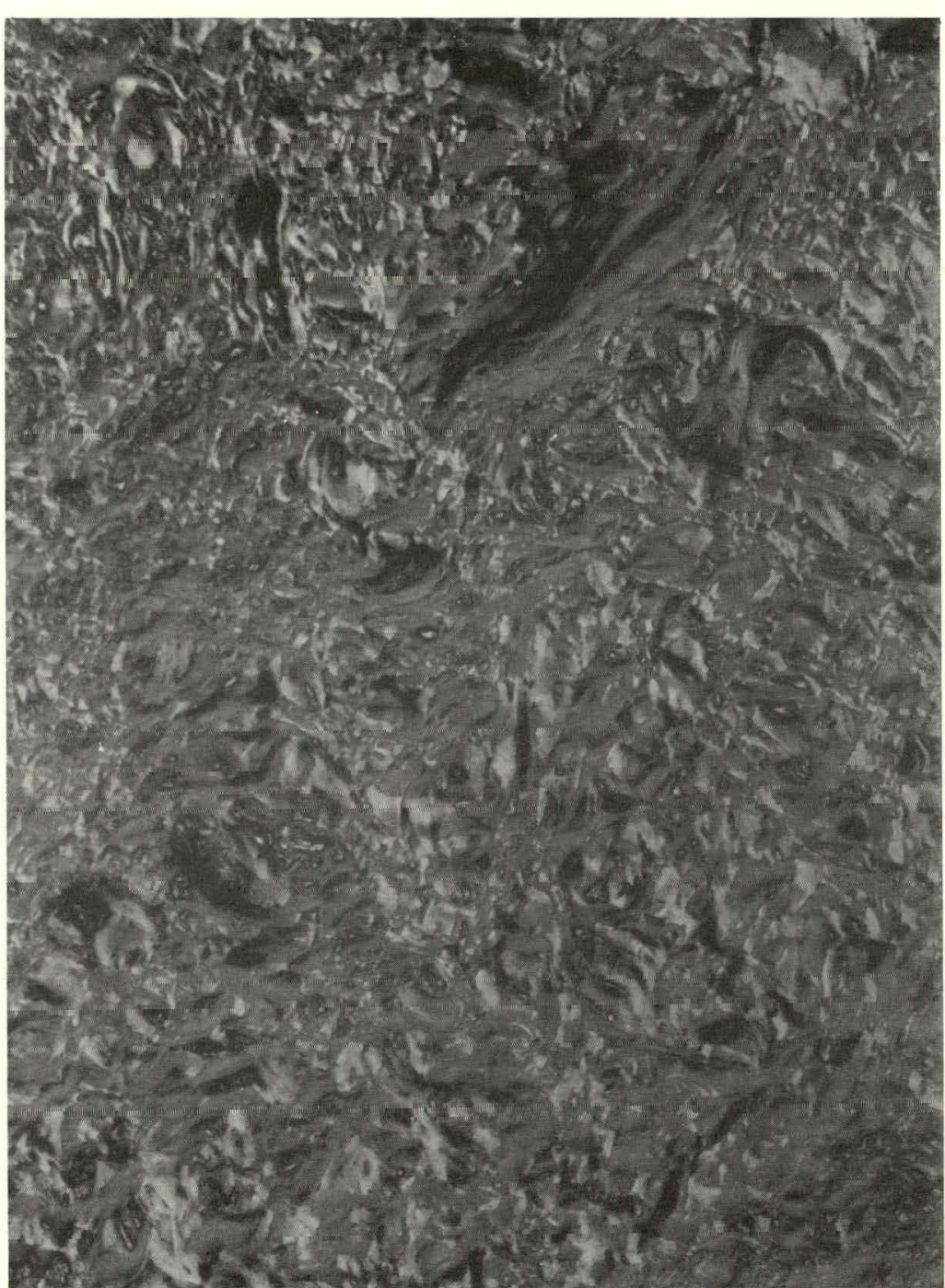

(b) With $40 \% \mathrm{XYN}$.

J249-9

Figure 1. MICRUSTRUCTURES OF CARBONS (AFTER $2,800^{\circ} \mathrm{C}$ ) DERIVED FROM $\alpha$-METHYLCINNAMYLIDENEINDENE/p-XYLYLIDENEINDENE MIXTURES. (Sensitive Tint; 250X) 


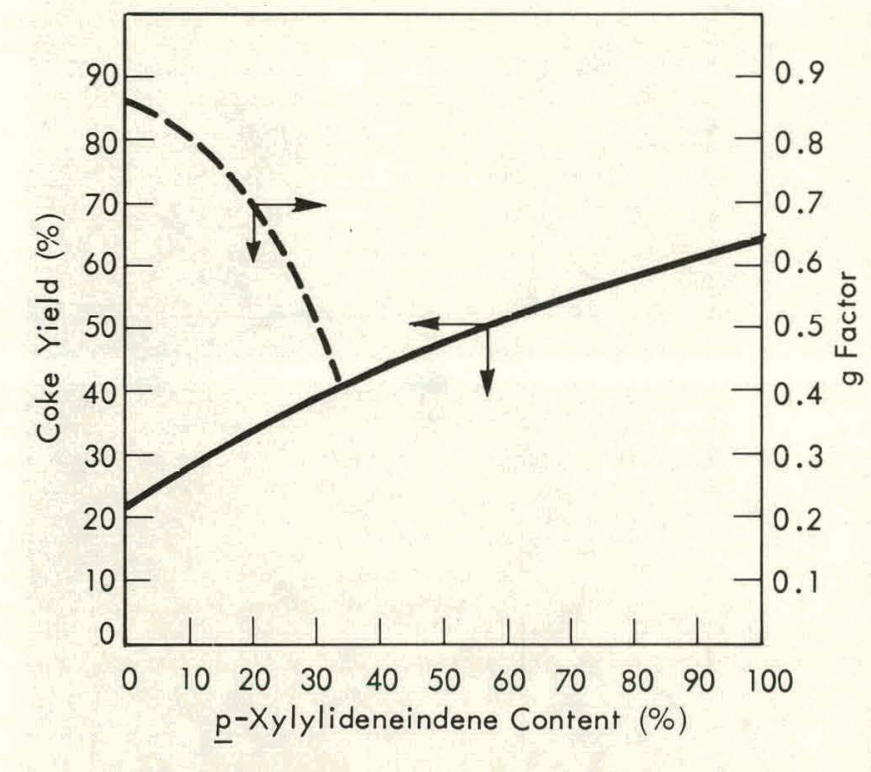

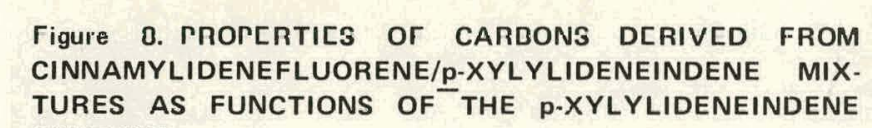
CONTENT

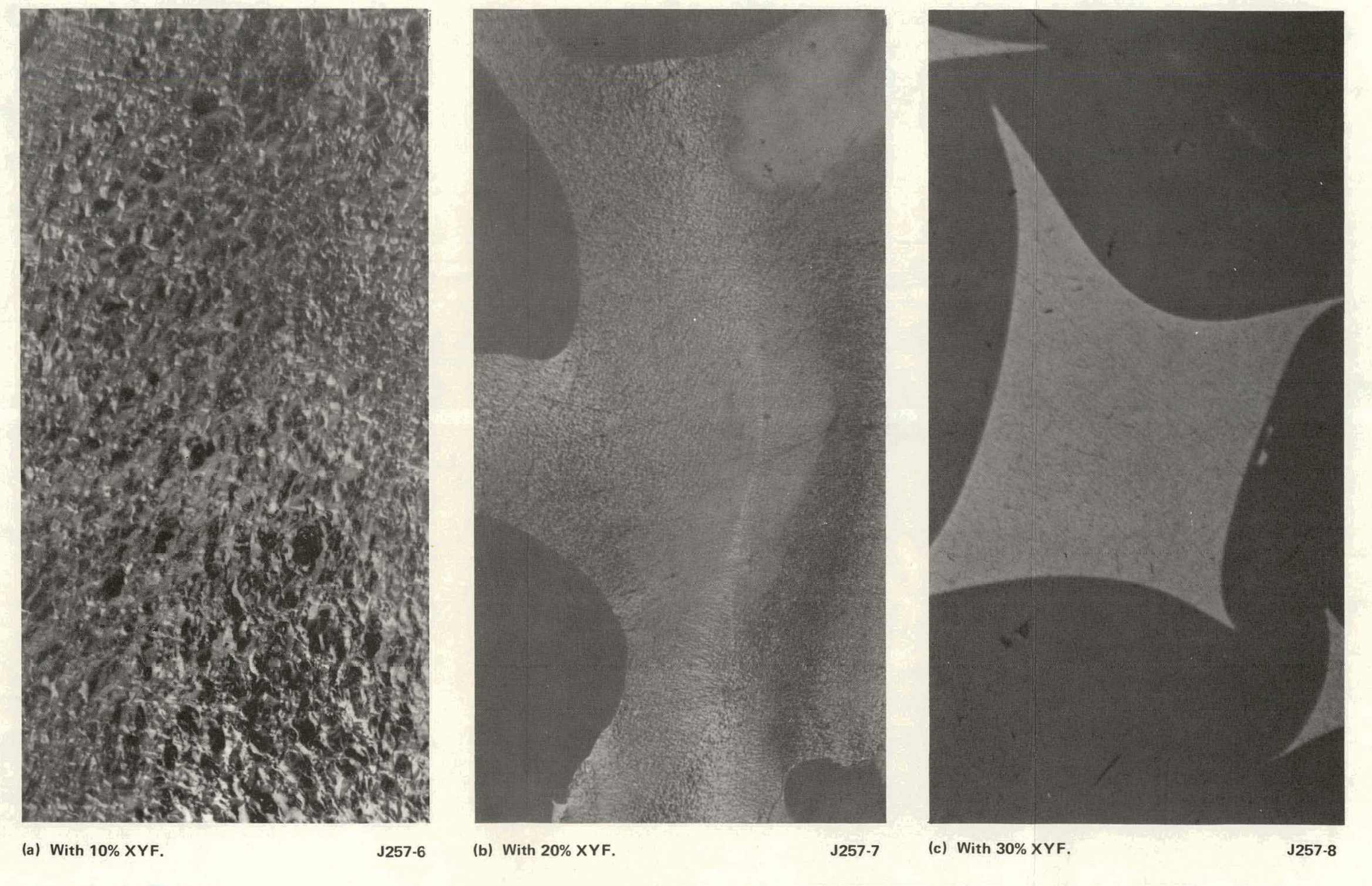

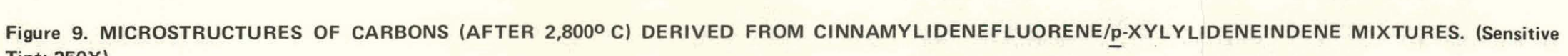




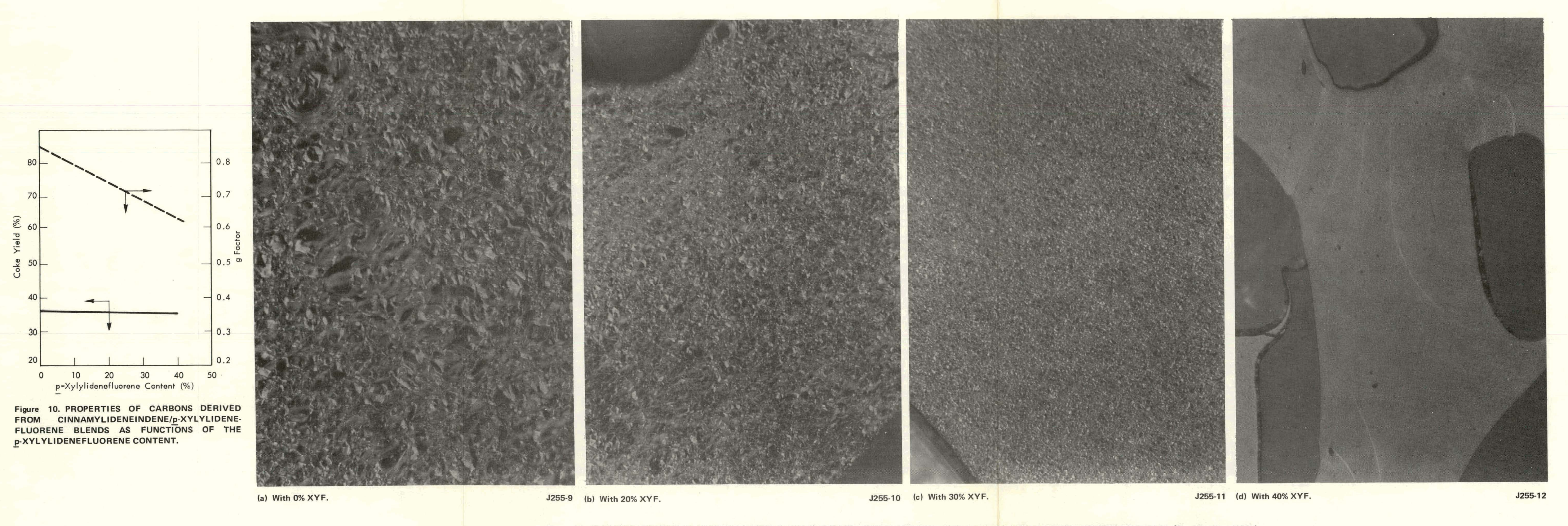

Figure 11. MICROSTRUCTURES OF CARBONS (AFTER 2,8000 C) DERIVED FROM CIINAMYLIDENEINDENE/P.XYLYLIDENEFLUORENE MIXTURES. (Sensitive Tint; 250X) 


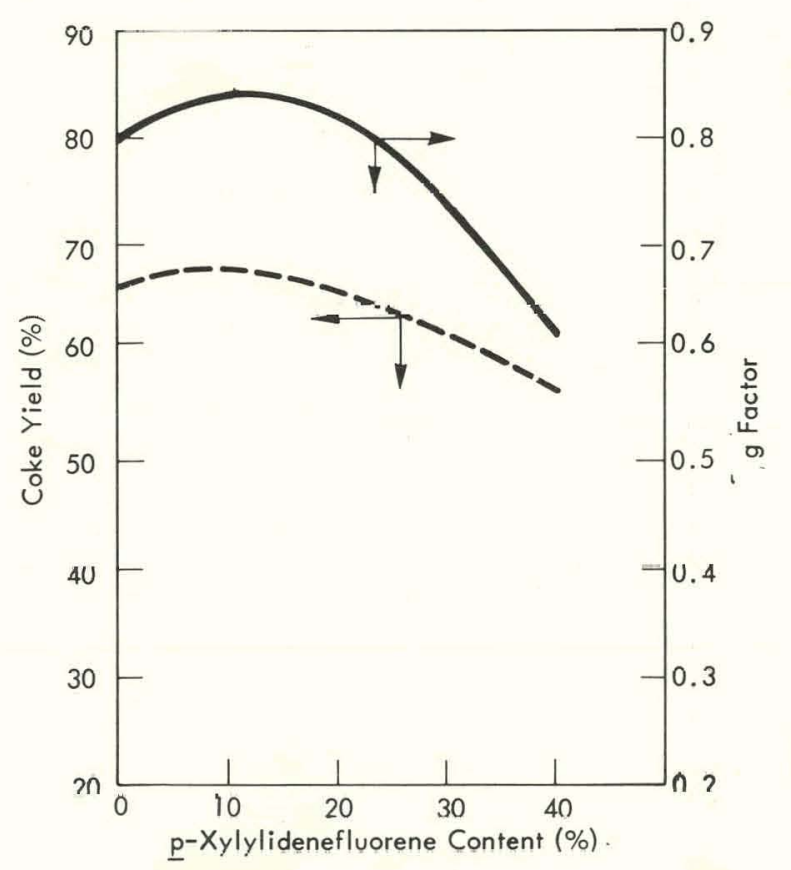

Figurc 12. PROPERTIES OF CARBONS DERIVED FROM HEAT-TREATED ISOTRUXENE/p-XYLYLIDENEFLUORENE MIXTURES AS FUNCTIONS OF THE p-XYLYLIDENEFLUORENE CONTENT.

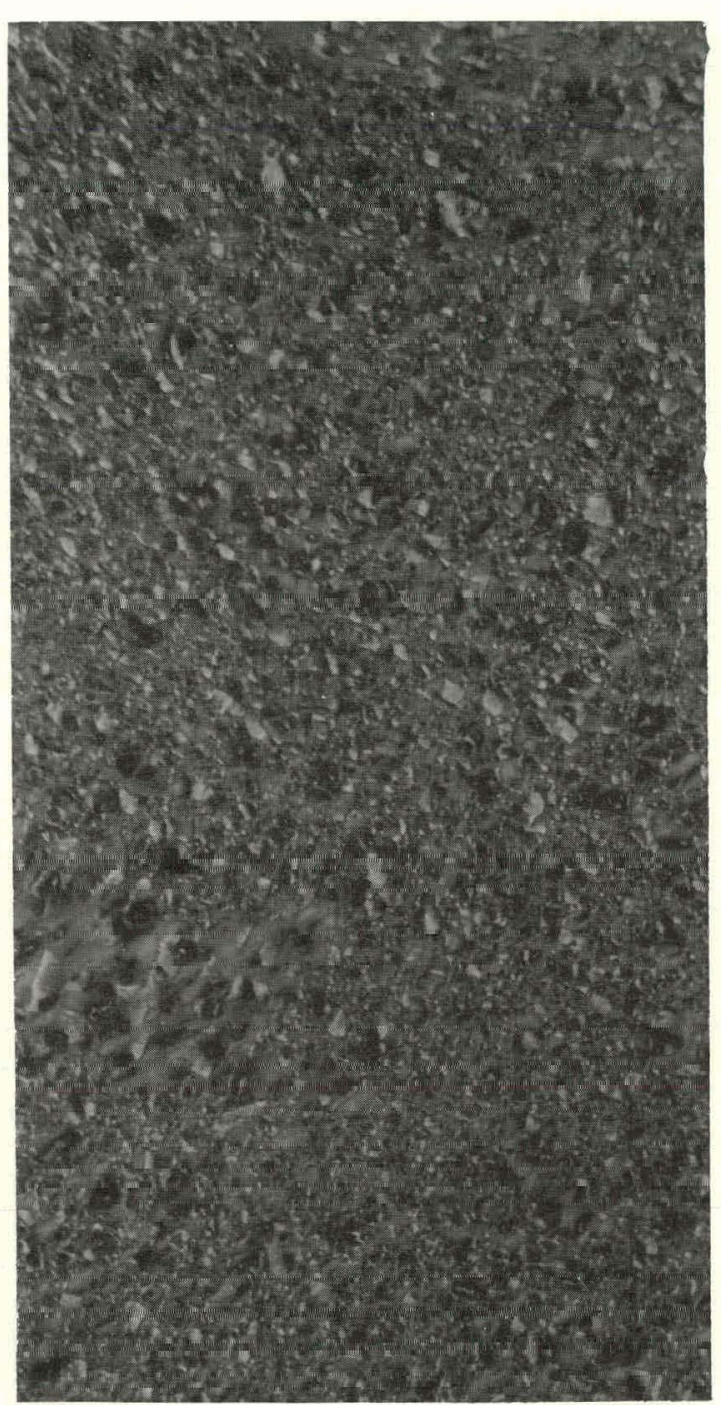

(a) With $20 \% \mathrm{XYF}$.

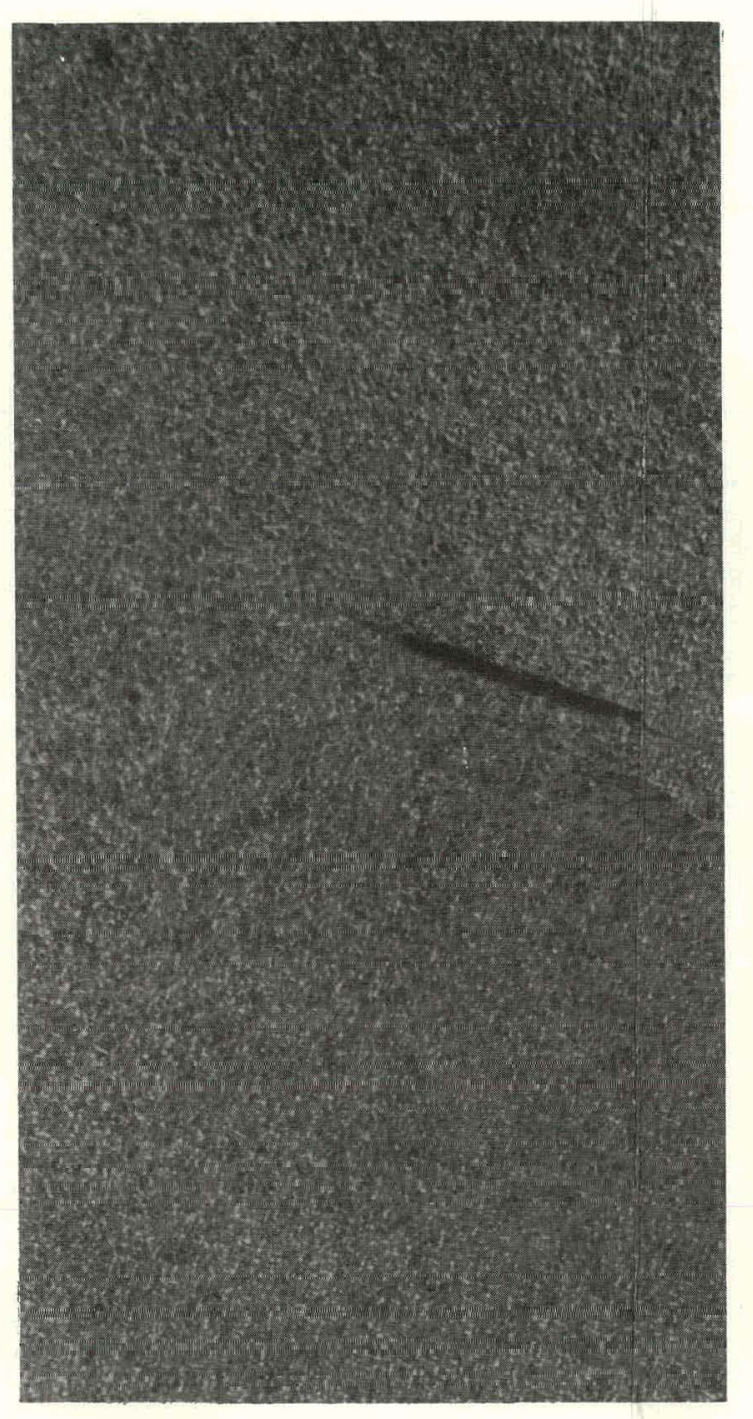

(b) With $30 \% \mathrm{XYF}$.

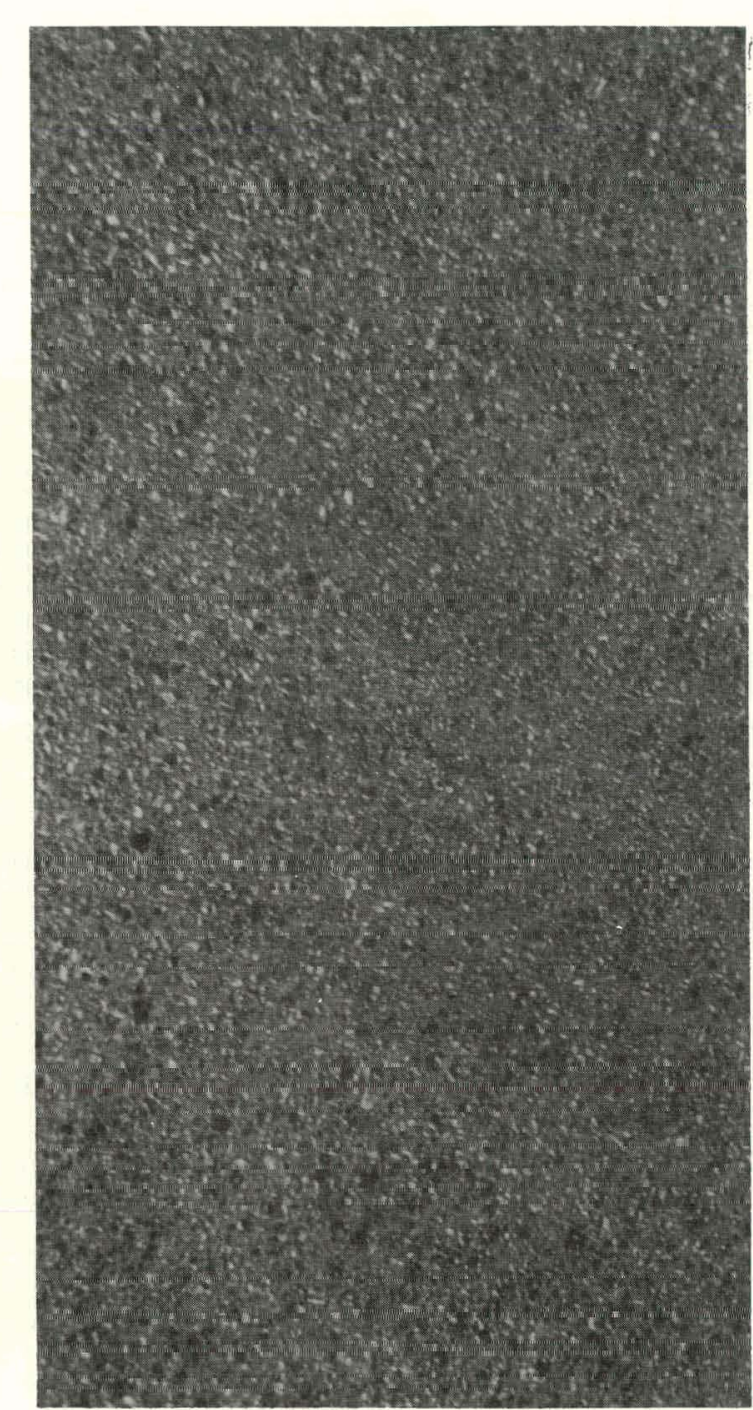

(c) With $40 \% \mathrm{XYF}$.

J256-12

Figure 13. MICROSTRUCTURES OF CARBONS (AFTER $2,800^{\circ} \mathrm{C}$ ) DERIVED FROM p-XYLYLIDENEFLUORENE/HEAT-TREATED ISOTRUXENE MIXTURES. (Sensitive Tint; 250X) 


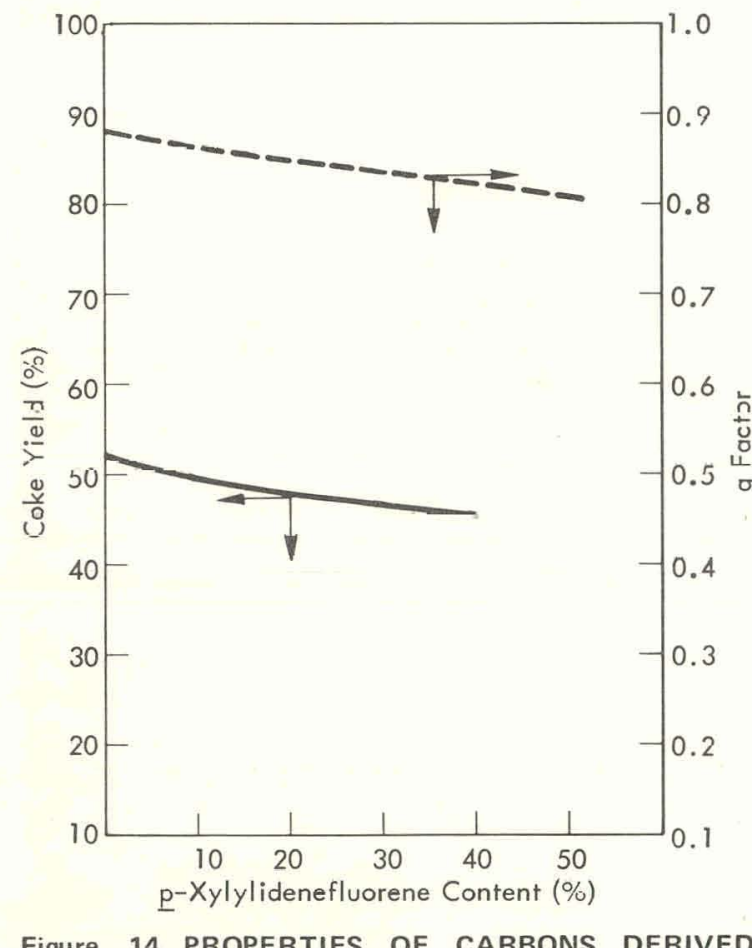

Figure 14. PROPERTIES OF CARBONS DERIVED FROM ASHLAND-240 PITCH/p-XYLYLIDENEFLUOR-
CNE DLCNDS AG TUNCTIONE OF THE - XYLYLI DENEFLUORENE CONTENT.

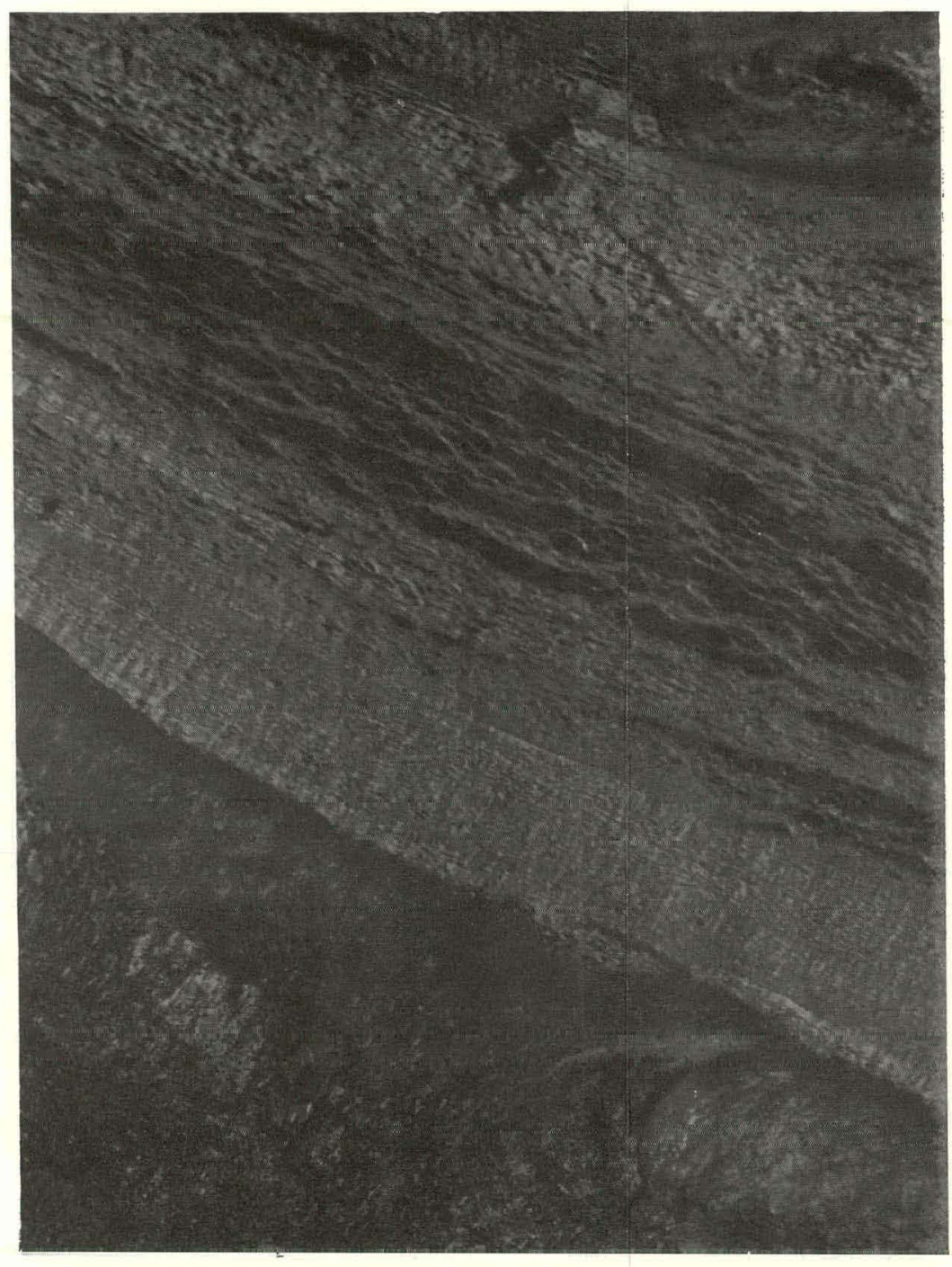

(a) With $20 \%$ XYF.

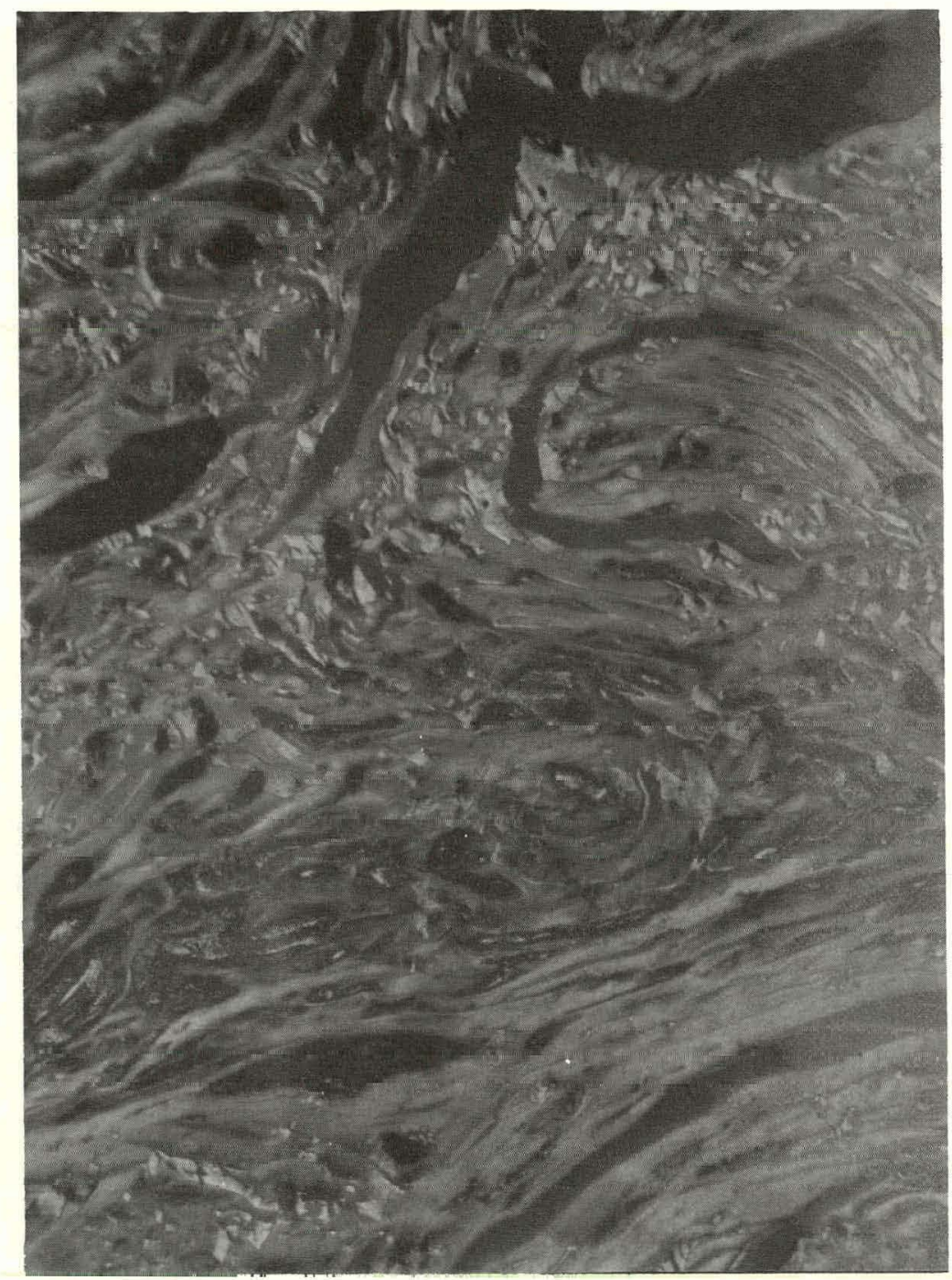

(b) With $40 \%$ XYF.

J256-8

Figure 15. MICROSTRUCTURES OF CARBONS (AFTER 2,800 C) DERIVED FROM ASHLAND-240 PITCH/p-XYLYLIDENEFLUORENE MIXTURES. (Sensitive Tint; 250X) 
Acenaphthylene/H-3 Resin Blends Microstructures of the $\mathrm{ACN} / \mathrm{H}$-3-derived carbons fired for one hour at $2800^{\circ} \mathrm{C}$ (Figure 18) revealed a rapid decrease in crystallinity from a highly crystalline carbon typical of that obtained from ACN to an extremely fine-grain carbon derived from the blend containing $20 \% \mathrm{H}-3$ resin. Blends containing greater than 20\% $\mathrm{H}-3$ resin were noncrystalline. Thus, $\mathrm{H}-3$ resin was an effective crosslinking agent for ACN.

Blends of H-3 Resin with Cinnamylideneindene, Heat-Treated Isotruxene, Ashland-240 Pitch, and 15-V Pitch-Microstructures of the $2800^{\circ} \mathrm{C}$ carbons derived from binary mixtures of $\mathrm{H}-3$ resin with CAI (Figure 19), heat-treated ITX (Figure 20), A-240 pitch (Figure 21), and 15-V pitch (Figure 22) revealed similar twophase carbons containing crystalline and noncrystalline regions. Since $\mathrm{H}-3$ resin (melting point of approximately $75^{\circ} \mathrm{C}$ ) thermosets rapidly at temperatures of approximately $120^{\circ} \mathrm{C}$, interaction between the resin and CAI (melting point of $190^{\circ} \mathrm{C}$ ) was expected to be minimal.

Decreased reactivity of ITX conferred by heat treatment overrides the possible interaction between the ITX and $\mathrm{H}-3$ resin which could have occurred due to the lower melting point of the ITX pitch $\left(130-150^{\circ} \mathrm{C}\right)$. Microstructures of blends of $\mathrm{H}-3$ with $\mathrm{A}-240$ (softening point of approximately $110^{\circ} \mathrm{C}$-Figure 21) and $15-\mathrm{V}$ (softening point of approximately $87^{\circ} \mathrm{C}$ - Figure 22) reflected the decreased reactivity of the pitches and/or the immiscibility of the $\mathrm{H}-3$ resin and pitches during polymerization and pyrolysis.

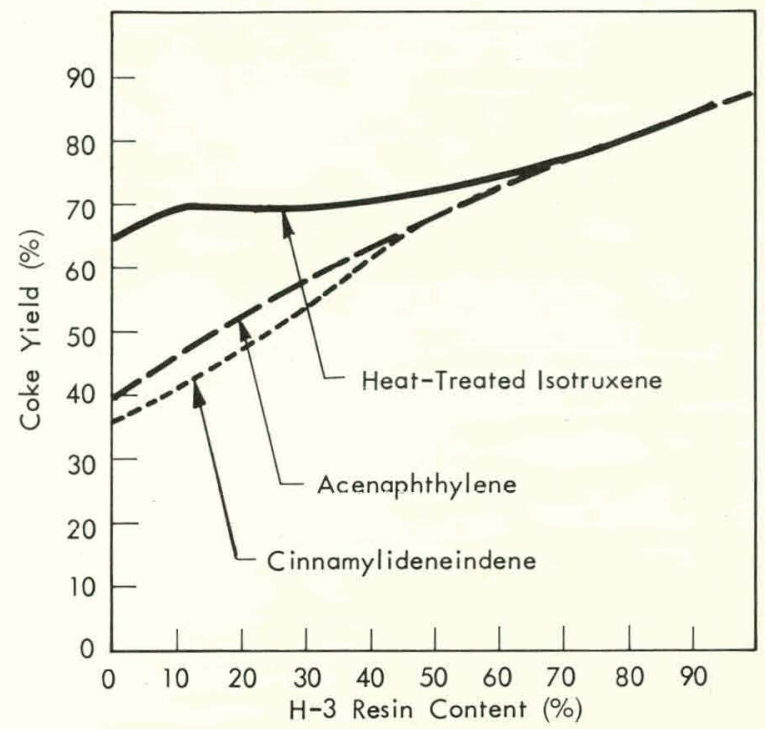

Figure 16. COKE YIELDS OF BINARY MIXTURES OF H-3 RESIN WITH ACENAPHTHYLENE, CINNAMYLIDENEINDENE, AND HEAT-TREATED ISOTRUXENE AS FUNCTIONS OF THE H-3 RESIN CONTENT.

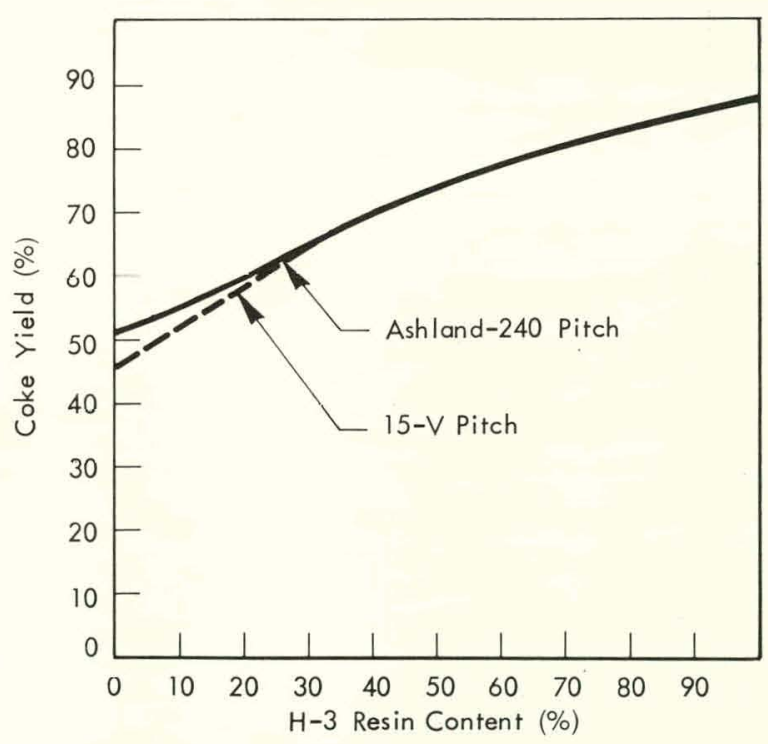

Figure 17. COKE YIELDS OF BINARY MIXTURES OF H-3 RESIN WITH ASHLAND-240 PITCH AND 15-V PITCH AS FUNCTIONS OF THE H-3 RESIN CONTENT.

Polymeric Cinnamylideneindene/H-3 Resin Blends-Since $\mathrm{H}-3$ had no effect on the properties of CAl-derived carbons, interest was focused on the potential crosslinking effect of $\mathrm{H}-3$ resin on a lower melting polymer of CAI. The polymer (CAI-340) had a ring-and-ball softening point of $67^{\circ} \mathrm{C}$. Thus, by sacrificing some amount of relative reactivity upon changing the monomer to polymer, a system was obtained in which both the $\mathrm{H}-3$ resin and CAI-340 were fluid prior to reaching the thermosetting temperature of the resin. 


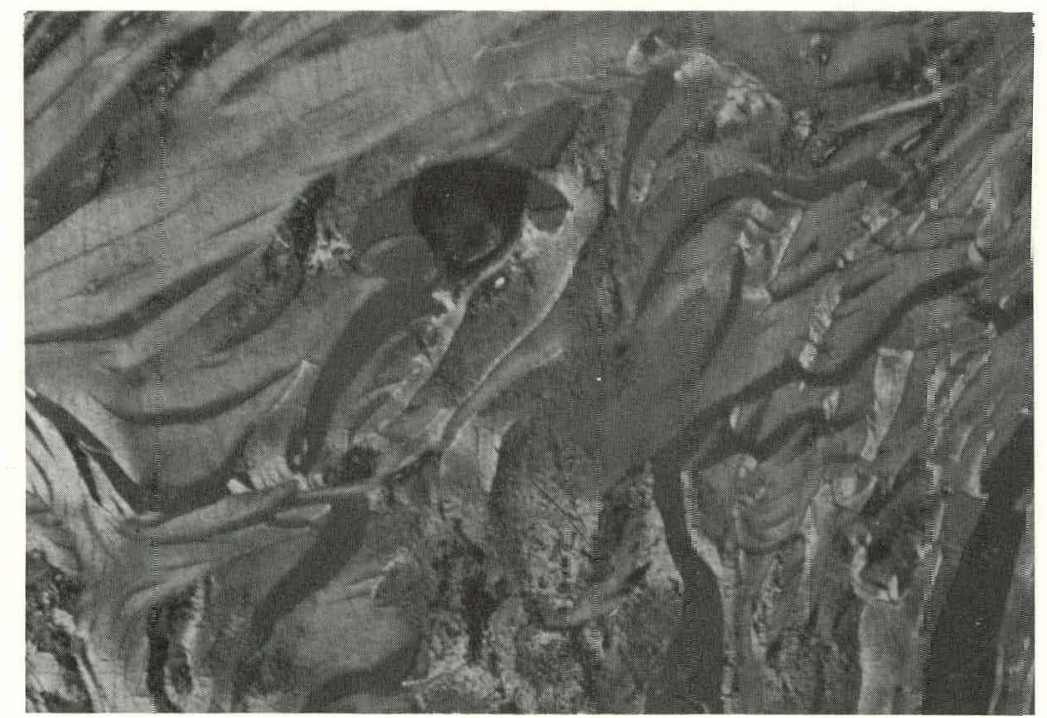

(a) With C\% Resin.

$326-3$

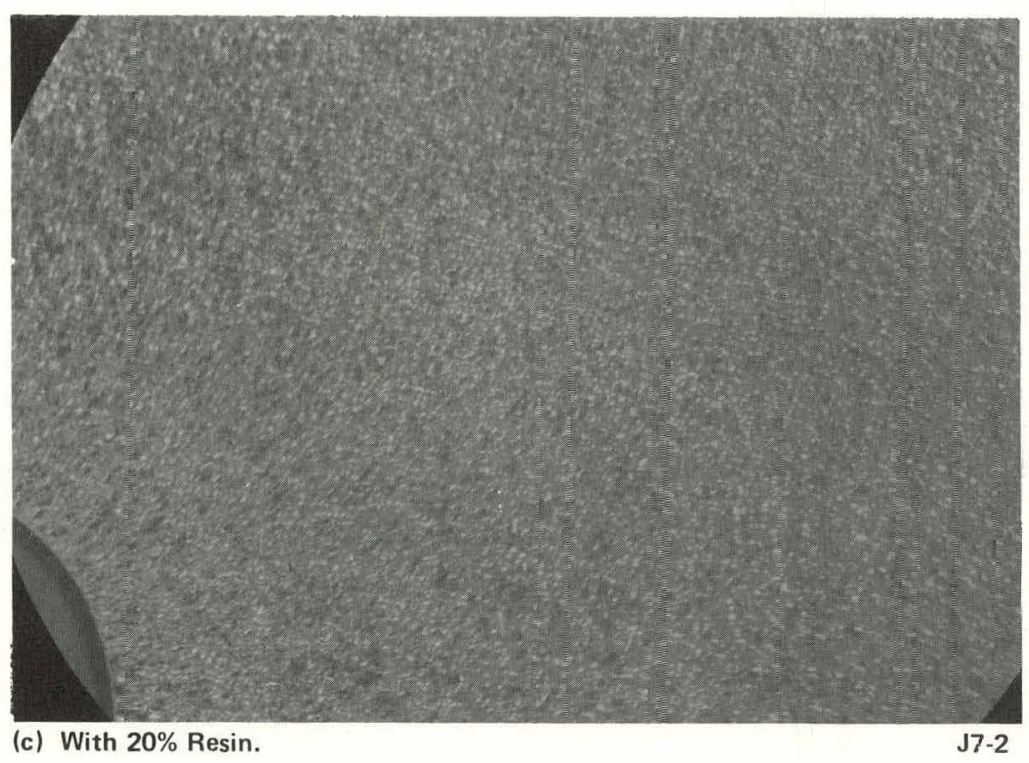

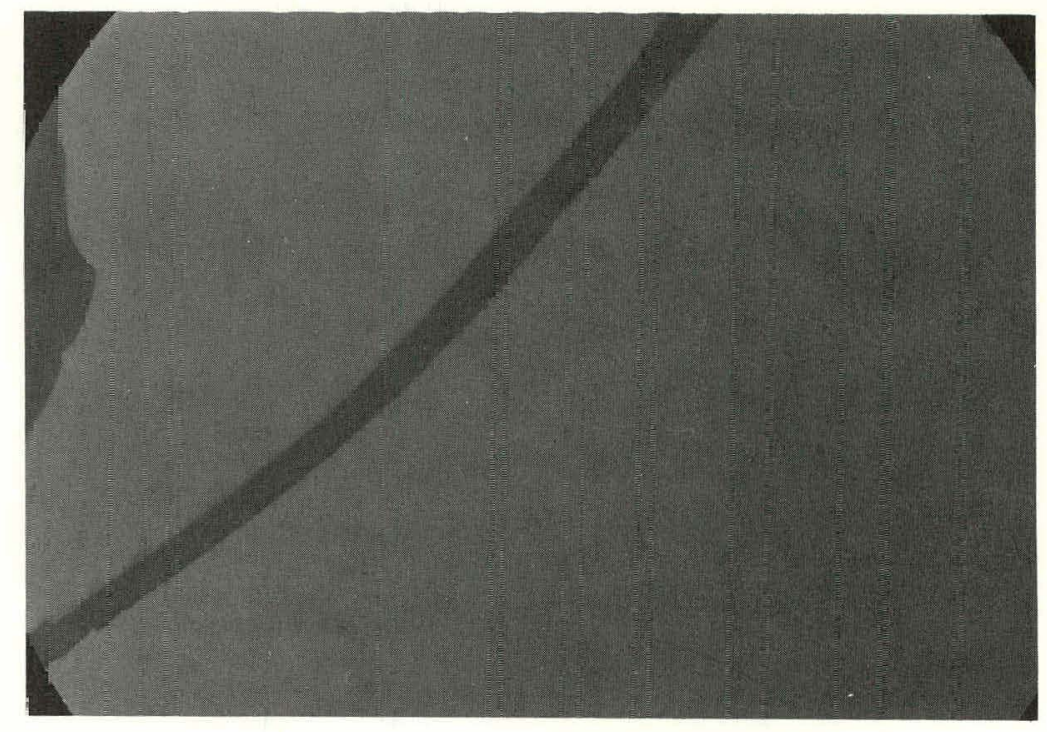

(b) With $10 \%$ Resin.

J7-1

Figure 18. MICROSTRUCTURES OF CARBONS (AFTER 2,800 C) DERIVED FRDM ACENAPHTHYLENE/H-3 RESIN BLENDS. (Sensit ve Tint; (250X) 


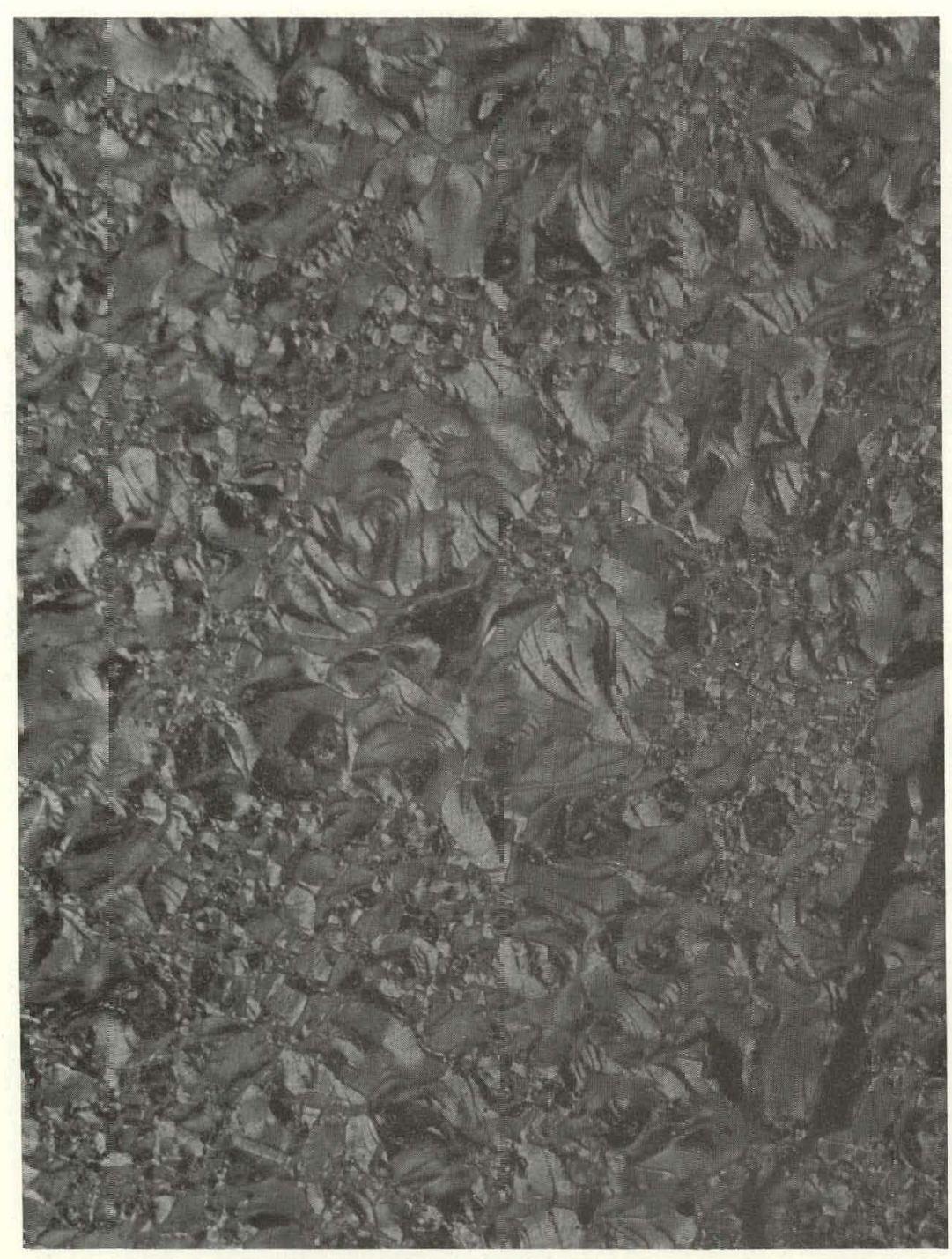

(a) Witา 0\% Resin.

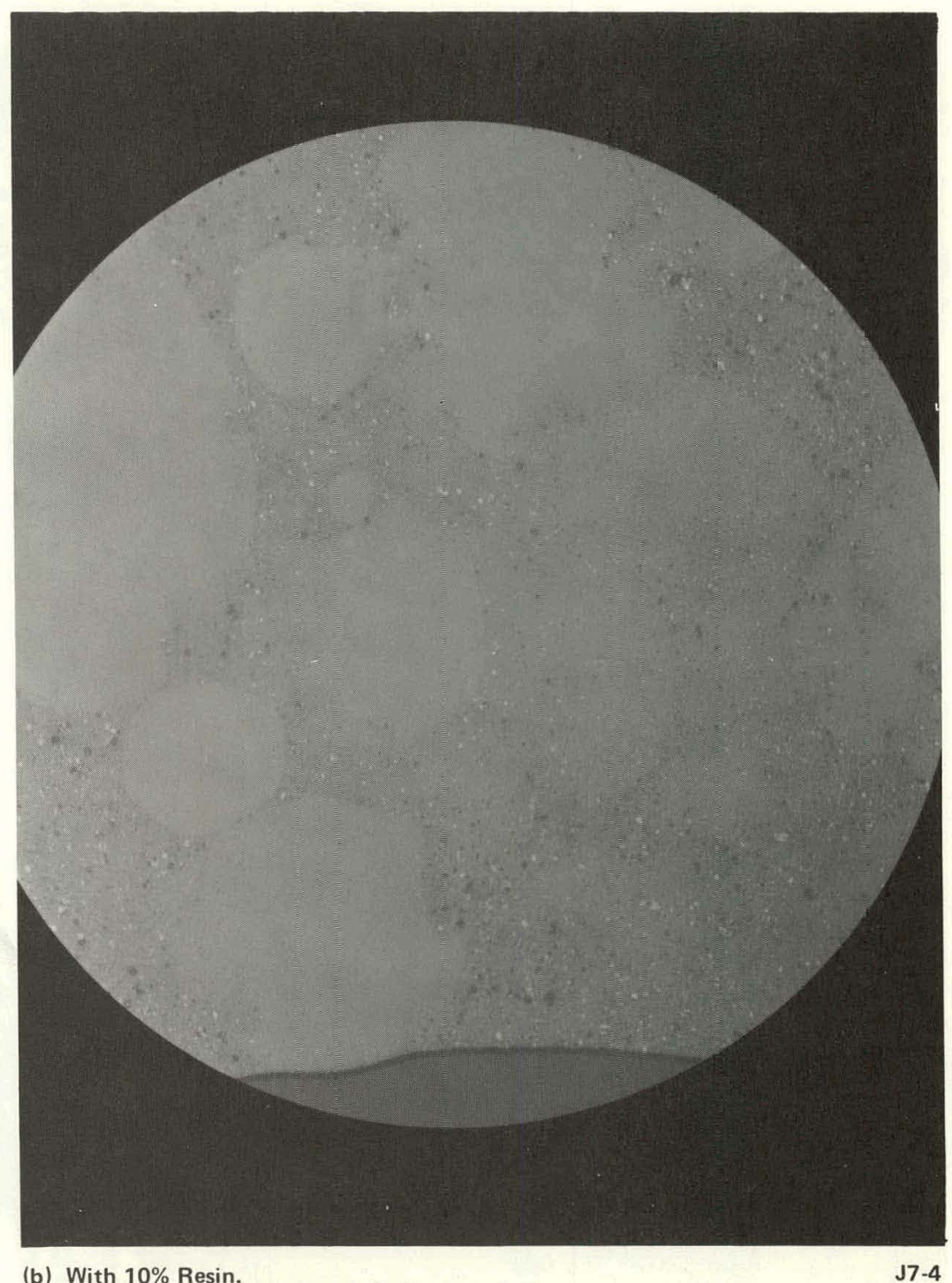

Figure 19. MICROSTRUCTURES OF CA.RBONS (AFTER 2,800 C) DERIVED FROM CINNAMYLIDENEINDENE/H-3 RESIN BLENDS. (Sensitive Tint; 250X) 


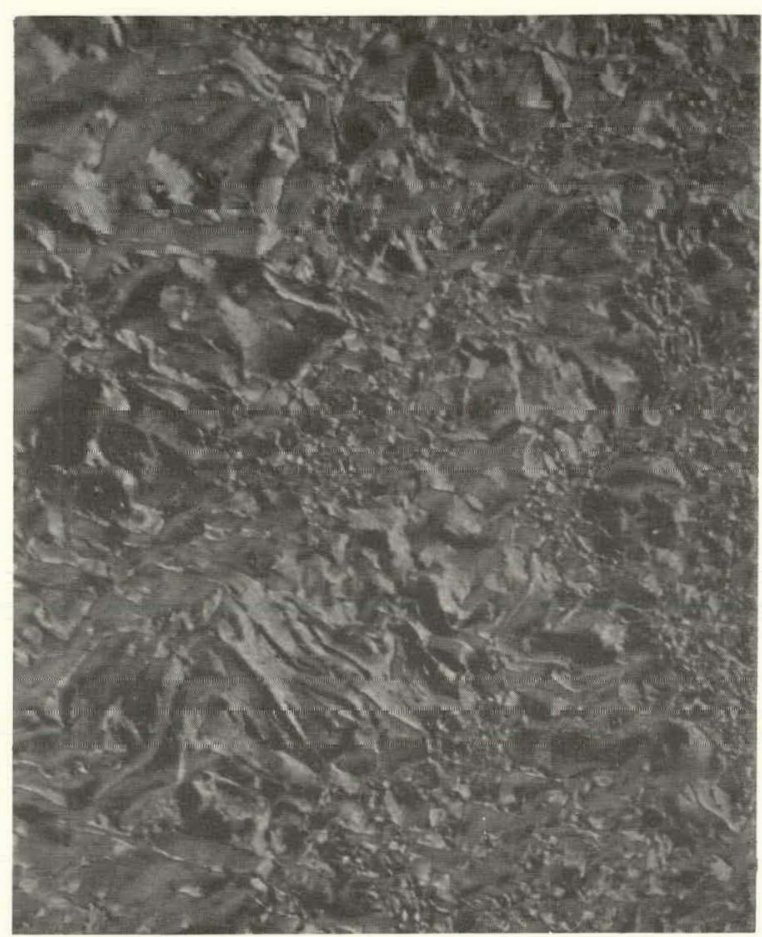

(a) With 0\% Resin.

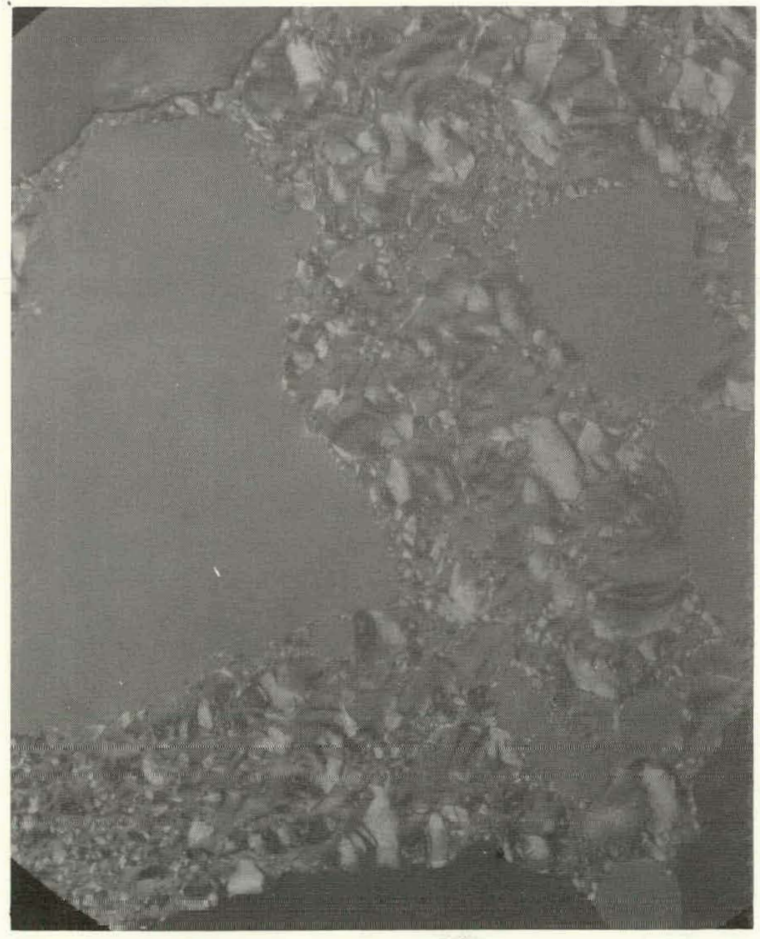

(c) With $30 \%$ Resin.
$\mathrm{J} 27-4$

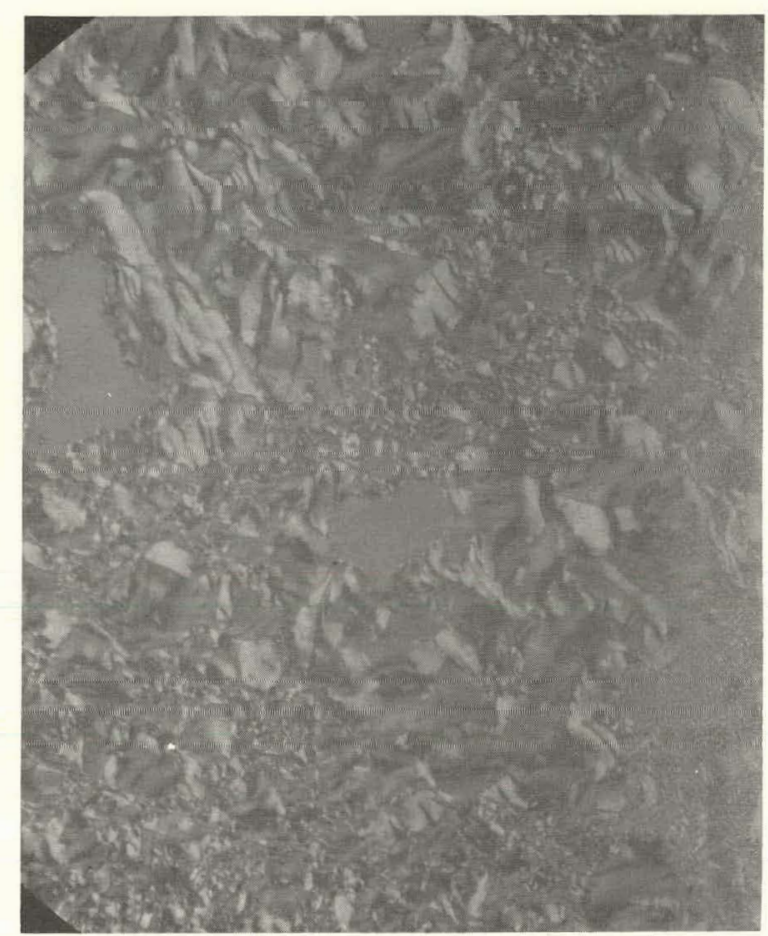

(b) With 10\% Resin.

J8-4

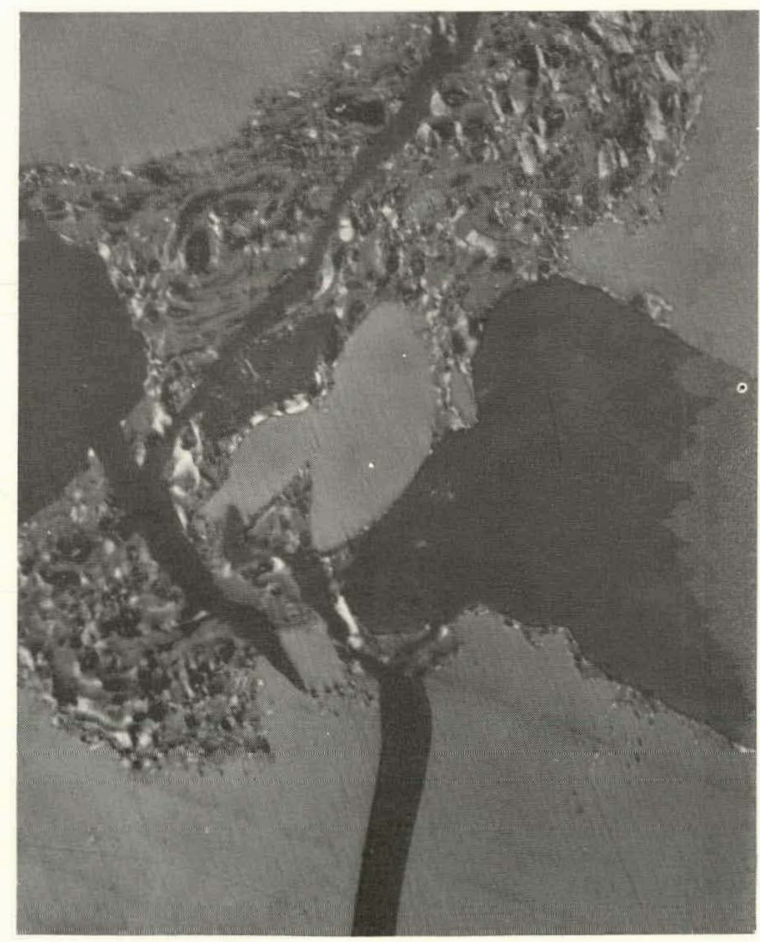

(d) With $40 \%$ Resin.

J27-3

Figure 20. MICROSTRUCTURES OF CARBONS (AFTER $2,800^{\circ} \mathrm{C}$ ) DERIVED FROM BLENDS OF HEAT-TREATED ISOTRUXENE AND H-3 RESIN. (Sensitive Tint; 250X) 


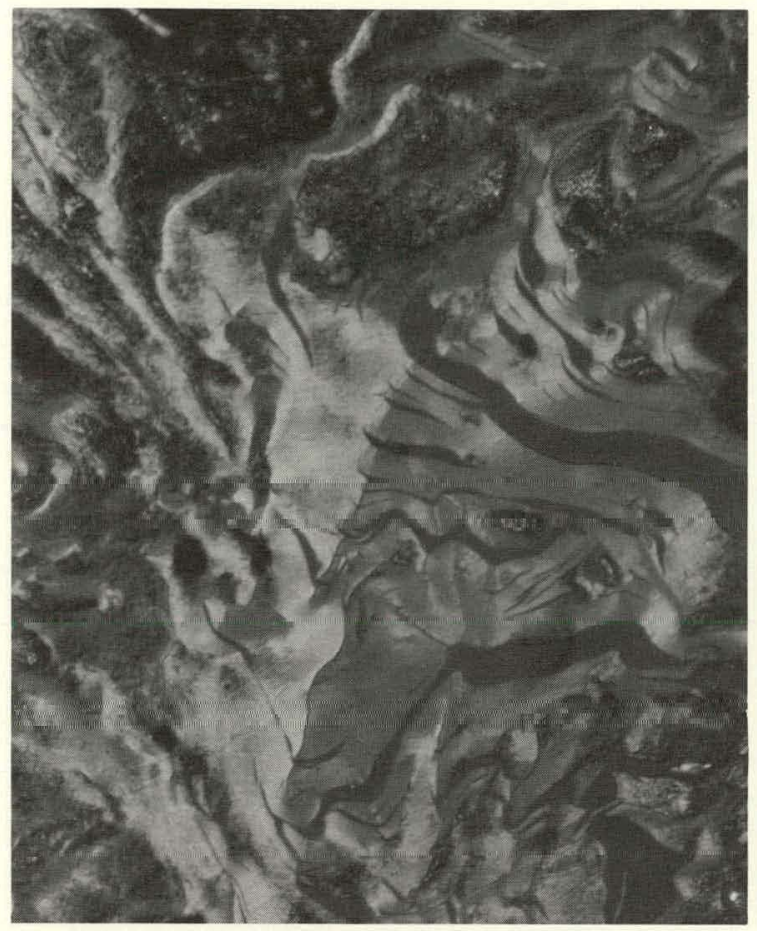

(a) With $0 \%$ Resin.

J27-2

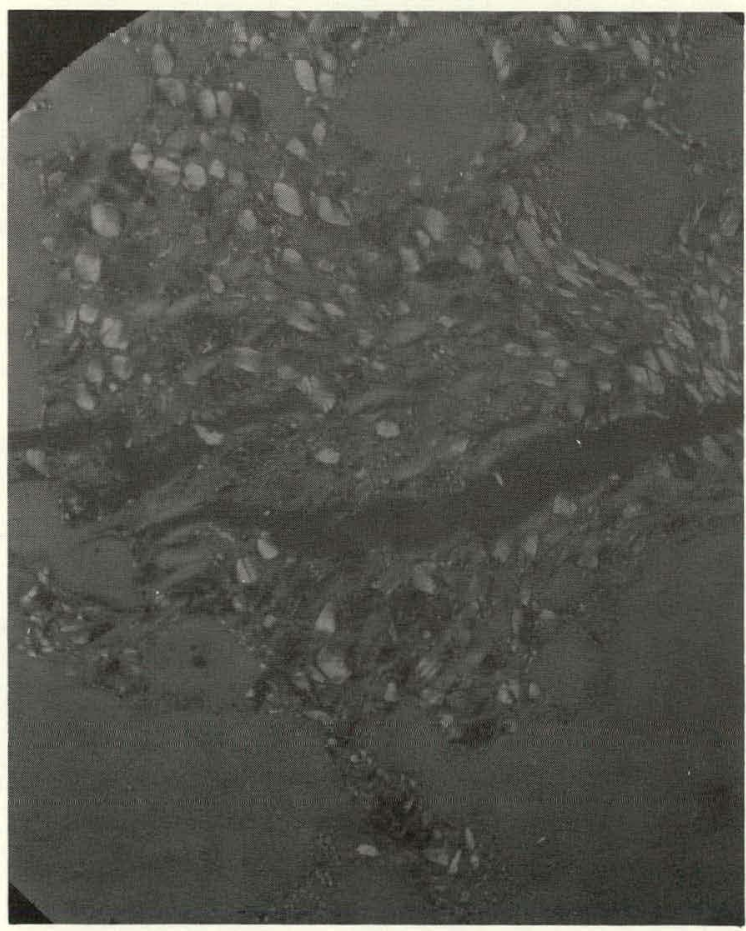

(c) With $30 \%$ Resin.

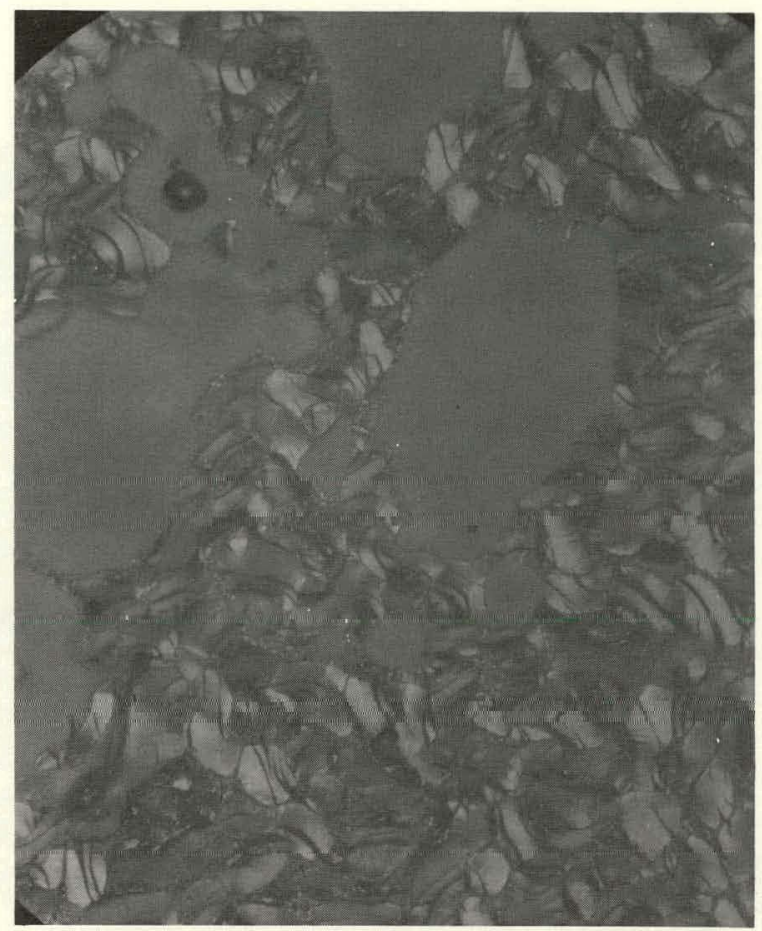

(b) With $20 \%$ Resin.

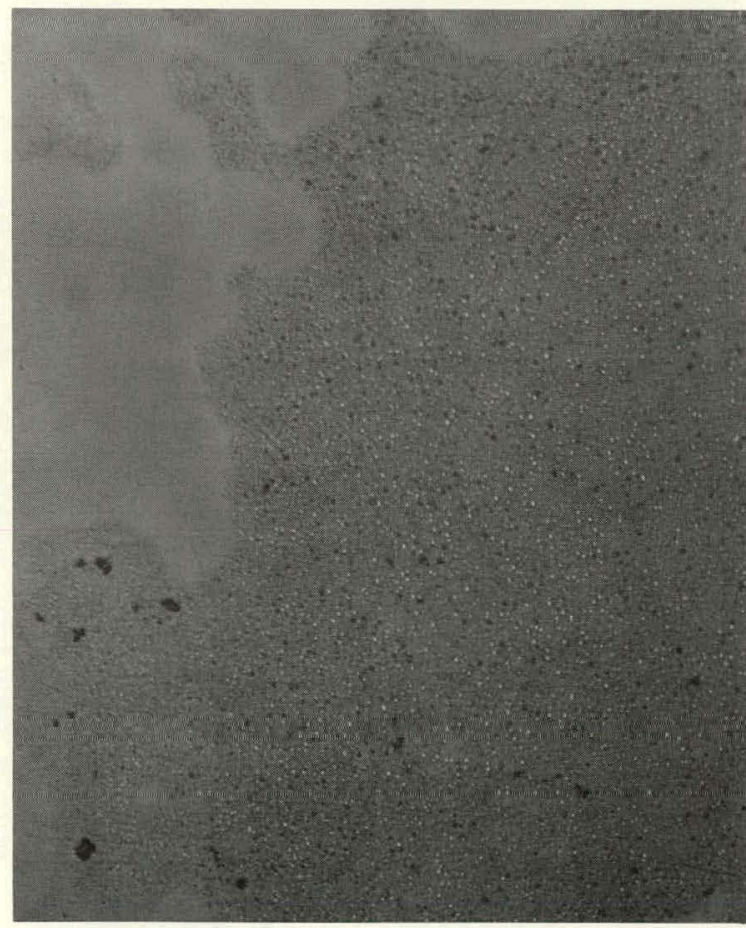

(d) With $40 \%$ Resin.

J27-1

Figure 21. MICROSTRUCTURES OF CARBONS (AFTER 2,800 C) DERIVED FROM BLENDS OF ASHLAND-240 PITCH AND H-3 RESIN. (Sensitive Tint; 250X) 


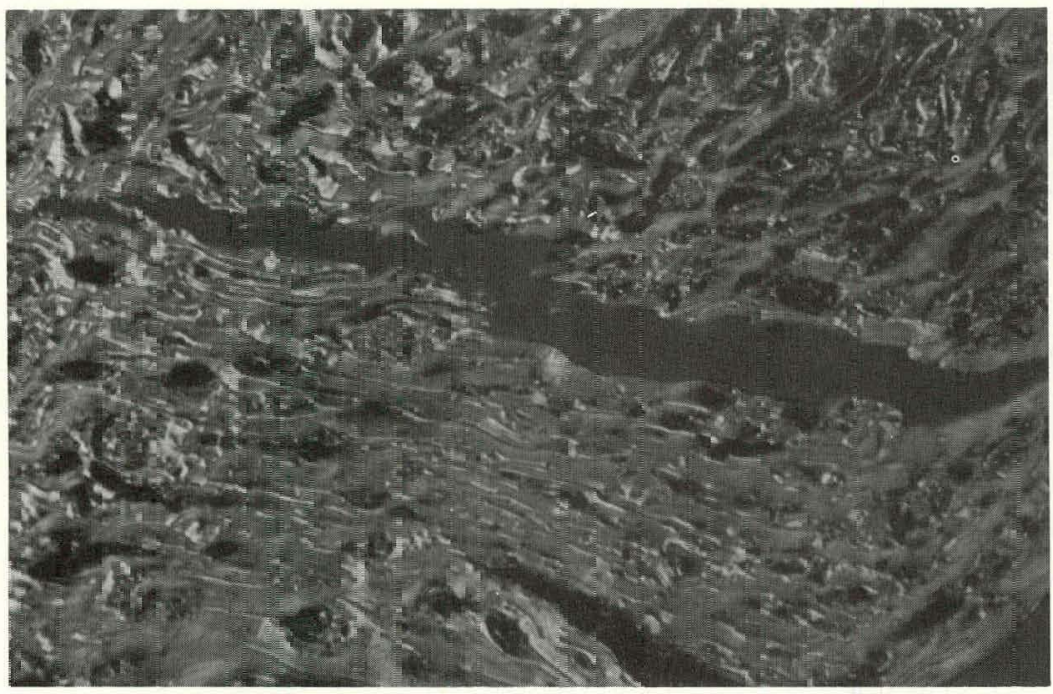

(a) With $0 \%$ Resin.

J2E-1

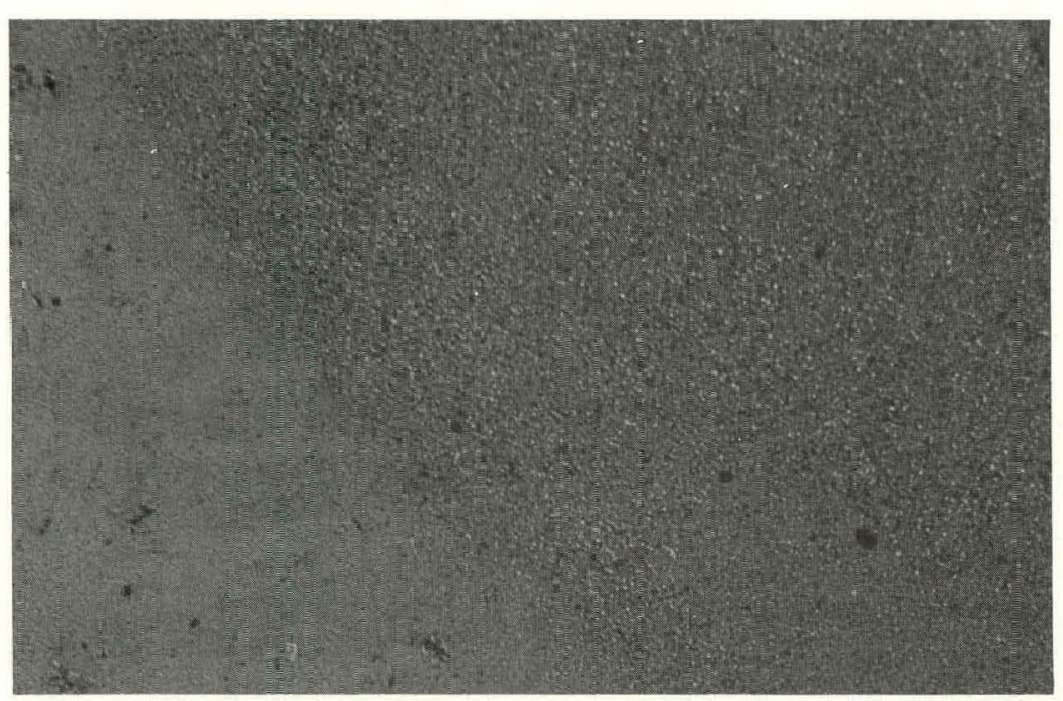

(c) With 3C\% Resin.

J22-4

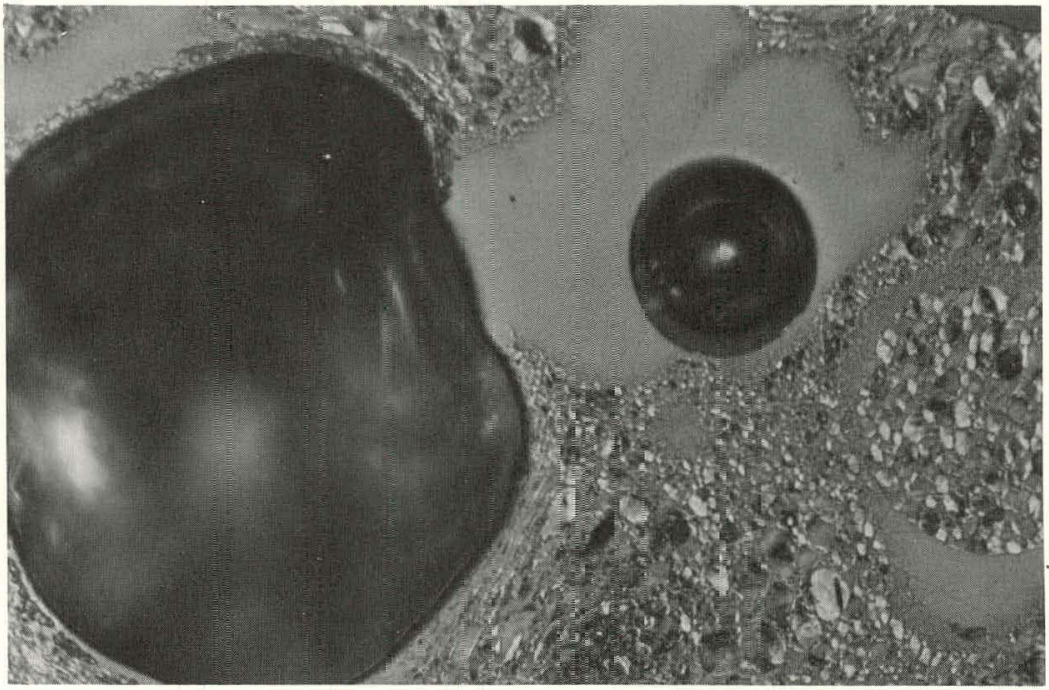

(b) With 10\% Resin.

J28-2

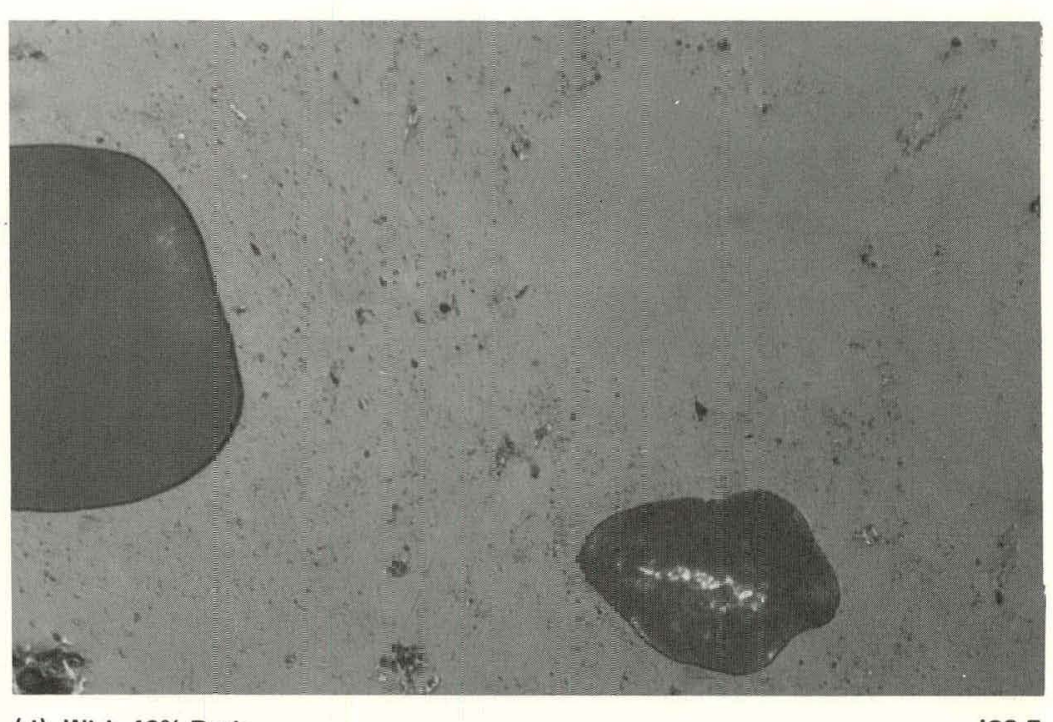

(d) With 40\% Resin.

Figure 22. MICROSTRUCTURES OF CARBONS (AFTER 2,800 C) CERIVED FROM BLENDS OF 15-V PITCH AND H-3 RESIN. (Sensitive Tint; 250X) 
Blends of CAI-340 and $\mathrm{H}-3$ resin were prepared by heating the CAI-340 until fluidity was obtained and then adding, with stirring, the $\mathrm{H}-3$ resin. The blends were then carbonized and heated to the graphitizing temperatures.

Carbon data, reported in Figure 23, indicated a rapid increase in coke yields with increasing $\mathrm{H}-3$ content, along with a rapid decrease in the degree of graphiticity of the derived carbons as indicated by the $\mathrm{g}$ factor.

Microstructures, as seen in Figure 24, also indicated a rapid decrease in crystallinity from a highly crystalline, heterogeneous carbon typical of that obtained from CAI-340 to a fine-grain, homogeneous carbon derived from the blend containing $20 \% \mathrm{H}-3$. Blends containing greater than $20 \% \mathrm{H}-3$ resulted in noncrystalline carbons.

Therefore, in contrast to the relative unreactivity of the CAI monomer, CAI-340 must be quite susceptible to the crosslinking effects of the $\mathrm{H}-3$ during pyrolysis, despite a loss of reactivity incurred by using the polymer.

In summary, $\mathrm{H}-3$ resin was an effective additive for the controlled variation of properties of carbons derived from CAI-340 and ACN. For $\mathrm{H}-3$ to be an effective crosslinking additive for other precursors, the percursor must be: (1) relatively reactive, and (2) fluid and miscible with the resin prior to the thermosetting temperature of the resin $\left(\sim 120^{\circ} \mathrm{C}\right)$.

\section{Evaluation of Pyromellitic Dianhydride as a Crosslinking Additive}

The structure of pyromellitic dianhydride (PMDA) is such that thermal degradation results in the production of highly reactive benzyne intermediatcs:

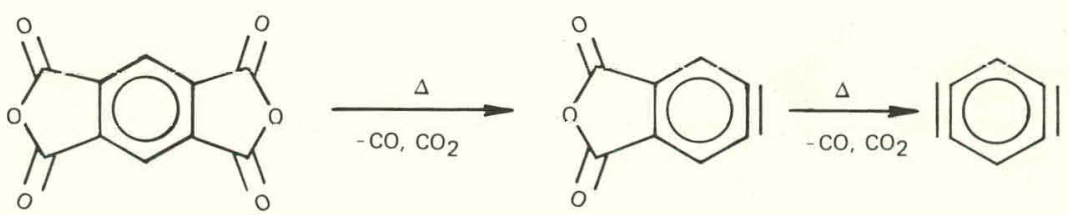

These highly reactive benzyne intermediates should be useful as crosslinking agents for controlling the degree of fluidity and/or molecular mobility of the carbon precursors during polymerization and pyrolysis, which should allow for control of the carbon properties. Usefulness of PMDA as a crosslinking additive for CAI and A-240 has been previously reported. $(2,4,6)$ Blends of PMDA with MCAI and CAF were carbonized to determine if PMDA could be used to obtain control of the properties of carbon derived from these two precursors.

$\alpha$-Methylcinnamylideneindene/Pyromellitic Dianhydride Blends-Coke yields of carbons derived from MCAI/PMDA blends increased to an apparent maximum at a PMDA content of approximately $30 \%$, as indicated in Figure 25 , while the $\mathrm{g}$ factors of the $2800^{\circ} \mathrm{C}$ carbons indicated a rapid decrease in crystallinity with increasing PMDA content. Microstructures of the $2800^{\circ} \mathrm{C}$ carbons, shown in Figure 26, also revealed the transition in crystallinity from a highly crystalline carbon typical of that obtained from MCAI to a fine-grain homogeneous carbon. Similar results were noted for CAI/PMDA blends. ${ }^{4}$ ) 
Cinnamylidenefluorene/Pyromellitic Dianhydride Blends-Coke yields of CAF/PMDA blends continue to increase as the PMDA content increased to 30\% (Figure 27). The degree of graphiticity, as indicated by the $\mathrm{g}$ factor, decreased quite rapidly, indicating interaction between the PMDA and CAF. Microstructures of the $2800^{\circ} \mathrm{C}$ carbons, shown in Figure 28, indicated a decrease in crystallinity as the PMDA content increased, much in the same manner as the CAI/PMDA blends. ${ }^{(4)}$ Thus, the inclusion of PMDA was an effective means for controlling properties of carbon derived from $\mathrm{MCAI}$ and $\mathrm{C} \wedge \mathrm{F}$.

\section{Evaluation of Dicyclopentadiene as a} Crosslınkıng Addıtıve

Efforts to obtain carbon property control have led to the search for organic systems which contain reactive double bonds which could give rise to crosslinking

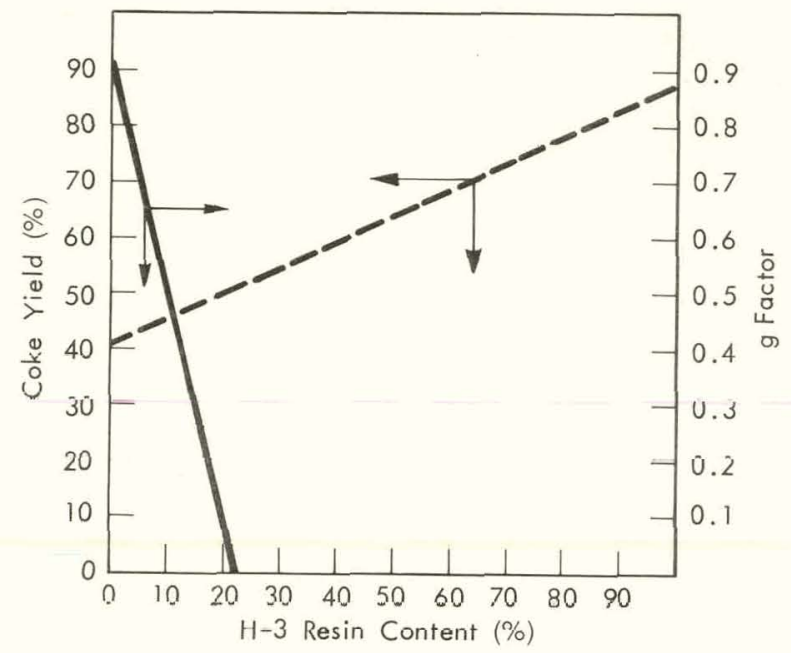

Figure 23. PROPERTIES OF CARBONS DERIVED FROM BLENDS OF H-3 RESIN AND AUTOCLAVE-POLY. MERIZED CINNAMYLIDENEINDENE. characteristics that lead to thermosetting rather than thermoplastic materials. This present study involved the evaluation of dicyclopentadiene (DCPD) as a crosslinking agent. Due to the volatility of dicyclopentadiene under normal carbonization conditions employed in this study, the binary mixtures of DCPD and the precursor were heated in a gas-pressure autoclave prior to carbonization. Coke yield data obtained from autoclaved CAI/DCPD and ACN/DCPD blends are illustrated in Figure 29.

Acenaphthylene/Dicyclopentadiene Blends-As indicated in Figure 2y, coke yields of ACN/DCPD blends were essentially constant for concentrations of DCPD less than approximately 67\%, while the coke yields increased rapidly as the DCPD content approached $100 \%$. Microstructures of the respective carbons after firing to $2800^{\circ} \mathrm{C}$ indicated a decrease in crystallinity as the DCPD content increased (Figure 30).

Blends containing 33 and 50 percent DCPD yielded highly crystalline, heterogeneous carbons, while a fairly homogeneous, fine-grain structure was obtained from the blend containing 67\% DCPD. As indicated in Figure 30, View d, carbon derived from autoclaved DCPD was heterogeneous, containing areas of varying degrees of crystallinity.

Cinnamylideneindene/Dycyclopentadiene Blends - Coke-yield values of autoclaved CAI/ DCPD blends were fairly constant as the dicyclopentadiene content increased to $50 \%$ (Figure 29), but increased from approximately 33 to $73 \%$ as the dicyclopentadiene increased to $100 \%$. Microstructures of the respective carbons after firing for one hour at $2800^{\circ} \mathrm{C}$ indicated a decrease in crystallinity as the dicyclopentadiene content increased (Figure 31).

Carbon derived from the polymerized blend containing 33\% dicyclopentadiene was heterogeneous, showing areas with flow lines and areas of a fine-grain microstructure 


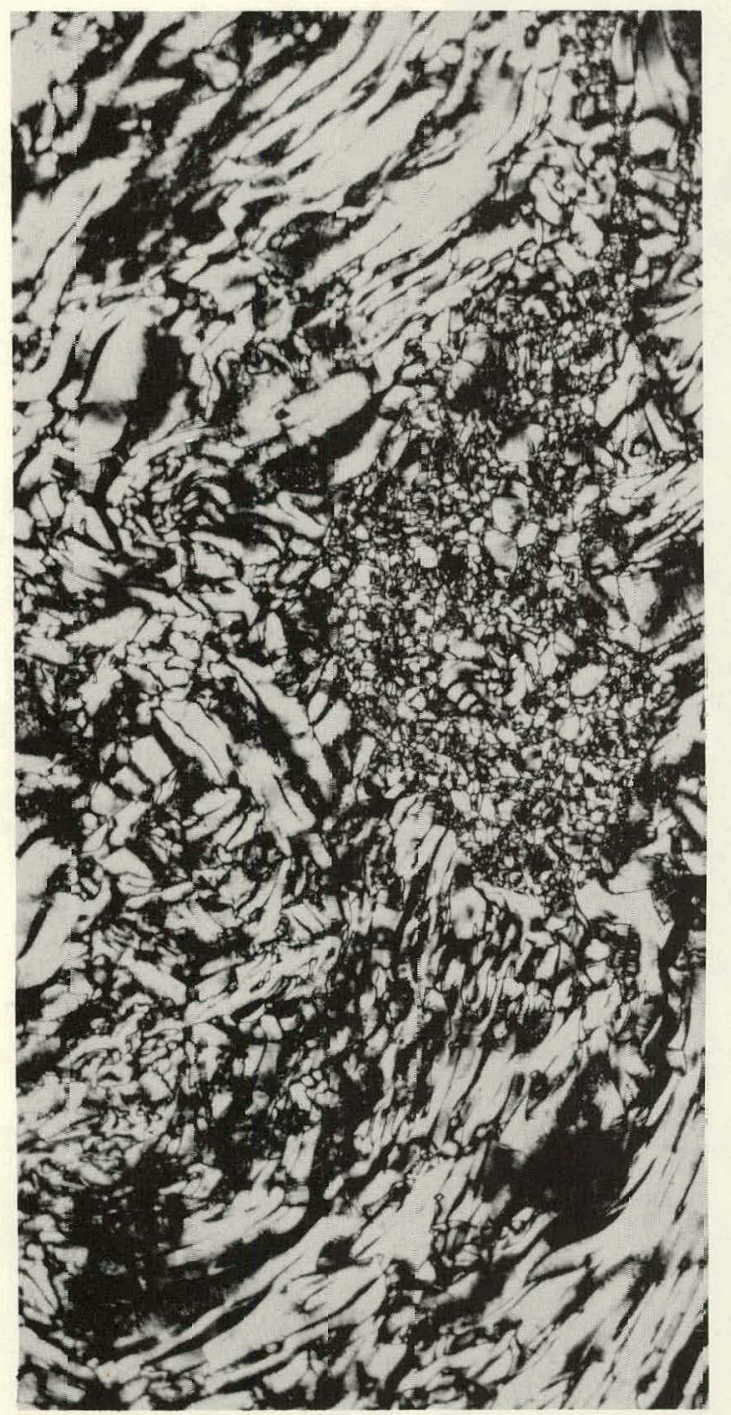

(a) With $0 \% \mathrm{H}-3$ Resin.

J111-1

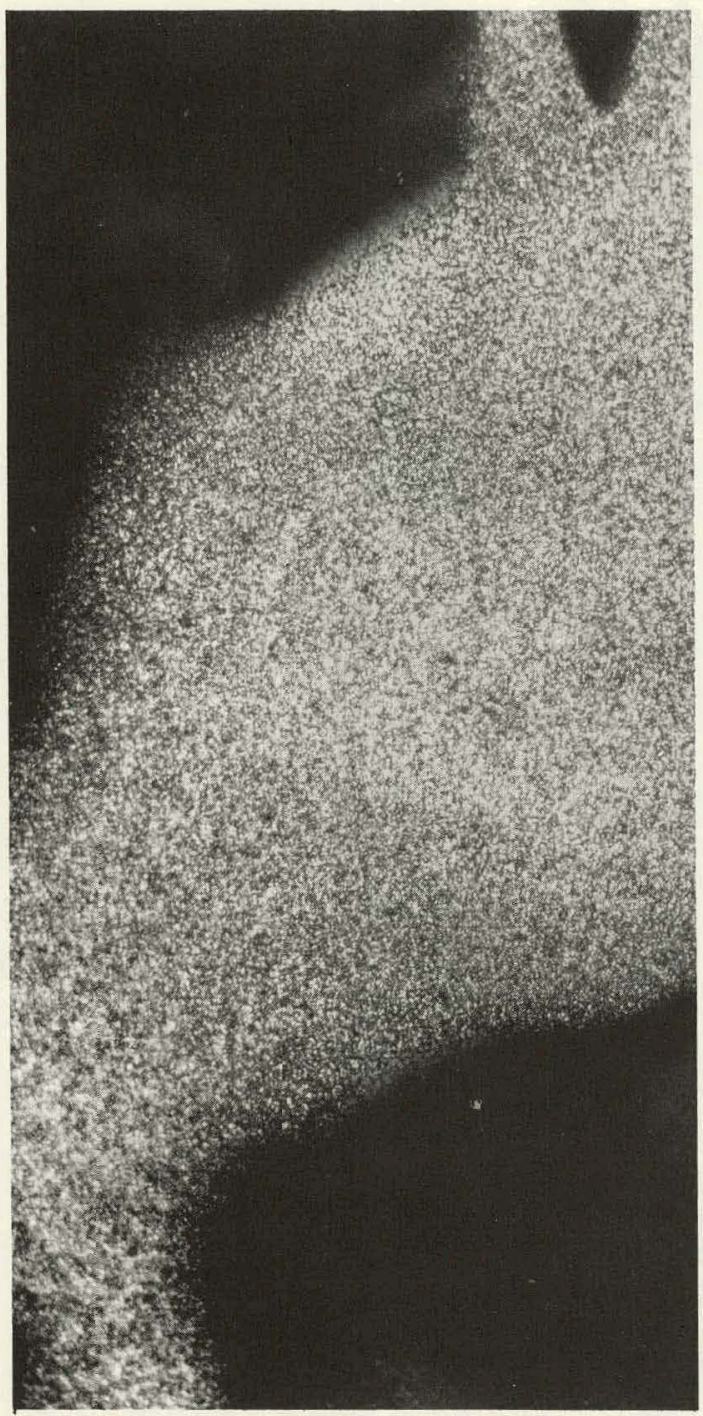

(b) With 10\% H-3 Resin..

J111-2

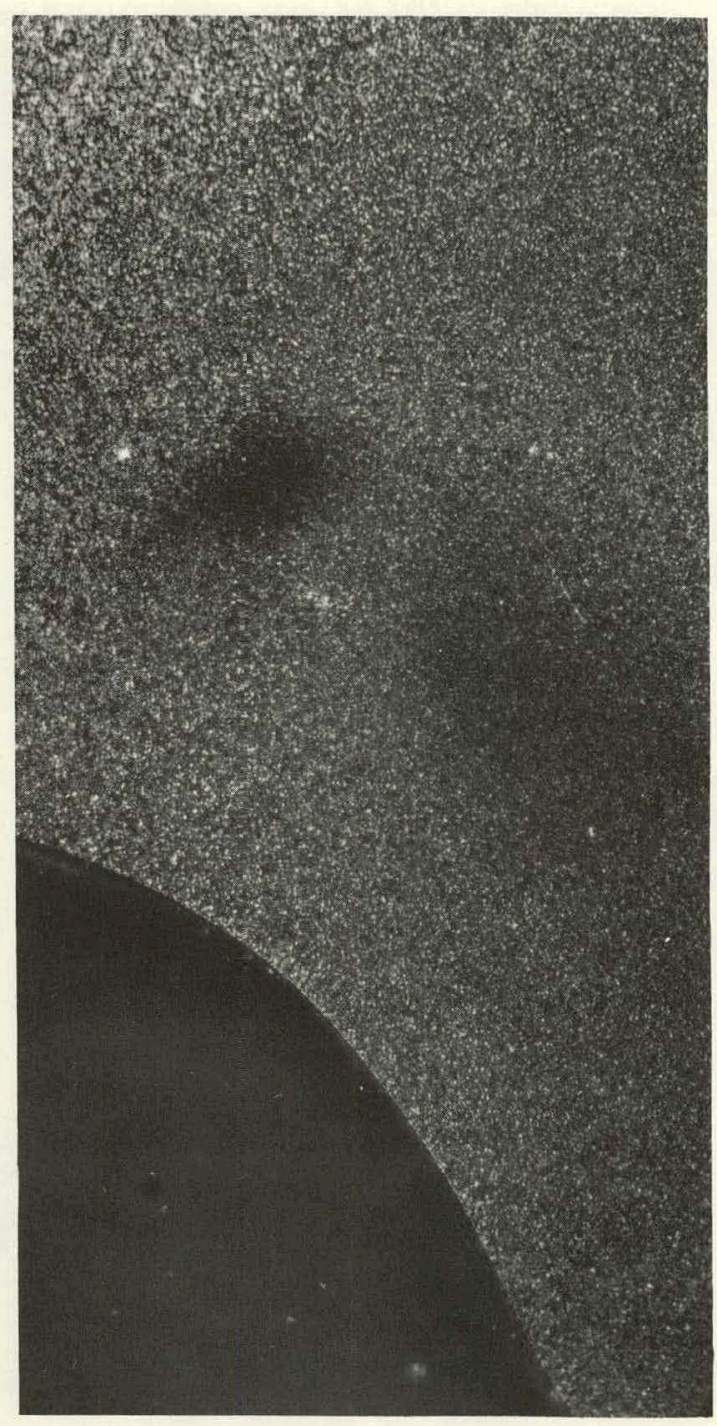

(c) With $20 \% \mathrm{H}-3$ Resin.

$\mathrm{J111-3}$

Figure 24. MICROSTFUCTURES OF CARBONS CINNAMYLIDENEINDENE. (Polarized Light; 250X)

(AFTER 2,800 C) DERIVED FROM BLENDS OF

H-3 RESIN AND AUTOCLAVE-POLYMERIZED 


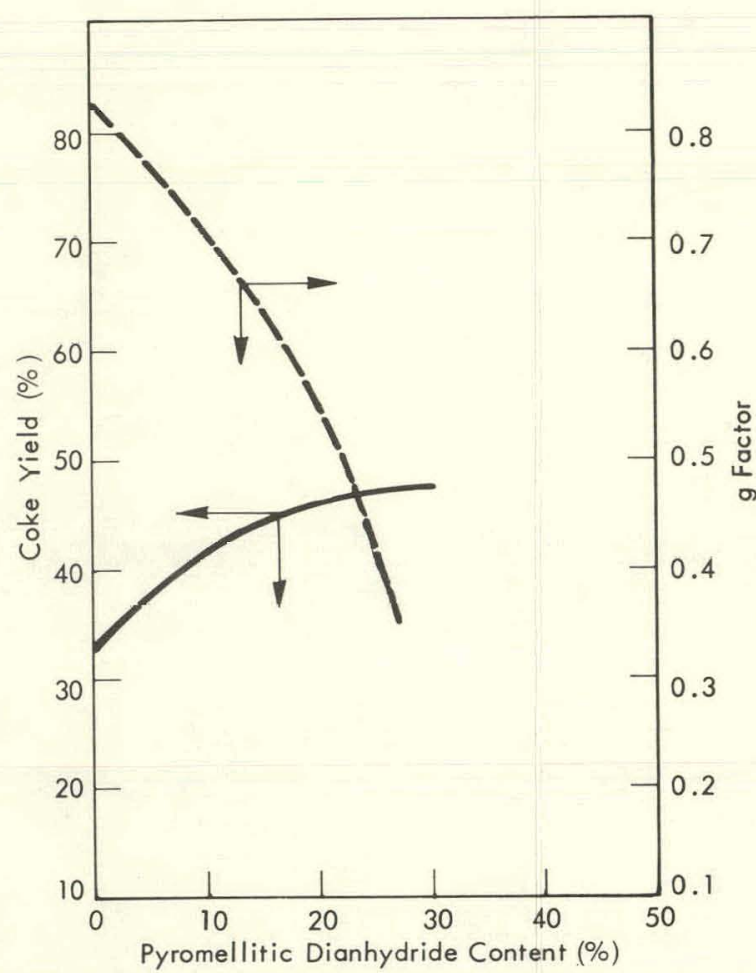

Figure 25. PROPERTIES OF CARBONS DERIVED FROM $\alpha$-METHYLCINNAMYLIDENEINDENE/PYROMELLITIC DIANHYDRIDE MIXTURES AS FUNC-
TIONS OF THE PYROMELLITIC DIANHYDRIDE CONTENT.

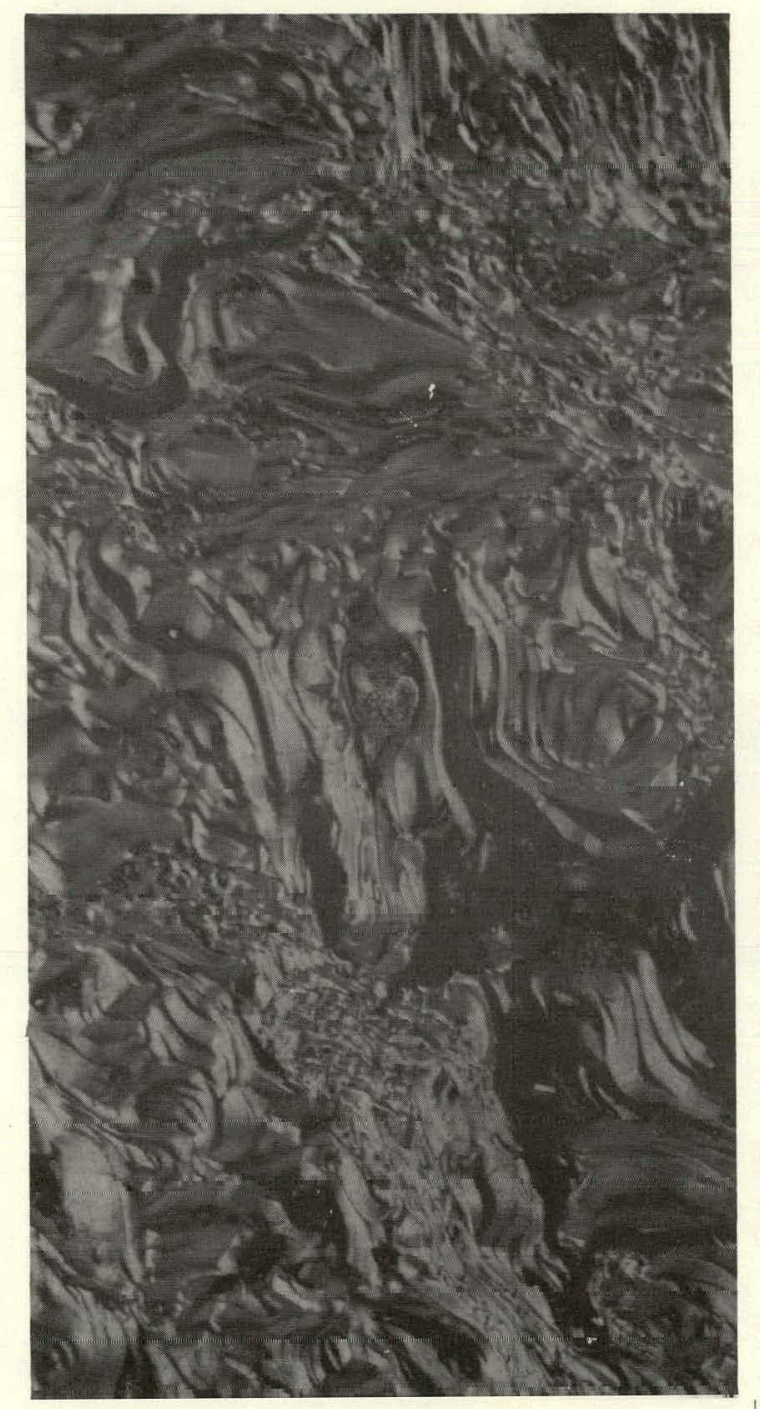

(a) With 0\% PMDA.

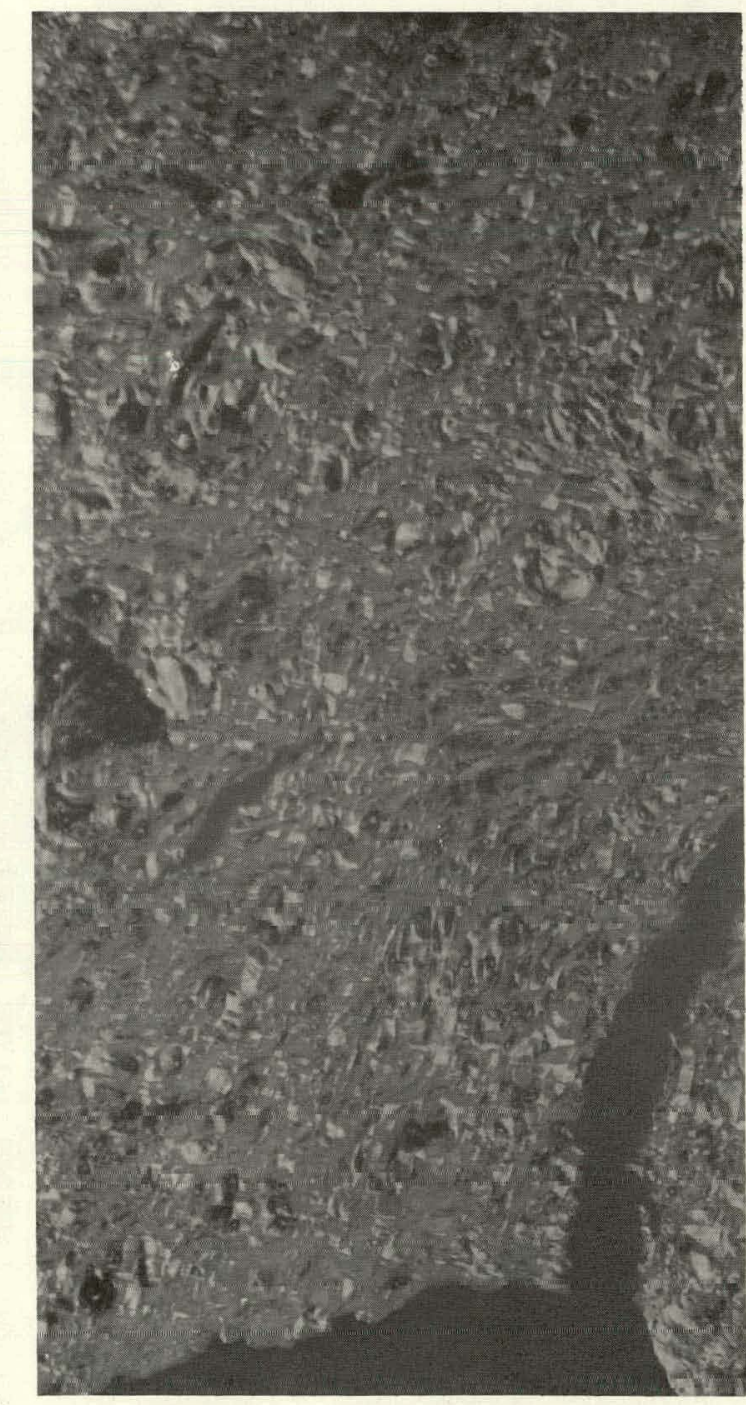

(b) With 10\% PMDA.

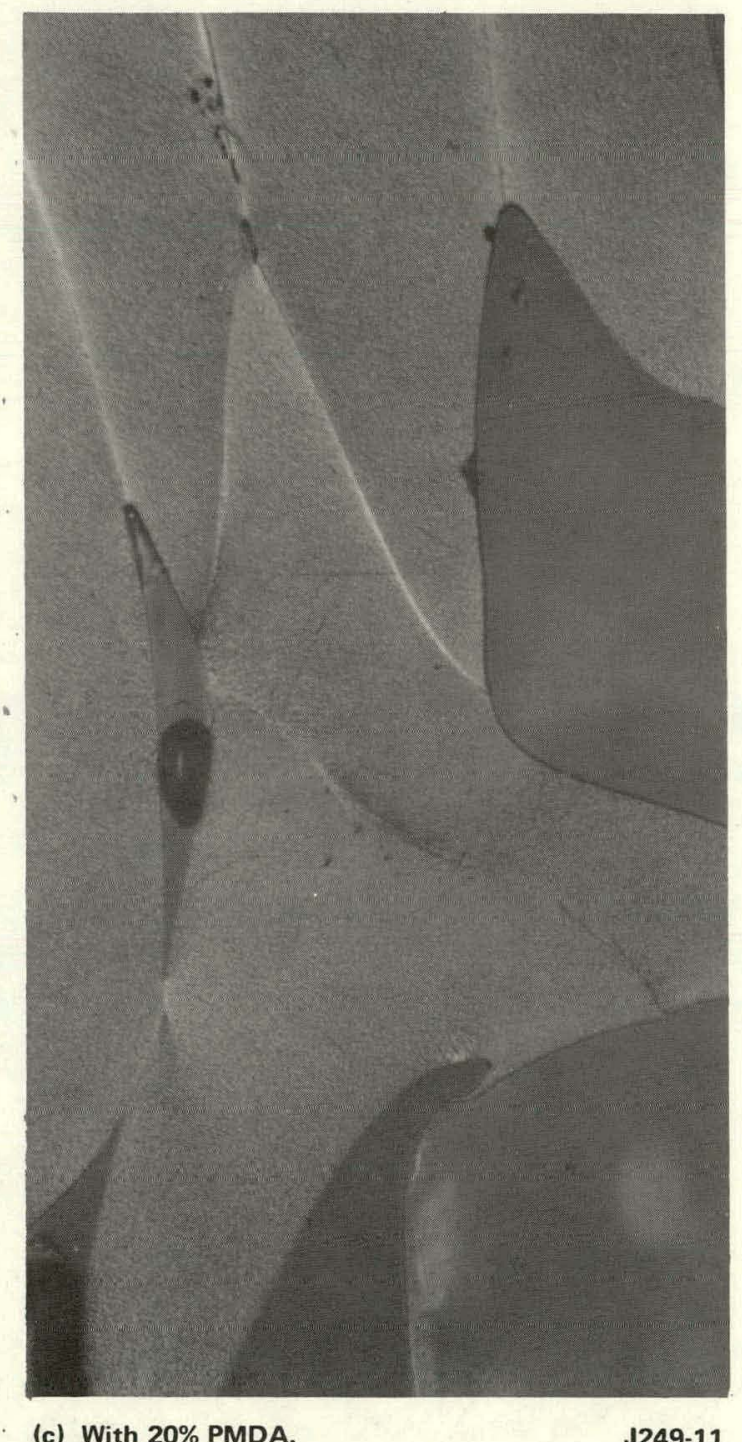

J249-11

Figure 26. MICROSTRUCTURFS OF CARBONS (AFTER $2,800^{\circ} \mathrm{C}$ ) DERIVED FROM $\alpha$-METHYLCINNAMYLIDENEINDENE/PYROMELLITIC DIANHYDRIDE MIXTURES. (Sensitive Tint; 250X) 


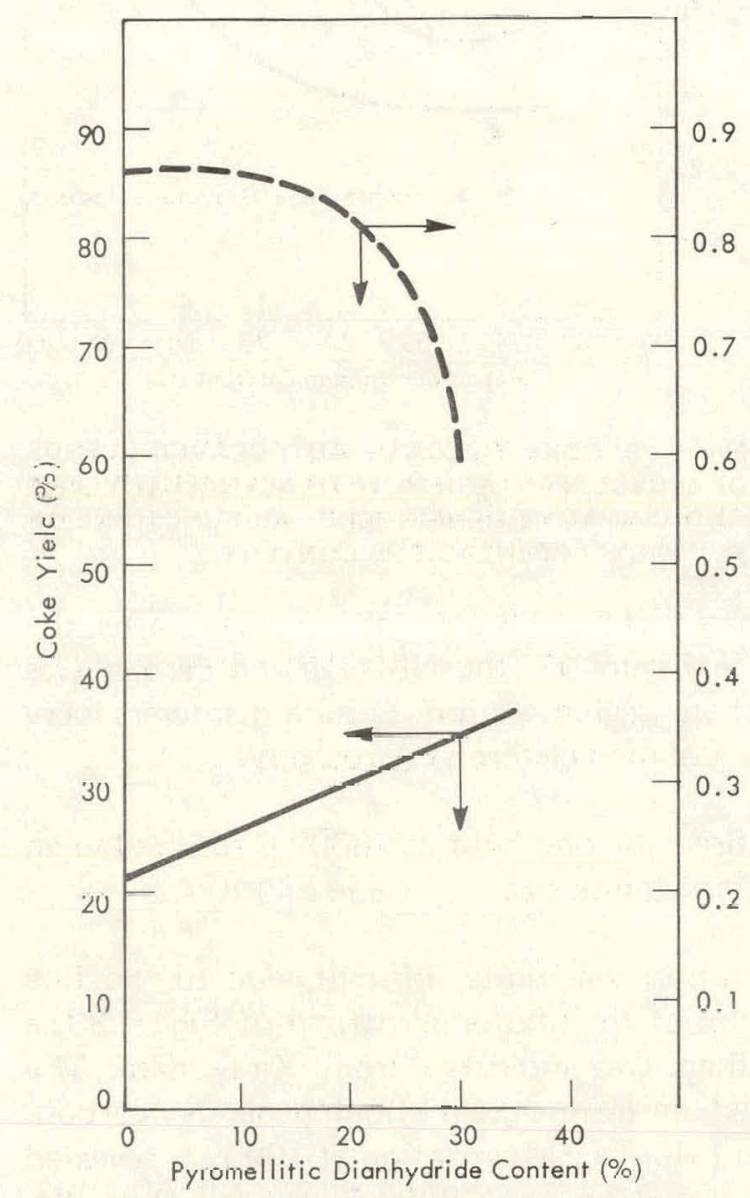

Figure 27. PROPERIIES OF CARBONS DERIVED FROM CINNAMYLIDENEFLUORENE/PYROMELLITIC DIAN HYDRIDE MIXTURES AS FUNCTIONS OF THE PYROMELLITIC DIANHYDRIDE CONTENT.

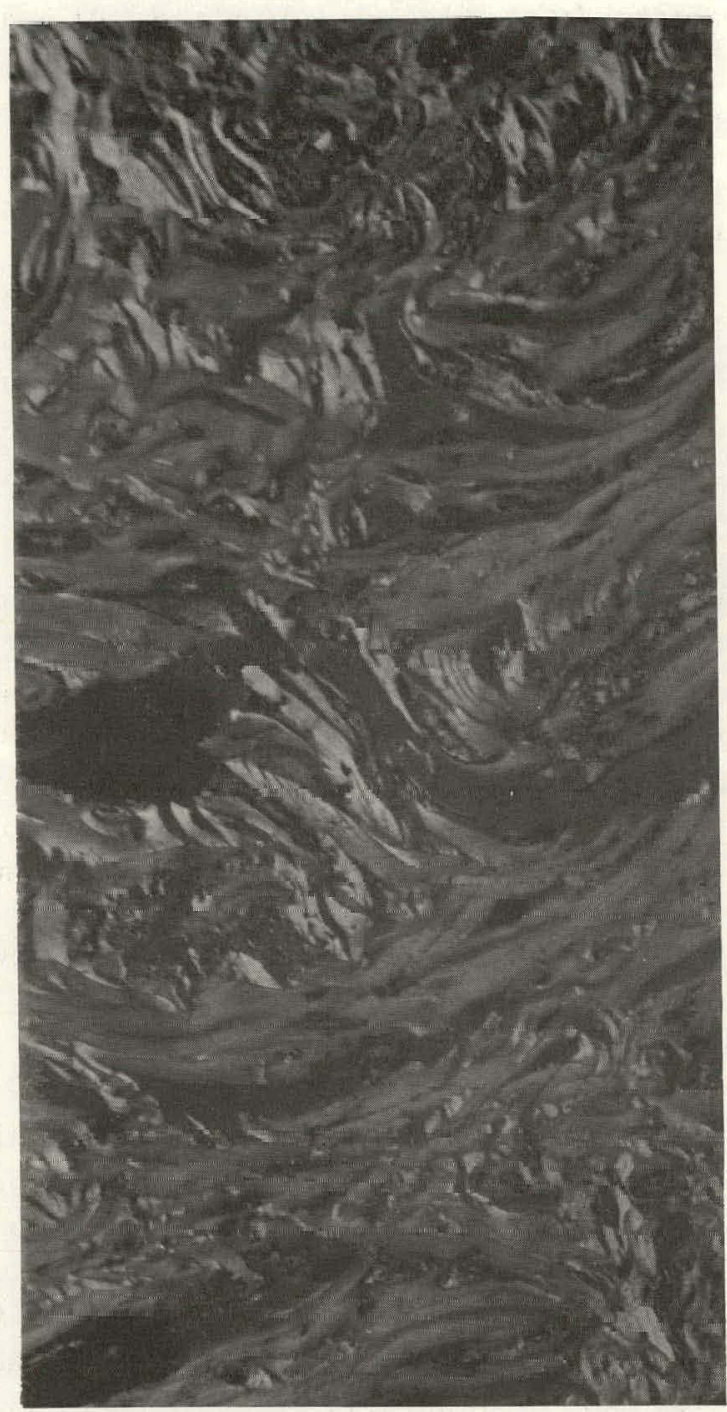

(a) With 10\% PMDA

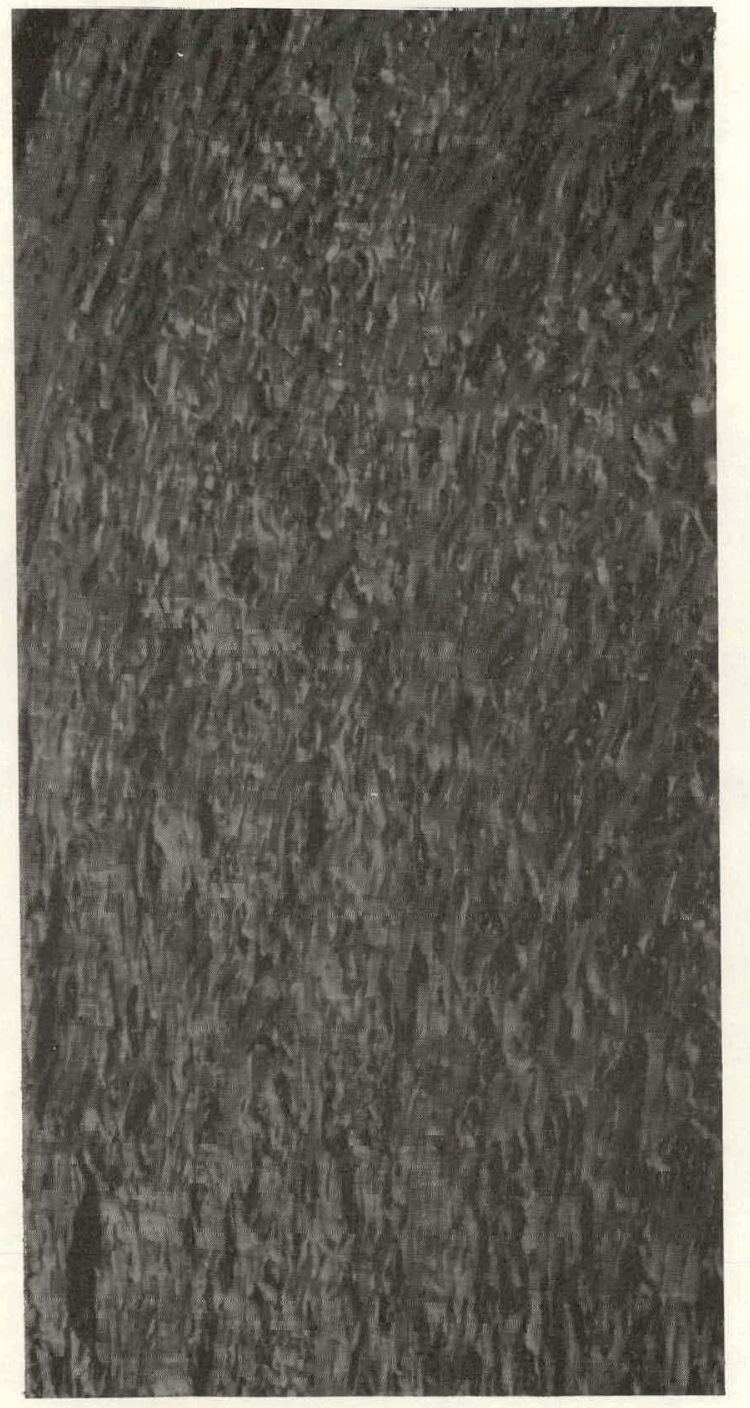

(b) With 20\% PMDA.
$1258-2$

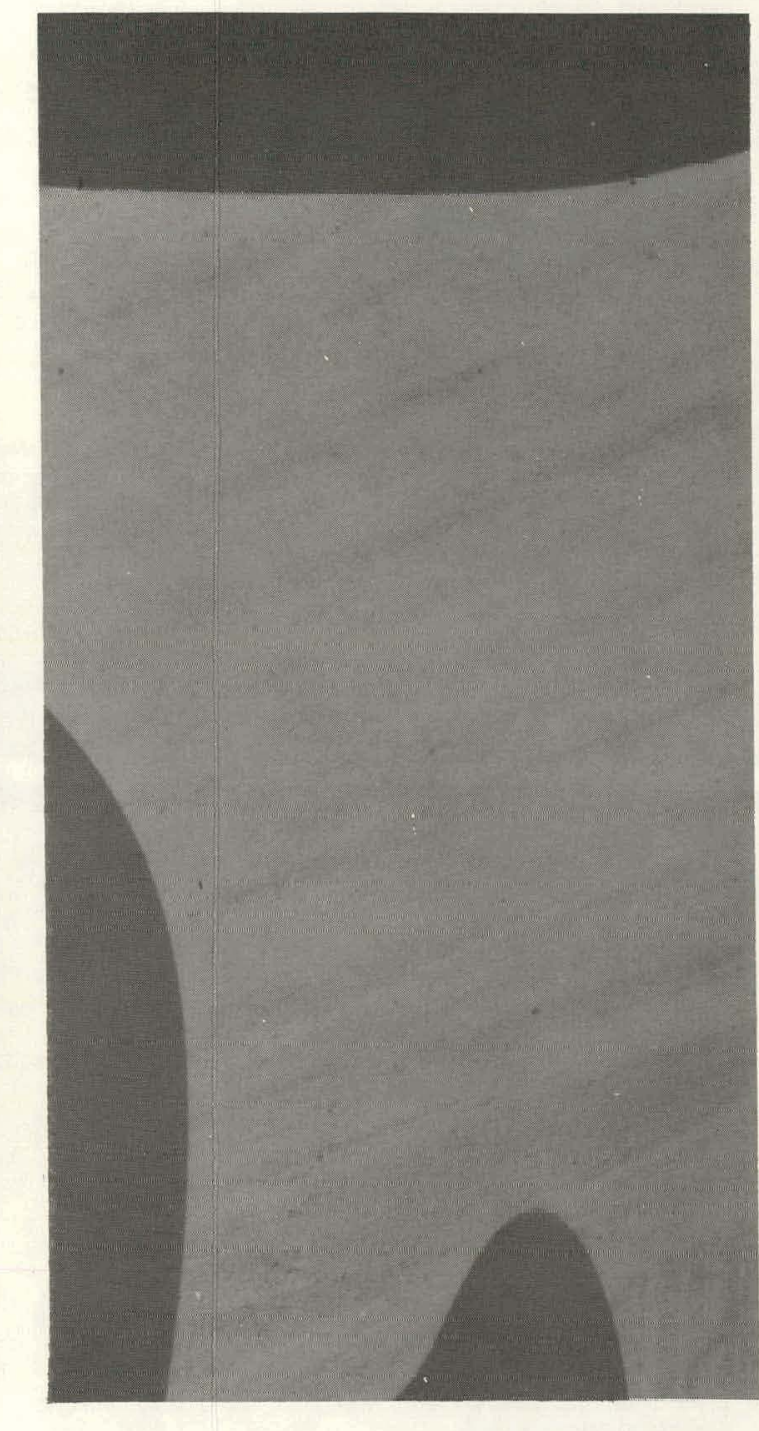

(c) With $30 \%$ PMDA.

J258-3

Figure 28. MICROSTRUCTURES OF CARBONS (AFTER $2,800^{\circ} \mathrm{C}$ ) DERIVED FROM CINNAMYLIDENEFLUORENE/PYROMELLITIC DIANHYDRIDE MIXTURES. (Sensitive Tint; 250X) 
(Figure 31, View a). As the dicyclopentadiene content in the preautoclaved blend increased to 50 and $67 \%$, the $2800^{\circ} \mathrm{C}$ carbons exhibited increasing homogeneity and decreasing grain size (Figure 31, Views $b$ and c). Thus, properties of carbons derived from autoclaved $\mathrm{ACN}$ and $\mathrm{CAI}$ can be altered by the addition of DCPD to the precursor prior to the autoclaving step.

\section{Fvaluation of Norbornadiene as a Cross- linking Additive}

Norbornadiene (NBD) was another organic rompound which was evaluated in efforts to obtain carbon property control.

Properties of Carbon Derived from Autoclaved Norbornadiene-A black, fluffy powder was obtained in $50 \%$ yield from NBD autoclaved for two hours at $340^{\circ} \mathrm{C}$ and at an initial room-temperature nitrogen

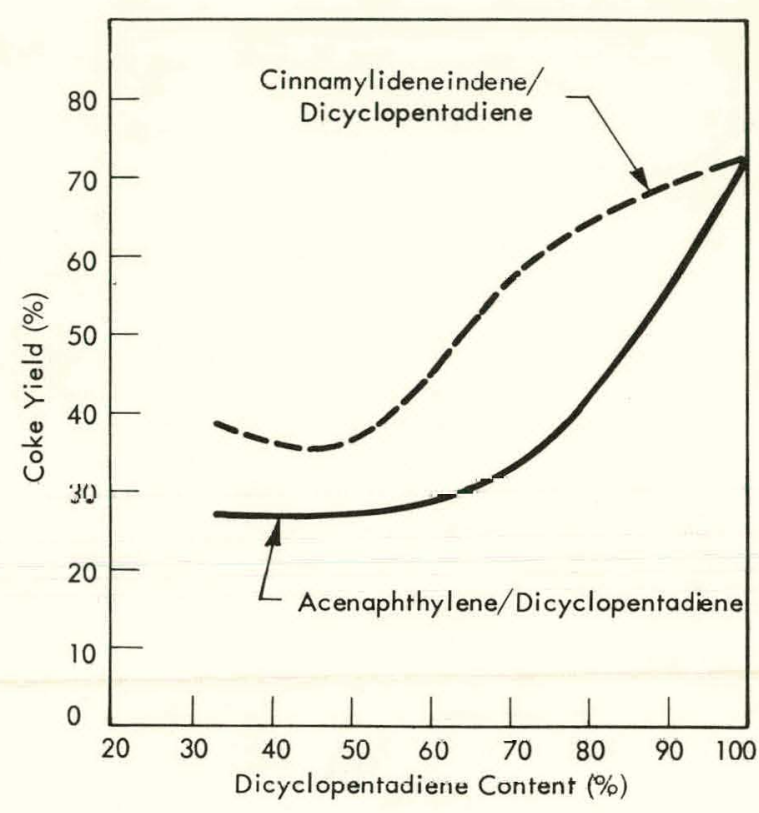

Figure 29. COKE YIELDS OF AUTOCLAVED BLENDS OF DICYCLOPENTADIENE WITH ACENAPHTHYLENE AND CINNAMYLIDENEINDENE AS FUNCTIONS OF THE DICYCLOPENTADIENE CONTENT.

pressure of 300 pounds per square inch. A coke yield of 88 percent was noted after the powder was heated to $1000^{\circ} \mathrm{C}$. As indicated in Figure 32, the NBD-derived carbon was uniformly spherical, with some evidence of sphere ayylumeration. Sphere diameters were approximately 0.75 micrometer, as estimated by scanning electron microscopy.

$X$-ray diffraction data obtained on the carton fired for one hour at $2800^{\circ} \mathrm{C}$ resulted in an interlayer-spacing $\left(\mathrm{d}_{002}\right)$ value of $3.405 \mathrm{~A}$ and a crystallite-size $\left(\mathrm{L}_{\mathrm{C}}\right)$ value of $140 \mathrm{~A}$.

Metallographic examination of the $2800^{\circ} \mathrm{C}$ carbon was quite difficult, due to the fine particle size of the powder. From an examination of the photomicrograph of Figure 33, a higher degree of graphitirity was expected than was indicated $f_{1} u{ }_{1} X^{\prime}-r d y$ data. The structurc appeared to be that of a medium-to-tine-yrdin homogeneous carbon. Metallographic examination of the black powder prior to carbonization at $1 \cap \cap n^{\circ} \mathrm{C}$. revealed a microstructure similar in appearance to that noted for the $2800^{\circ} \mathrm{C}$ carbon. Thus, the microstructure of the NBD carbon was established at a very early stage nf pyrolysis and was essentially maintained on firing to higher temperatures.

Blends of NBD with CAI and A-240 were autoclaved and carbonized to determine if the properties of the carbon derived from these two precursors could be altered by the addition of NBD.

Cinnamylideneindene/Norbornadiene Blends - As indicated in Figure 34, coke yields of CAI/NBD blends increased rapidly for NBD contents greated than $50 \%$, while coke yields of A-240/NBD blends were essentially constant over the NBD concentration range from 0 to $75 \%$. 


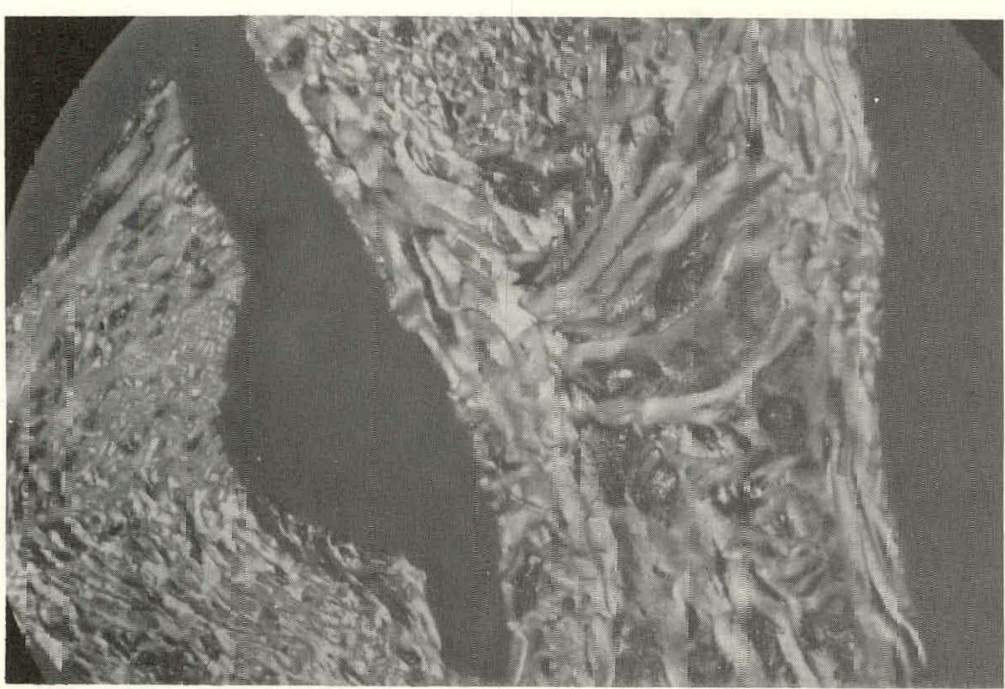

(a) With $33 \%$ DCFD.

$1372-10$

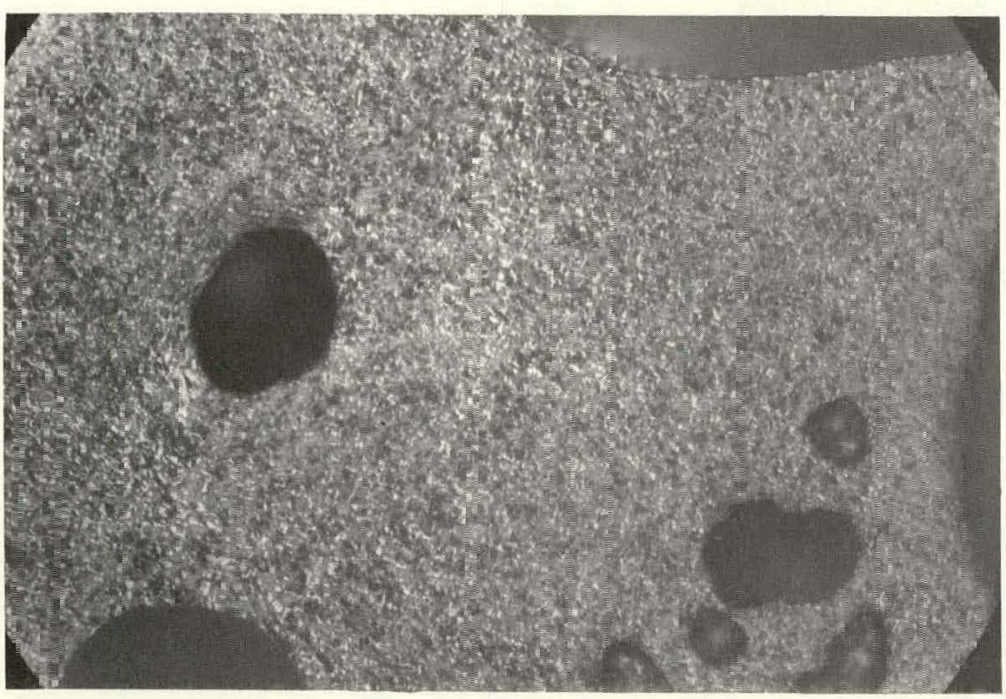

(c) With 67\% DCPD.

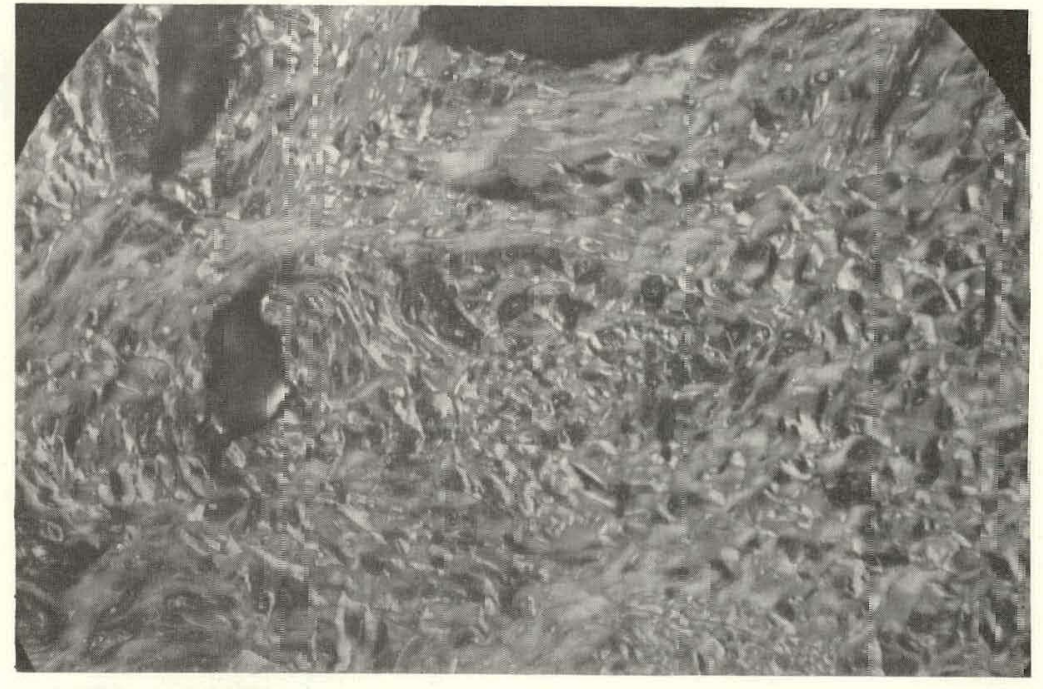

(b) With $50 \%$ DCPD.

$1372-9$

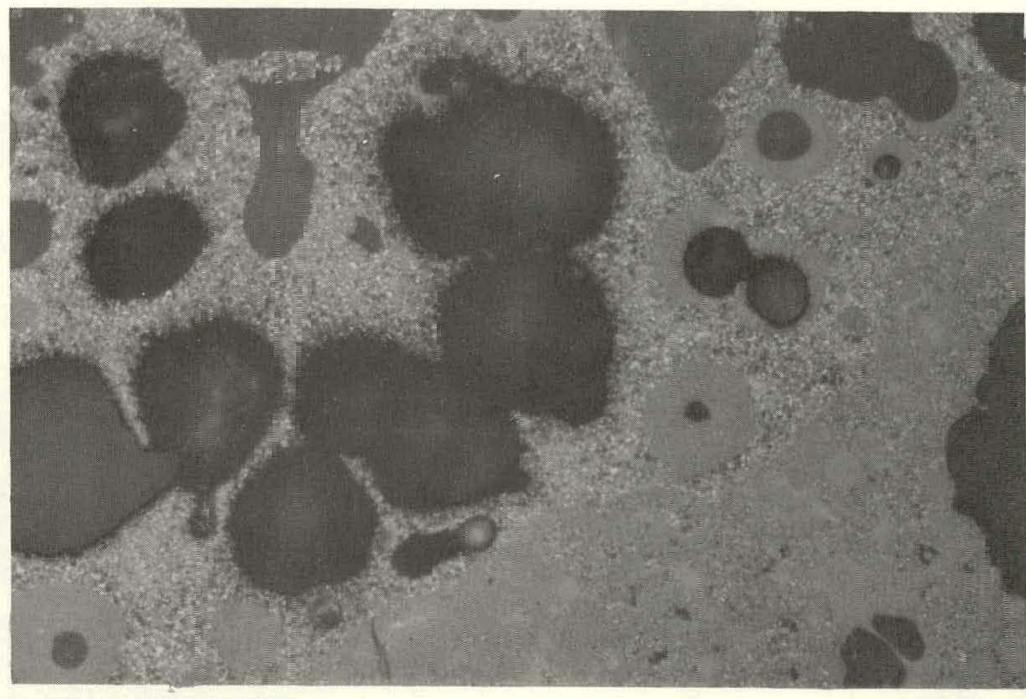

(d) With 100\% DCPD.

1161-2

Figure 30. MICROSTRUCTURES CF CARBONS (AFTER 2,800 C) DERIVED FROM AUTOCLAVED ACENAPHTHYLENE/DICYCLOPENTADIENE BLENDS. (Sensitive Tin:; 250X) 


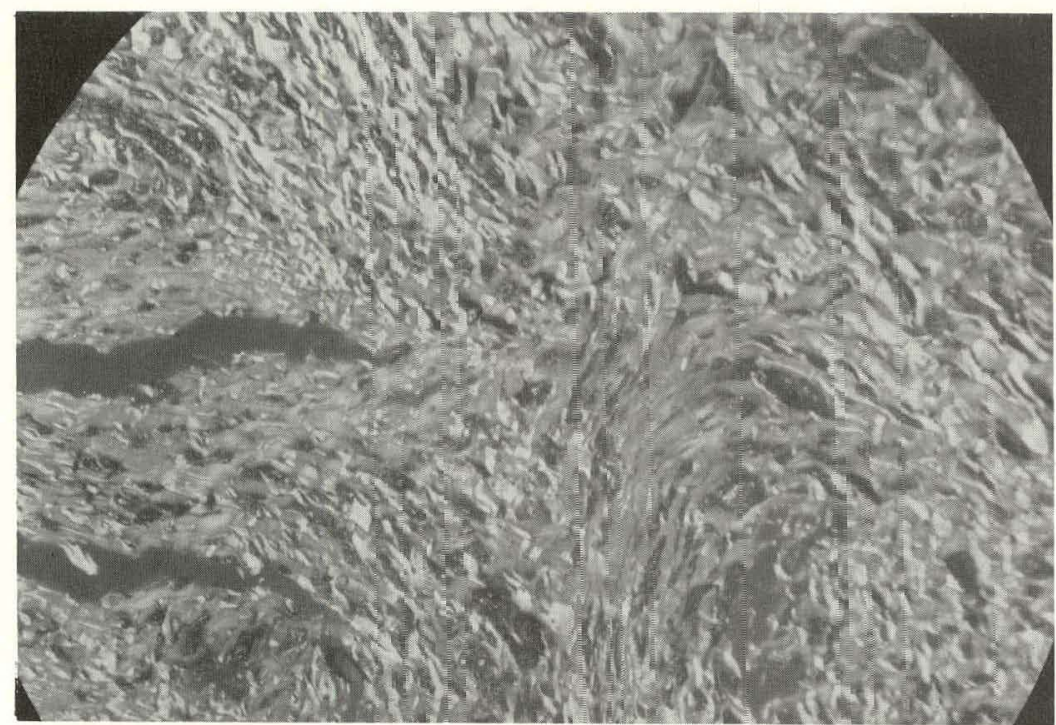

(a) With $33 \%$ DCPD.

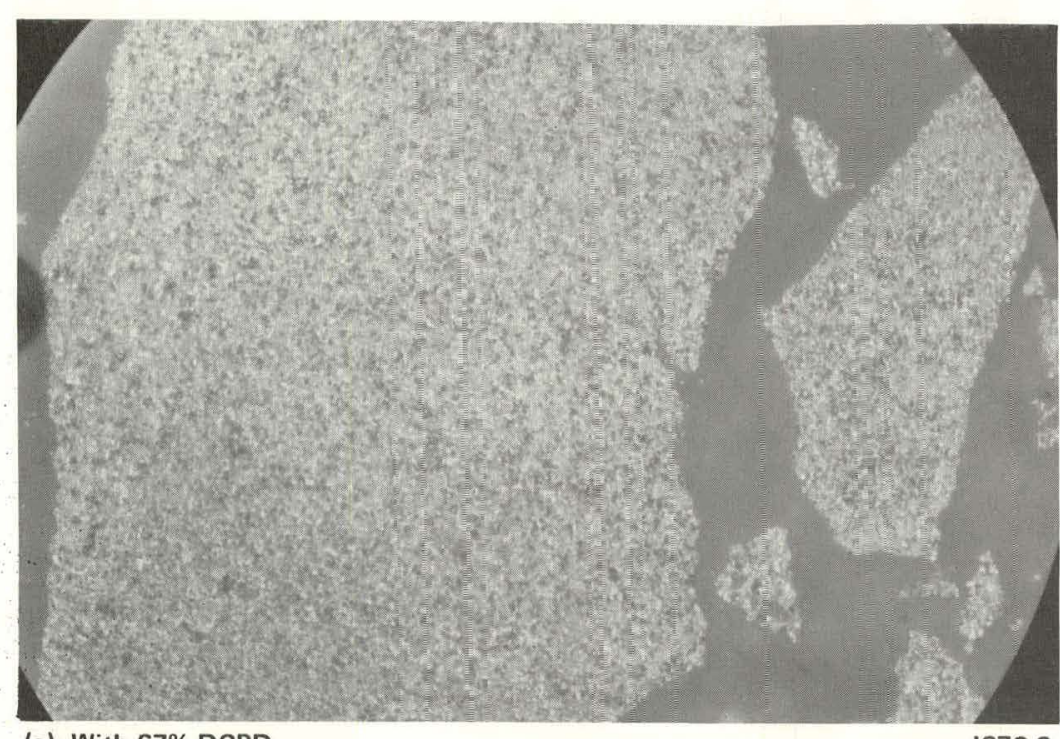

(c) With $67 \%$ DCPD.

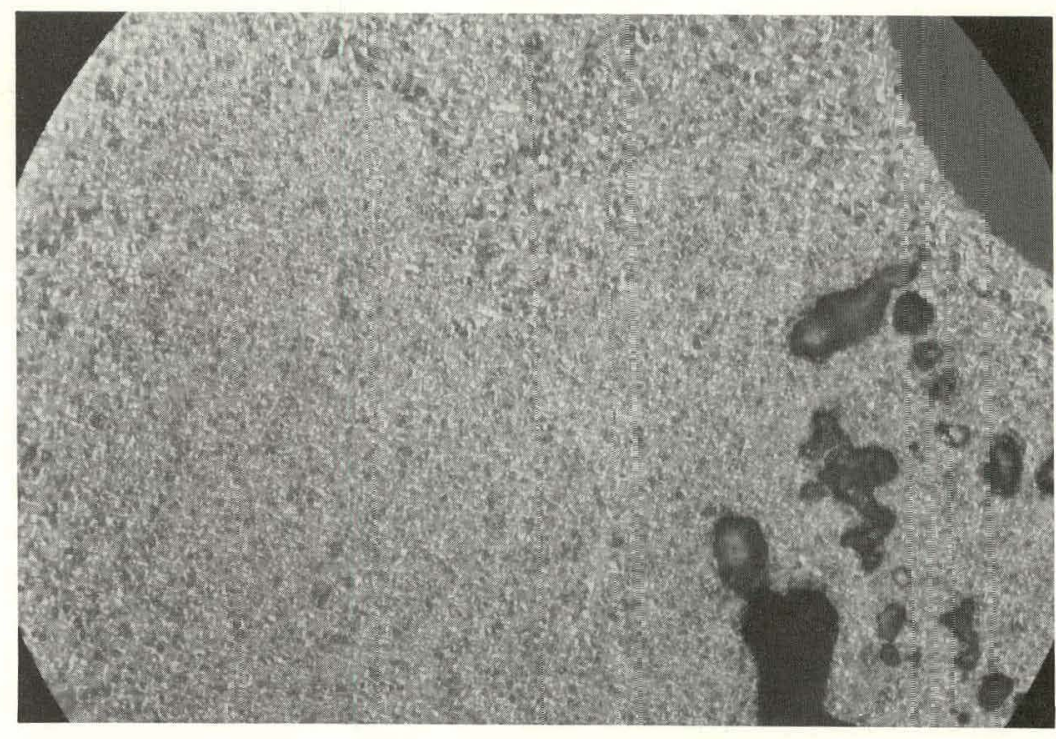

(b) With 50\% DCPD.

$1372-1$

Figure 31. MICROSTRUCTURES OF CARBONS (AFTER 2,800 $\mathrm{C}$ ) DERIVED FROM AUTOCLAVED BLENDS OF DICYCLOPENTADIENE AND CINNAMYLIDENEINDENE. (Sensitive Tint; 250X) 


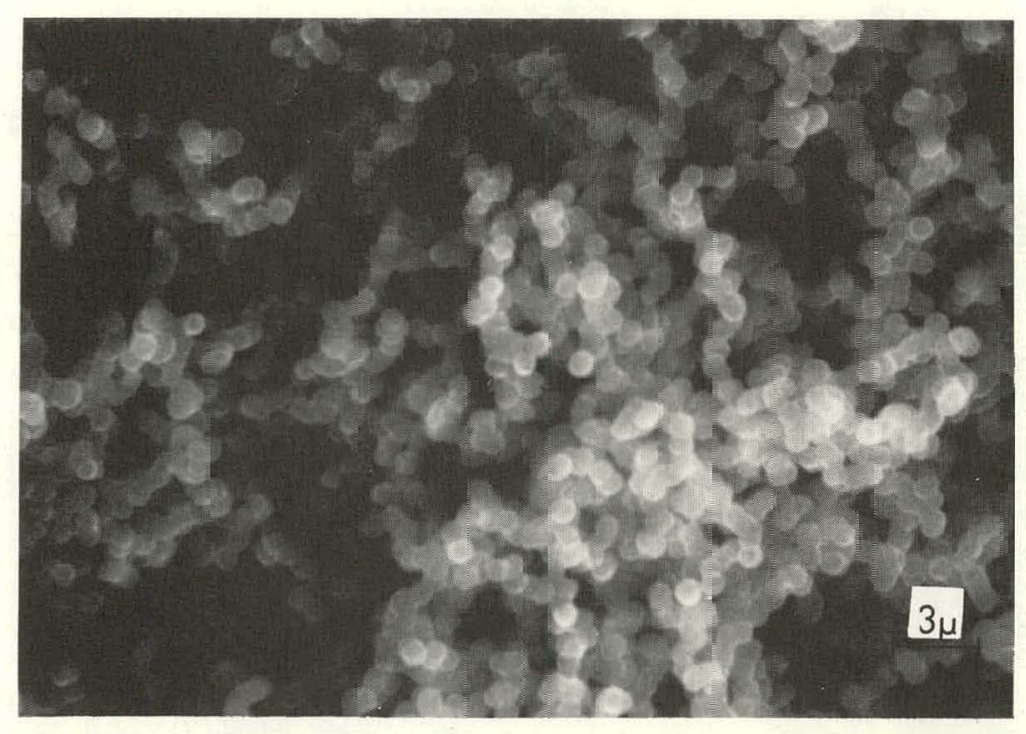

(a) At 3,000X.

SM-38543

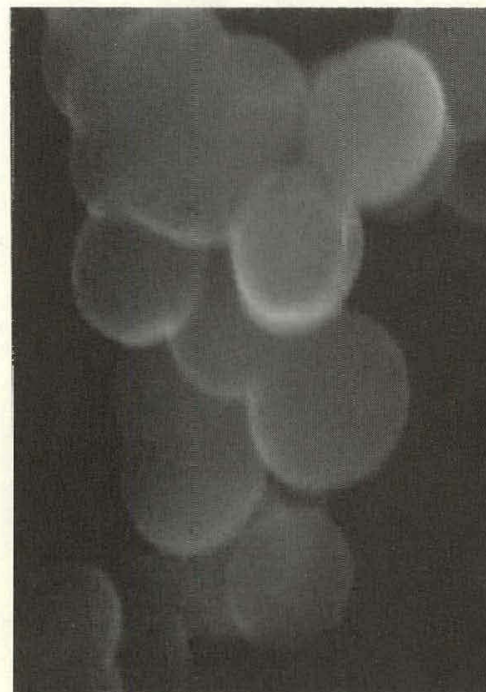

(c) At $20,000 x$
$7 \mu$

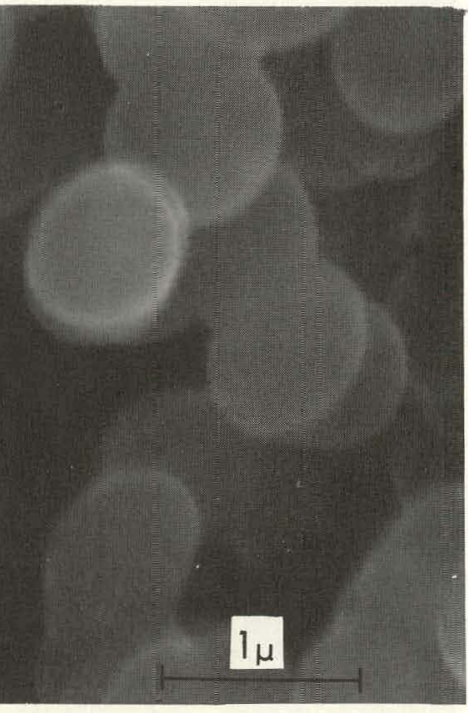

SM-38541

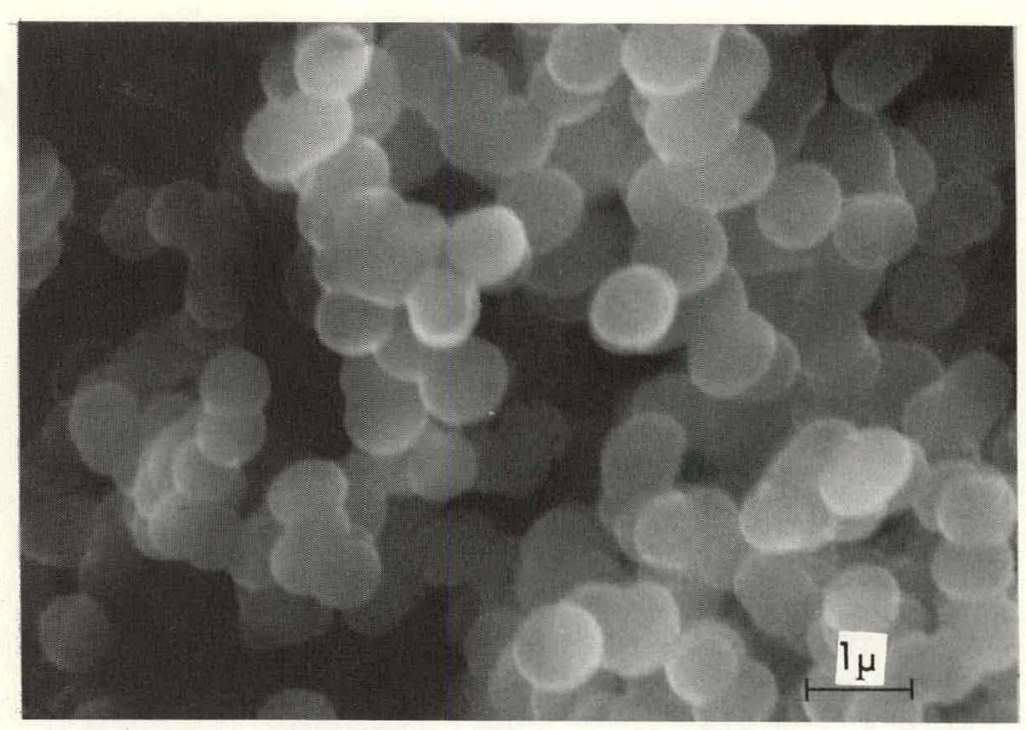

(b) At $10,000 x$.

SM-38542

Figure 32. SCANNING ELECTRON MICROGRAPHS OF CARBONS (AFTER $\left.1,000^{\circ} \mathrm{C}\right)$ DERIVED FROM AUTOCLAVED NOBORNADIENE. 


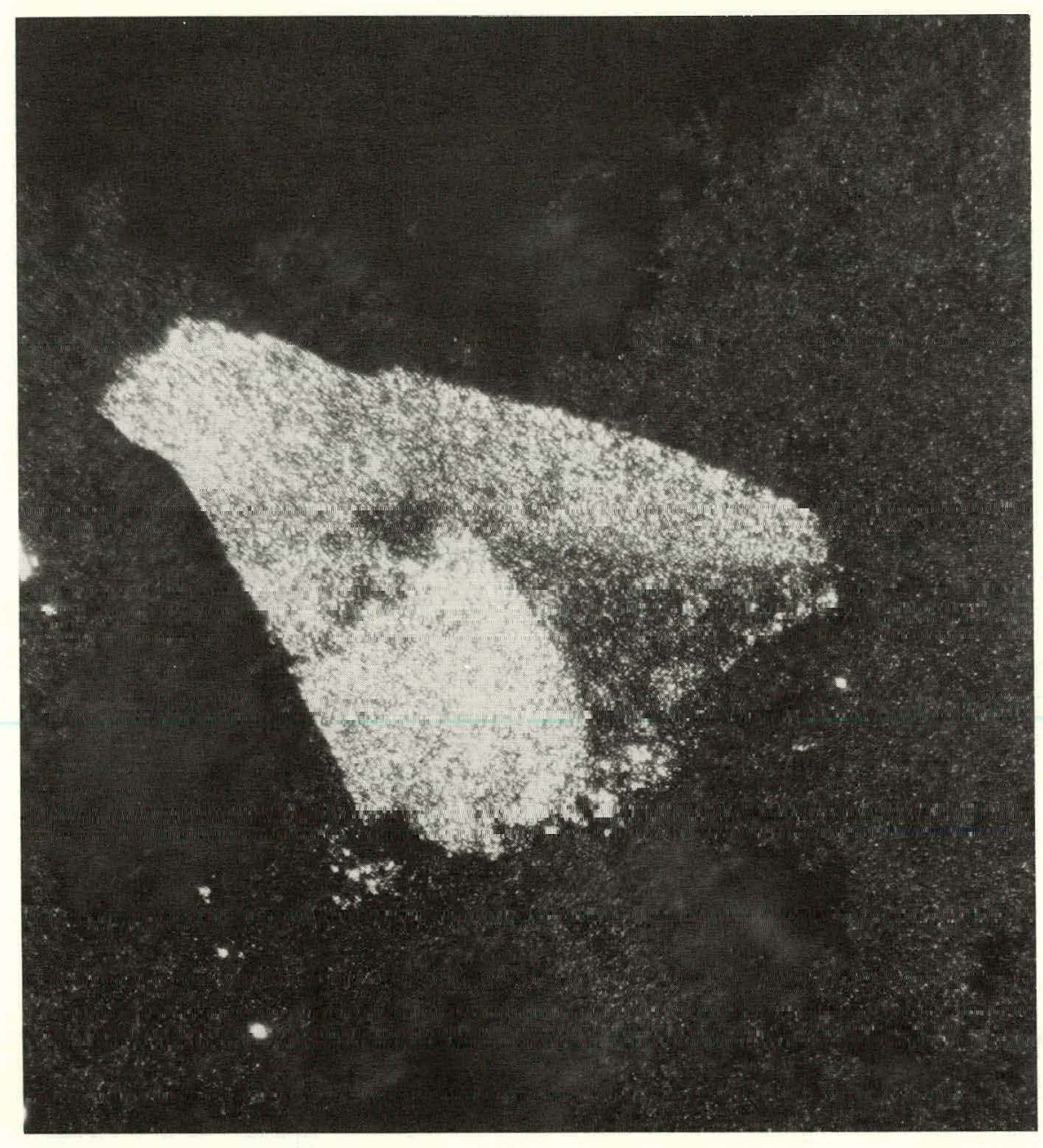

J207-1A

Figure 33. MICROSTRUCTURES OF CARBONS (AFTER $2,800^{\circ} \mathrm{C}$ ) DERIVED FROM AUTOCLAVED NOBORNADIENE. (Polarized Light; 250X)

Microstructures of carbons (after $1000^{\circ} \mathrm{C}$ ) derived from autoclaved CAI/NBD blends revealed a rapid decrease in crystallinity as the NBD content increased from 50 to $75 \%$ (Figure 35), indicating some crosslinking effect of the NBD. All carbons derived from $\mathrm{CAl} / \mathrm{NBD}$ mixtures containing $50 \%$ or less NBD contained highly crystalline microstructures. Since the microstructural chanqes are noted at such a high NBD concentration, the mechanism evoking the change could be one of dilution rather than crosslinking.

Ashland-240 Pitch/Norbornadiene Blends - As noted in Figure 36, carbons derived from autoclaved A-240/NBD mixtures decreased in crystallinity as the NBD content increased. Subtle changes are evident as the NBD content increased from 25 to $50 \%$, while a fairly homogeneous, fine-grain carbon was obtained from the blend containing $75 \%$ NBD. Again, dilution of the precursor is suspected to be the mode of reactivity rather than crosslinking due to the presence of at least two phases in the sample after autoclaving. 


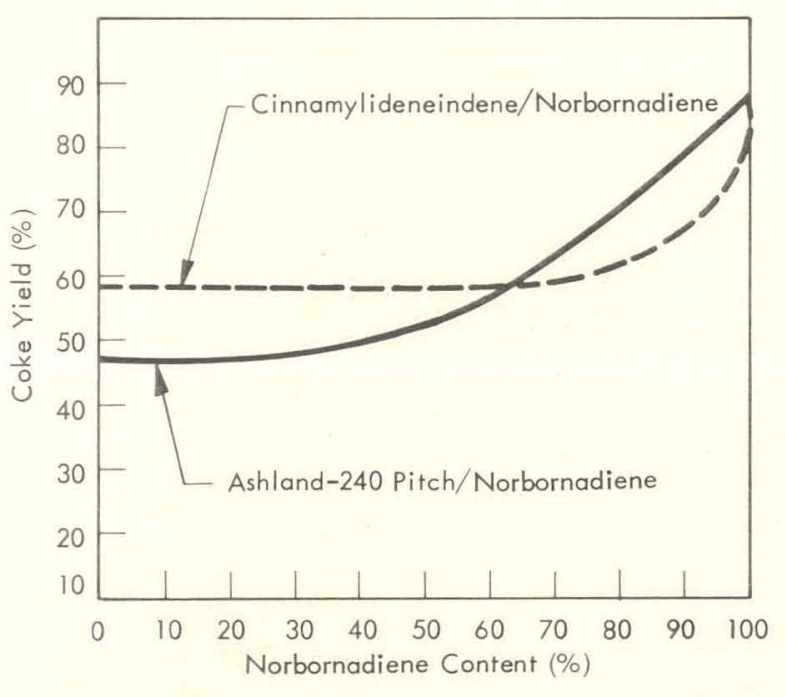

Figure 34. COKE YIELDS OF AUTOCLAVED BLENDS OF NORBORNADIENE WITH CINNAMYLIDENEINDENE AND ASHLAND 240 PITCH AS FUNCTIONS OF THE NORBORNADIENE CONTENT.

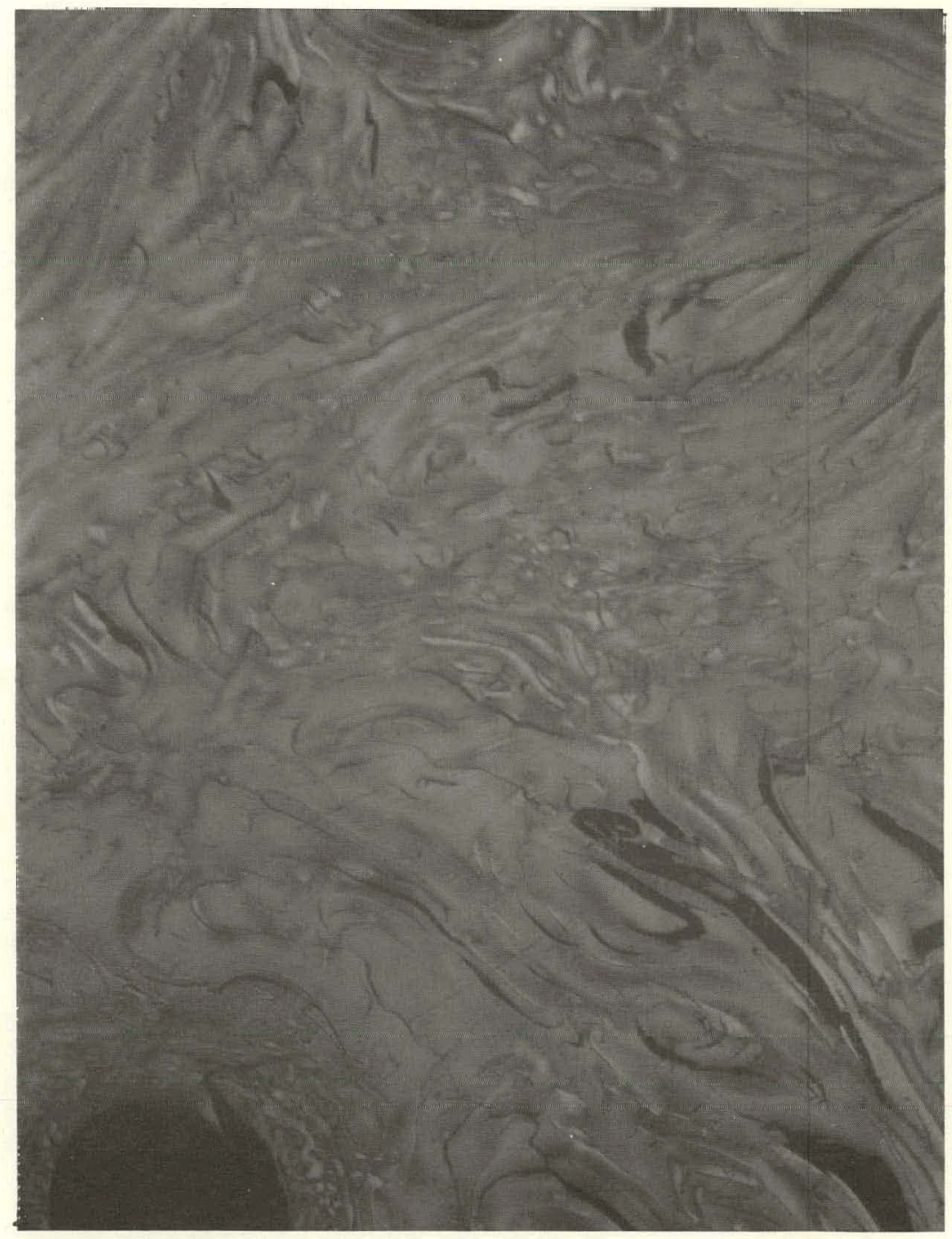

(a) With $50 \%$ NBD

J318-5

Figure 35. MICROSTRUCTURES OF CARBONS (AFTER $1,000^{\circ} \mathrm{C}$ ) DERIVED FROM AUTOCLAVED BLENDS OF CINNAMYLIDENEINDENE AND NORBORNADIENE. (Sensitive Tint; 250X) (b) With $75 \% \mathrm{NBD}$

J318-6

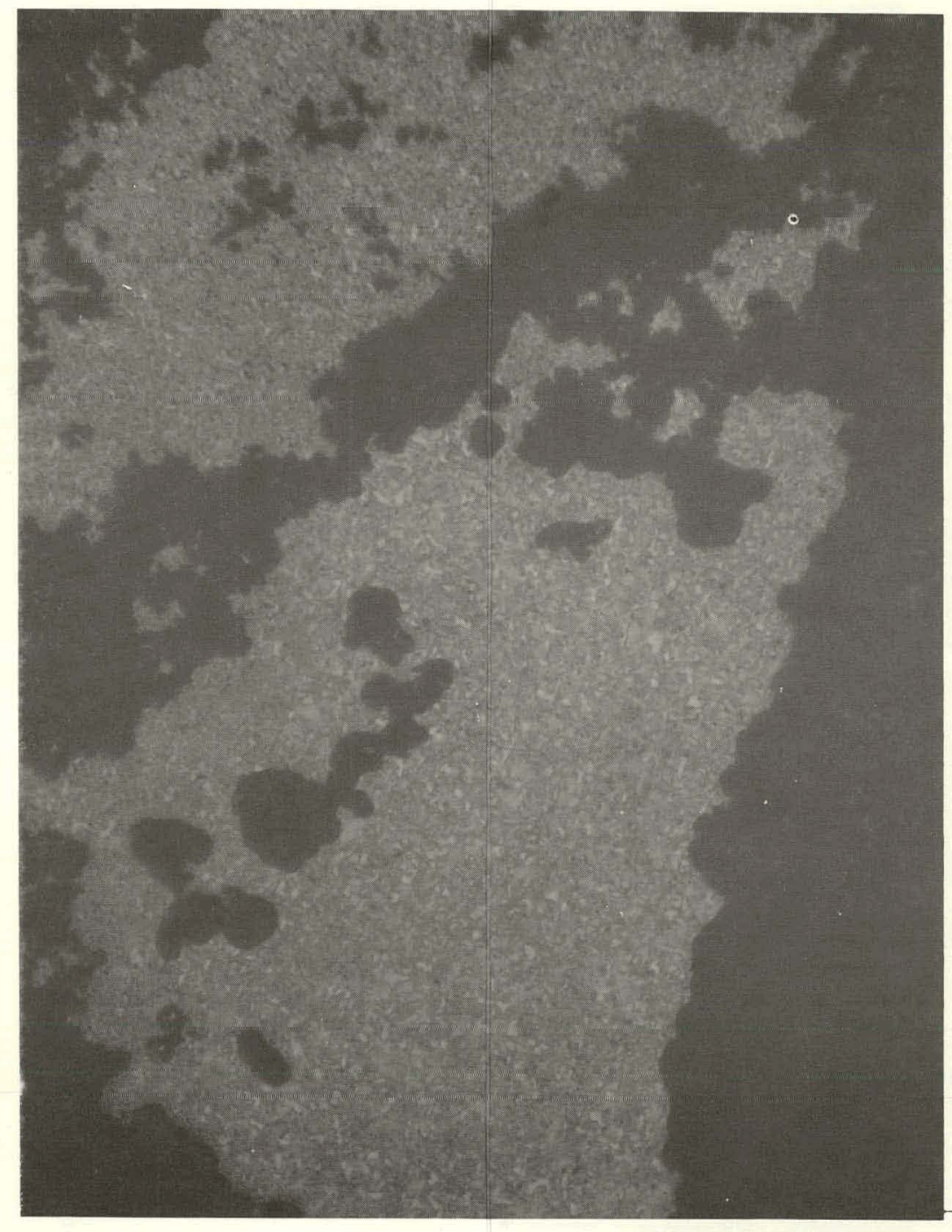

18-6 


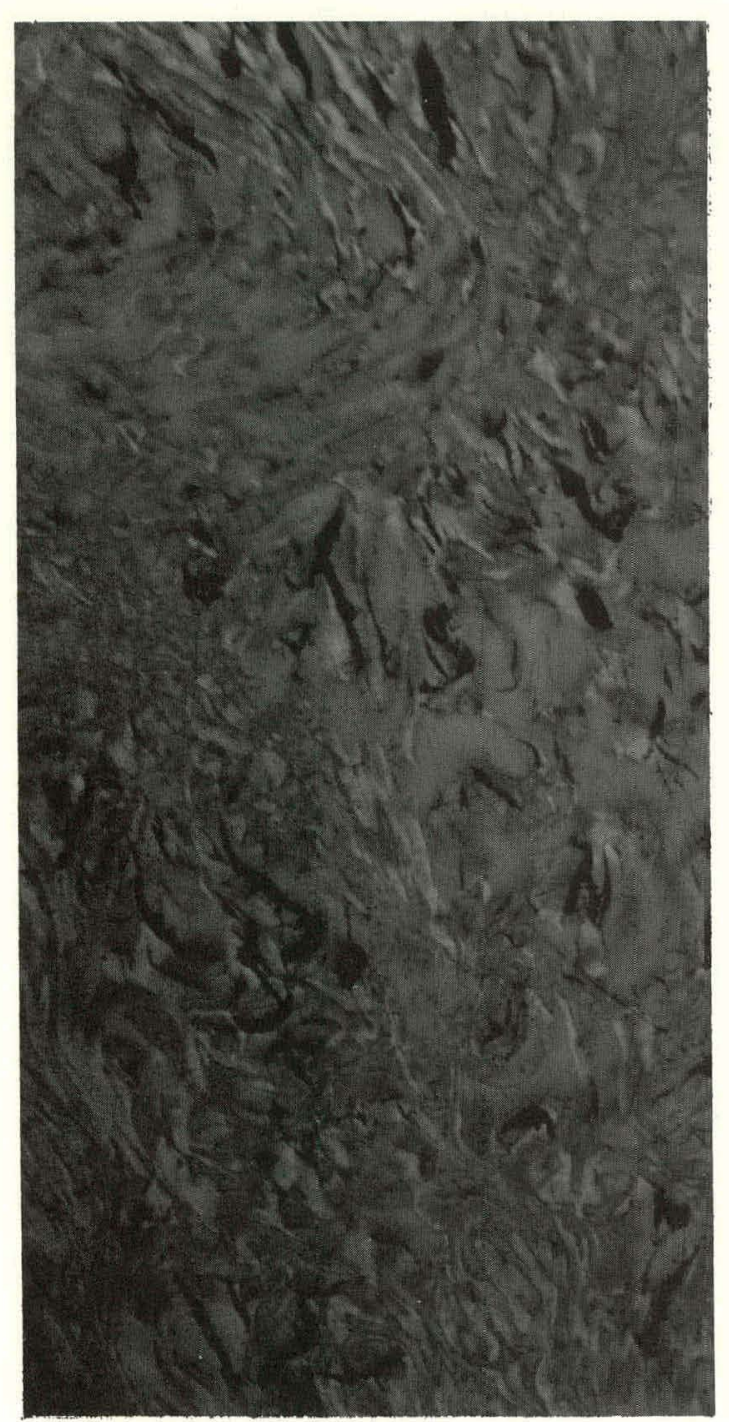

(a) With 25\% NBD.

J318-1

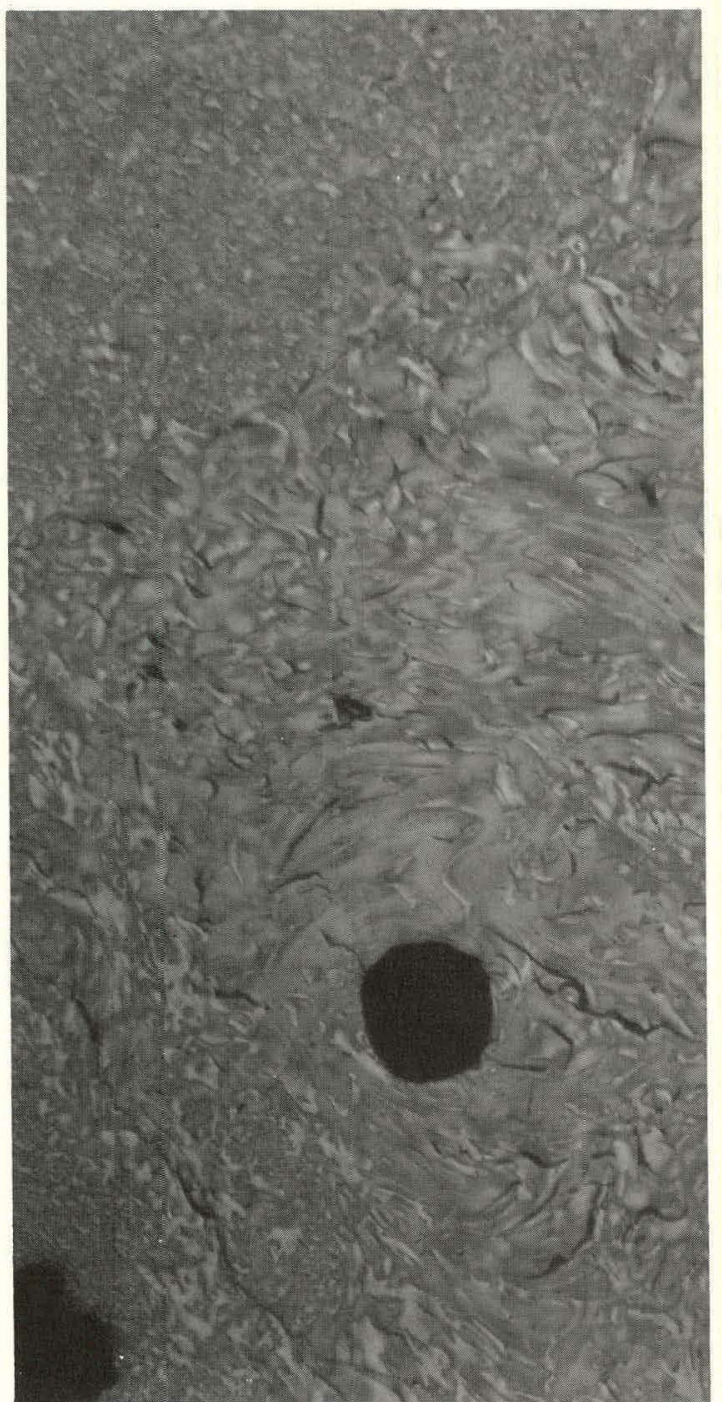

(b) With $50 \%$ NBD.

J318-2

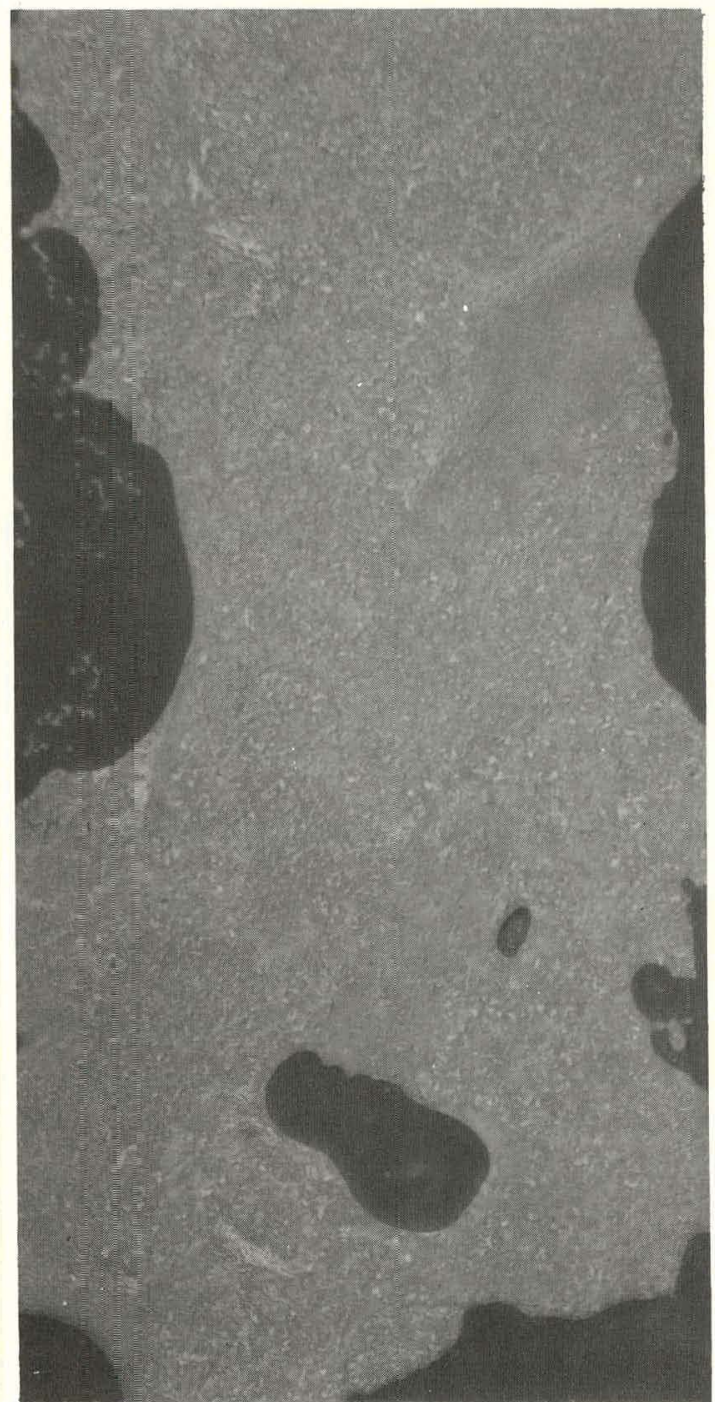
Tint; 250X) 
In summary, autoclaving NBD resulted in a fluffy, carbonaceous powder which, in turn, yielded a high coke yield on heating to $1000^{\circ} \mathrm{C}$. A homogeneous, medium-to-fine grain structure was noted for the 340,1000 , and $2800^{\circ} \mathrm{C}$ samples. Microstructural changes in carbons derived from autoclaved CAI/NBD and A-240/NBD mixtures occur only at high concentrations of NBD $(\sim 75 \%)$ and are probably effected by the dilution of the precursor with NBD. Thus, little or no control of properties of CAI or A-240-derived carbon was obtained by the inclusion of NBD.

\section{CONCLUSIONS}

Data presented in the report show the effect of various crosslinking additives on the properties of carbons derived from selected precursors. It was found that $\mathrm{H}-3$ resin and dicyclopentadiene were effective crosslinking additives for acenaphthylene. Properties of carbons derived from cinnamylideneindene were altered by the addition of furfurylidenefluorene, $\mathrm{p}$-Xylylidenefluorene, or norbornadiene to the precursor prior to carbonization. Furfurylindeneindene, p-xylylideneindene, and pyromellitic dianhydride were found to be effective crosslinking additives for cinnamylidenefluorene. Properties of carbons derived from Ashland-240 pitch were altered by the addition of $p$-xylylidenefluorene and NBD. Thus, by selecting the appropriate precursor and additive, carbons with a wide range of crystalline properties can be produced in a controlled and reproducible manner. 


\section{REFERENCES}

(1) Horne, O. J.; Mesophase Formation in Polymers of Cinnamylideneindene and Acenaphthylene, Y-1799; Union Carbide Corporation-Nuclear Division, Oak Ridge Y-12 Plant, Oak Ridge, Tennessee; August 18, 1971.

(2) Horne, O. J. Smith, W. E., and Napier, B., Jr; Properties of Carbons Derived from Acenaphthylene and Cinnamylideneindene, $\mathrm{Y}-1880$ Union Carbide Corporation-Nuclear Division, Oak Ridge Y-12 Plant, Oak Ridge, Tennessee; December 7, 1973.

(3) Smith, W. E., Napier, B., Jr, and Harper, W. L.; Preparation and Characterization of Hydrocarbon Derivatives of Indene, Y-1712; Union Carbide Corporation-Nuclear Division, Oak Ridge Y-12 Plant, Oak Ridge, Tennessee; April 21, 1970.

(4) Smith, W. E., Horne, O. J., Napier, B., Jr, Larson, E. A., and Harper, W. L.; Properties of Carluon Derived fruml Imdene Cumpunmis, ' $r$-1790; Unlun Carblde CurpurationNuclear Division, Oak Ridge Y-12 Plant, Oak Ridge, Tennessee; September 15, 1971.

(5) Thiele, Johannes, and Henle, Franz; "Derivatives of Fulvene. III. Condensation Products of Fluorene", Ann, 347, p 290 (1906).

(6) Horne, O. J., Smith, W. E., and Napier, B., Jr; Properties of Carbon Derived from Petroleum Pitches, Y-1875; Union Carbide Corporation-Nuclear Division, Oak Ridge Y-12 Plant, Oak Ridge, Tennessee; June 21, 1973.

(7) Wuest, H. M.; "Isomerism of Benzfulvenes and Indenes", Ann, 415, p 291 (1918).

(8) Ruland, W.; "X-Ray Diffraction Studies on: Carbon and Graphite", Chemistry and Physics of Carbon, 4, p 1, Edited by P. L. Walker, Jr; Marcel Dekker, Inc, New York (1968).

(9) Maire, J. and Mering, J.: Proceedings of the Fourth Carbon Conference, o 345; Pergamon Press, New York (1960). 
DISTRIBUTION

\section{Aerojet-General}

Swope, L. S.

Aerospace Corporation - El Segundo

Blaes, H. M.

McDonald, W. R.

Meyer, R. A.

Aerospace Corporation - Los Angeles

Barry, W. T.

McClelland, J. D.

Army Materials and Mechanics

Research Center

Dignan, J. F.

Ashland Oil and Refining Company

Chapman, D.

Hoertz, C.

Newman, J.W.

Atomic Energy Commission - ORO

Hickman, H. D.

Zachry, D. S., Jr

Defense Nuclear Agency

Atkins, M/DDST

Jackson, R.

Moulton, J./APÁS

Department of the Navy

Stoessl, L./SPR-27201

Director of Defense Research and Engineering

Persh, J.

Fiber Materials, Inc

Cook, J.

Lachman, W.
General Electric-Reentry and

Environmental Systems Division

Hall, K.

Musckant, S.

Stover, E. R.

Great Lakes Research Corporation

Whittaker, M. P.

Gulf-General Atomic

Engle, G. B.

Lawrence Livermore Laboratory

Hurger, $\mathrm{H}$.

Lockheed Missile and Space Company

Vidoz, A.

Los Alamos Scientific Laboratory

Williams, J. M.

McDonnelf-Douglas Astronautics Company Acne, C.

Eitman, D.

NASA-Ames Research Center

Lundell, J. H.

Naval Air Systems Command

Schmidt, R.

Naval Ordinance Laboratory

Barnet, F. R./Kaubek, F. J.

Gowen, L./Code 2302

Rester, D. O.

Naval Ordinance Systems Command

Kinna, M. A./ORD-0333A

Oak Ridge Gaseous Diffusion Plant

Wilcox, W. J., Jr

Winkel, R. A. 
Oak Ridge National Laboratory

Bradley, R.

Eatherly, W. P.

Horne, O. J. (15)

Overholser, L. G.

Oak Ridge Y-12 Plant

Adary, Z. L.

Briscoe, O.W.

Burditt, R. B.

Burkhart, L. E.

Davis, R. M.

Denny, A.

Ebert, T. H.

Fraser, R. J.

Keith, Alvin

Kite, H. T.

Lambdin, F.

Lundin, M. I.

Marrow, G. B.

McLendon, J. D.

Napier, B., Jr (5)

Napier, J. M.

Peterson, G. R.

Phillips, L. R.

Schreyer, J. M.

Smith, R. D.

Smith, W. E. (5)

Taylor, A. J

Valentine, C. K.

Weathersby, W. E.

Williams, R. D.

Yaggi, W. .l.

$Y-12$ Central Files (5)

$Y-12$ Central Files (master copy)

$Y-12$ Central Files (route)

$Y-12$ Central Files ( $Y-12 R C$ )

Paducah Gaseous Dittusion Plant

Levin, R. W.

\section{Penn State University}

Walker; P. L., Jr
Samso

Green, G./RSF

Mentzer, D./RSSR

Shover, D./RSSE

Sandia - Albuquerque

Auerback, I.

McDonald, J. E.

Peurifoy, R. L., Jr

Zimmerman, J. C.

Sandia - Livermore

Rychnovsky, R. E.

I.Inion Carbide Corporation Corbon

Products Division

Browning, J. B.

Singer, L.

Townsend, H. N.

Union Carbide Corporation-Chemical and Plastics Division

Shechter, L.

\section{Wright-Patterson Air Force Base}

Materne, H. A.

Pratt, C./MAAS

Schmidt, D./LNC

In addition, this report is distributed in accordance with the category UC-4, Chemistry as given in the USAEC Standard Distribution Lists for Unclassified Scientific and TEchnical Reports, TID-4500. 